Prepared for the U.S. Department of Energy under Contract DE-AC05-76RL01830

\title{
Pacific Northwest National Laboratory Facility Radionuclide Emissions Units and Sampling Systems
}

\author{
JM Barnett \\ JH Brown \\ BA Walker
}

April 2012

Pacific Northwest

NATIONAL LABORATORY

Proudly Operated by Battelle Since 1965 



\title{
DISCLAIMER
}

This report was prepared as an account of work sponsored by an agency of the United States Government. Neither the United States Government nor any agency thereof, nor Battelle Memorial Institute, nor any of their employees, makes any warranty, express or implied, or assumes any legal liability or responsibility for the accuracy, completeness, or usefulness of any information, apparatus, product, or process disclosed, or represents that its use would not infringe privately owned rights. Reference herein to any specific commercial product, process, or service by trade name, trademark, manufacturer, or otherwise does not necessarily constitute or imply its endorsement, recommendation, or favoring by the United States Government or any agency thereof, or Battelle Memorial Institute. The views and opinions of authors expressed herein do not necessarily state or reflect those of the United States Government or any agency thereof.

\author{
PACIFIC NORTHWEST NATIONAL LABORATORY \\ operated by \\ BATTELLE \\ for the \\ UNITED STATES DEPARTMENT OF ENERGY \\ under Contract DE-AC05-76RL01830
}

Printed in the United States of America
Available to DOE and DOE contractors from the Office of Scientific and Technical Information,
P.O. Box 62, Oak Ridge, TN 37831-0062;
ph: (865) 576-8401
fax: (865) 576-5728
email: reports@adonis.osti.gov

\author{
Available to the public from the National Technical Information Service, \\ U.S. Department of Commerce, 5285 Port Royal Rd., Springfield, VA 22161 \\ ph: (800) 553-6847 \\ fax: (703) 605-6900 \\ email: orders@ntis.fedworld.gov \\ online ordering: http://www.ntis.gov/ordering.htm
}

This document was printed on recycled paper. 



\title{
Pacific Northwest National Laboratory Facility Radionuclide Emission Units and Sampling Systems
}

\author{
JM Barnett \\ JH Brown \\ BA Walker
}

April 2012

Prepared for

the U.S. Department of Energy

under Contract DE-AC05-76RL01830

Pacific Northwest National Laboratory

Richland, Washington 99352 



\section{Summary}

Battelle-Pacific Northwest Division operates numerous research and development (R\&D) laboratories in Richland, WA, including those associated with Pacific Northwest National Laboratory (PNNL) on the U.S. Department of Energy (DOE)'s Hanford Site and PNNL Site that have the potential for radionuclide air emissions. The National Emission Standard for Hazardous Air Pollutants (NESHAP 40 CFR 61, Subparts H and I) requires an assessment of all emission units that have the potential for radionuclide air emissions. Potential emissions are assessed annually by PNNL staff members. Sampling, monitoring, and other regulatory compliance requirements are designated based upon the potential-to-emit dose criteria found in the regulations. The purpose of this document is to describe the facility radionuclide air emission sampling program and provide current and historical facility emission unit system performance, operation, and design information.

For sampled systems, a description of the buildings, exhaust units, control technologies, and sample extraction details is provided for each registered emission unit. Additionally, applicable stack sampler configuration drawings, figures, and photographs are provided. Deregistered emission unit details are provided as necessary for up to 5 years post closure. 



\title{
Acronyms, Abbreviations, and Terms
}

\author{
$\mathrm{AABC}$ \\ American Air Balance Council \\ ANSI \\ American National Standards Institute \\ CAM \\ continuous air monitor \\ CAP88 \\ Clean Air Act Assessment Package-1988 \\ CFR \\ Code of Federal Regulations \\ $\mathrm{cfm}$ \\ cubic feet per minute \\ DEPO \\ Deposition Computer Software Code \\ deregistered \\ A report of closure has been transmitted to the Washington State \\ Department of Health indicating that operations of an emission unit with \\ the potential-to-emit (PTE) radioactive materials has ceased. \\ DOE \\ U.S. Department of Energy \\ EDE \\ effective dose equivalent \\ EM \\ Effluent Management \\ EMS \\ Environmental Management System \\ EMSL \\ Environmental Molecular Science Laboratory \\ EPA \\ U.S. Environmental Protection Agency \\ EPRP \\ Environmental Protection and Regulatory Programs. This designator to \\ procedures supersedes other designators such as EM, EMS, and EMSD \\ that have historically been used. \\ ESTD \\ Energy Science and Technology Directorate \\ ETD \\ Environmental Technology Directorate \\ $\mathrm{F} \& \mathrm{O}$ \\ Facilities \& Operations \\ FSD \\ Fundamental Science Directorate \\ HDI \\ How Do I? (PNNL standards-based management system) \\ HEPA \\ high efficiency particulate air (filter) \\ HPS \\ Health Physics Society \\ HTO \\ condensable tritium \\ HT \\ non-condensable tritium \\ ID \\ identification; may also be used as "inside diameter" for piping \\ measurements \\ inactive \\ Although the emission unit is still registered, there are no operations \\ occurring with the PTE radioactive materials through the emission unit.
}




\begin{tabular}{|c|c|}
\hline major & $\begin{array}{l}\text { An emission unit with the potential to contribute greater than or equal to } \\
0.1 \text { millirem (mrem)/yr dose to the maximally exposed individual (MEI) } \\
\text { off site. }\end{array}$ \\
\hline minor & $\begin{array}{l}\text { An emission unit with the potential to contribute less than } 0.1 \mathrm{mrem} / \mathrm{yr} \\
\text { dose to the MEI off site. }\end{array}$ \\
\hline MEI & maximally exposed individual \\
\hline mrem & millirem \\
\hline NA & not available \\
\hline NESHAP & National Emission Standards for Hazardous Air Pollutants \\
\hline NOC & notice of construction \\
\hline NRC & Nuclear Regulatory Commission \\
\hline PIC & potential impact category \\
\hline PNNL & Pacific Northwest National Laboratory \\
\hline PSF & Physical Sciences Facility \\
\hline PTE & potential-to-emit \\
\hline QA & quality assurance \\
\hline QC & quality control \\
\hline RAES & radiological air emissions sampling \\
\hline $\mathrm{R} \& \mathrm{D}$ & research and development \\
\hline RPL & Radiochemical Processing Laboratory \\
\hline RTL & Research Technology Laboratory \\
\hline RS\&EG & Radiochemical Sciences and Engineering \\
\hline $\operatorname{scfm}$ & standard cubic feet per minute \\
\hline SOW & statement of work \\
\hline TEDE & total effective dose equivalent \\
\hline TSD & treatment, storage, and disposal \\
\hline TSDF & Treatment, Storage, and Disposal Facility \\
\hline WAC & Washington Administrative Code \\
\hline WDOH & Washington State Department of Health \\
\hline$\sigma_{\mathrm{g}}$ & $\begin{array}{l}\text { geometric standard deviation; a measure of particle size spread around the } \\
\text { mean diameter for a log normal distribution }\end{array}$ \\
\hline$\mu$ & micron \\
\hline
\end{tabular}




\section{Contents}

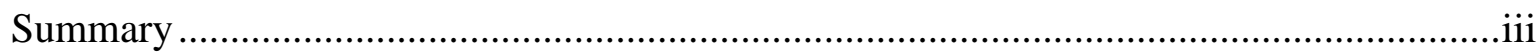

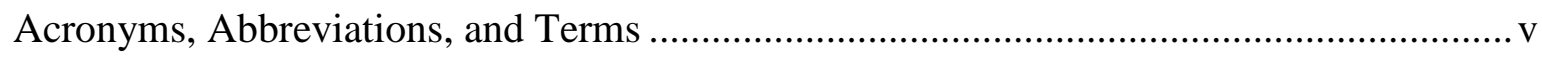

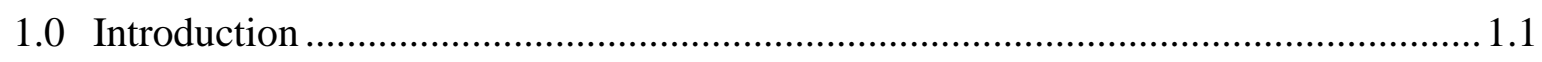

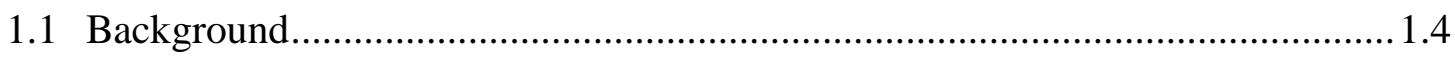

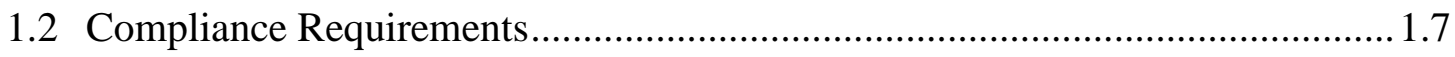

2.0 Sampling System Design ......................................................................... 2.1

2.1 Stack Velocity and Cyclonic Flow Measurements ........................................ 2.1

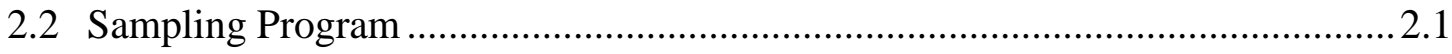

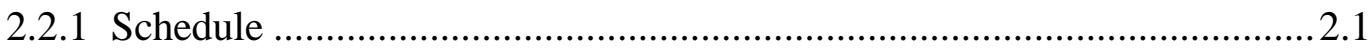

2.2.2 Particulate Sample Collection and Analysis........................................2.1

2.2.3 Sample Flow Rate Systems ........................................................... 2.2

2.2.4 Tritium Sample Collection and Analysis ........................................... 2.2

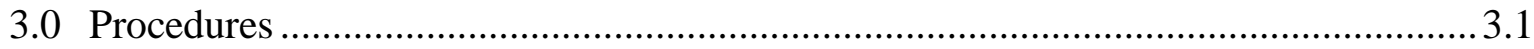

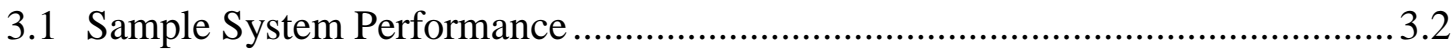

4.0 Potential Off-Site Dose and Principle Radionuclides ........................................ 4.1

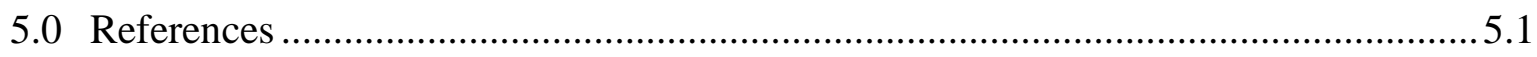

Appendix A Particulate Sample Analysis and Data Evaluation .................................. A.1

Appendix B Tritium Sample Analysis and Data Evaluation ........................................ B.1

Appendix C Recommendation of Particle Line-Loss Code.......................................... C.1

Appendix D Hanford Site/300 Area Stack Sampler Systems ..................................... D.1

Appendix E PNNL Site Stack Sampler Systems ........................................................ E.1

Appendix F Battelle Private Stack Sampler Systems ................................................F.1

Appendix G Deregistered/Transitioned Emission Units .............................................. 1 


\section{Figures}

Figure D.1. 318-01-S Building Effluent Pathway................................................. D.2

Figure D.2. 325-01-S Building Effluent Pathway.................................................. D.6

Figure D.3. 331-01-V Building Effluent Pathway ……………………………...... D.15

Figure E.1. 3410-01-S Building Effluent Pathway ........................................................2

Figure E.2. 3420-01-S Building Effluent Pathway .......................................................6

Figure E.3. 3430-01-S Building Effluent Pathway ..................................................... 9

Figure F.1. RTL-10-V Effluent Pathway ……………….......................................

Figure F.2. RTL-11-V Effluent Pathway ....................................................................7

Figure G.1. 320-01-S Effluent Pathway ……………….......................................... G.2

Figure G.2. 320-02-S Effluent Pathway ……………….........................................6.6

Figure G.3. 320-04-S Effluent Pathway ..................................................................... G.9

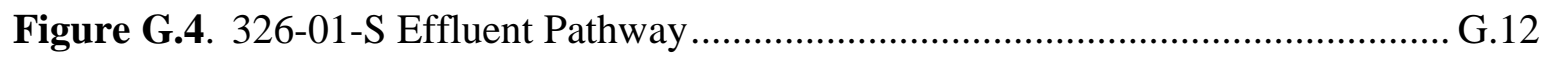

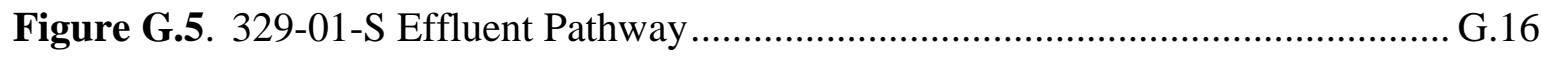

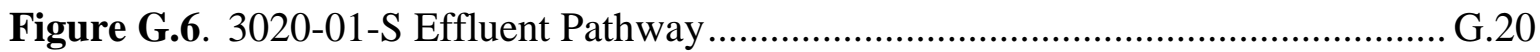




\section{Tables}

Table 1.1. Schedule for Routine Radionuclide Air Emission Sampling ........................ 1.2

Table 1.2. Facility Radiological Air Emission Sampling Systems ................................ 1.4

Table 1.3. Summary of Radionuclide Emission Sampler Efficiencies* ......................... 1.5

Table 1.4. Verification of Absence of Cyclonic Flow Conditions in Stacks and Vents .... 1.6

Table 1.5. Facility NESHAP Compliance Summary .............................................. 1.10

Table 3.1. Effluent Management Radiological Air Monitoring/Sampling Procedures...... 3.1

Table D.1. 318-01-S Building Exhaust Unit Flow Rate ............................................ D.3

Table D.2. $318-01-S$ Building Exhaust Unit Temperature ...................................... D. 3

Table D.3. 325-01-S Building Exhaust Unit Flow Rate............................................. D.7

Table D.4. 325-01-S Building Exhaust Unit Temperature........................................... D.7

Table D.5. 331-01-V Building Exhaust Unit Flow Rate ........................................ D.16

Table D.6. 331-01-V Building Exhaust Unit Temperature ....................................... D.16

Table E.1. 3410-01-S Building Exhaust Unit Flow Rate.............................................3

Table E.2. 3410-01-S Building Exhaust Unit Temperature.......................................... 3

Table E.3. 3420-01-S Building Exhaust Unit Flow Rate..............................................6.6

Table E.4. 3420-01-S Building Exhaust Unit Temperature .........................................6

Table E.5. 3430-01-S Building Exhaust Unit Flow Rate...............................................9

Table E.6. 3430-01-S Building Exhaust Unit Temperature ......................................... 9

Table F.1. RTL-10-V Exhaust Unit Flow Rate .................................................. 3

Table F.2. RTL-10-V Exhaust Unit Temperature ...................................................F.3

Table F.3. RTL-11-V Exhaust Unit Flow Rate ..........................................................4

Table F.4. RTL-11-V Exhaust Unit Temperature ...................................................F.4

Table G.1. 320-01-S Exhaust Unit Flow Rate........................................................... G.3

Table G.2. 320-01-S Exhaust Unit Temperature ..................................................... G.3

Table G.3. 320-02-S Exhaust Unit Flow Rate.........................................................6.6

Table G.4. $320-02-S$ Exhaust Unit Temperature ................................................... G.7

Table G.5. 320-04-S Exhaust Unit Flow Rate...........................................................9.

Table G.6. 326-01-S Exhaust Unit Flow Rate........................................................... G.13

Table G.7. 326-01-S Exhaust Unit Temperature .........................................................13

Table G.8. 329-01-S Exhaust Unit Flow Rate......................................................... G.17

Table G.9. 329-01-S Exhaust Unit Temperature ................................................... G.17

Table G.10. 3020-01-S Effluent Pathway ................................................................. G.20 



\subsection{Introduction}

Pacific Northwest National Laboratory (PNNL) conducts numerous R\&D activities that have the potential for radionuclide air emissions. The U.S. Environmental Protection Agency (EPA) regulations in 40 Code of Federal Regulations [CFR] 61 "National Emission Standard for Hazardous Air Pollutants" [NESHAP], Subpart H (2002) and Subpart I (2002) requires an assessment of all emission units that have the potential for radionuclide air emissions. NESHAP requires that "major" emission units be sampled continuously, while "minor" emission units do not. Major and minor designations are determined using potential dose criteria specified in the regulations (see Acronyms, Abbreviations, and Terms). Washington Administrative Code (WAC) 246-247, "Radiation protection-air emissions" (WAC 2005), provides radioactive air emission licensing and regulation guidance for facilities that have the potential to emit radionuclides. The potential for emissions from PNNL facilities is assessed annually to verify sampling requirements. The methodology used to evaluate the potential for emissions is documented in Assessment of Unabated Facility Emission Potentials for Evaluating Airborne Radionuclide Monitoring Requirements at Pacific Northwest National Laboratory (Ballinger and Gervais 2011).

There are eight registered emission units that are sampled by PNNL for airborne radionuclide emissions (Table 1.1). Of the eight registered emission units, five are currently designated as "major" and are sampled continuously to determine compliance with air emission standards as required by Washington State Department of Health (WDOH) and EPA regulations. Some of the "minor" emission units may be sampled continuously as a best management practice. The remaining minor emission units are either sampled periodically to provide confirmatory evidence that no significant emissions exist, or undergo administrative review using 40 CFR 61, Appendix D (1989). Only emission units that are currently being sampled are fully reported/covered in this document. Emission units that are not being sampled may be deregistered, transitioned, fugitive, or administratively reviewed (Table 1.1). Table 1.2 provides system heights and exhaust flow rates for sampled emission units. 
Table 1.1. Schedule for Routine Radionuclide Air Emission Sampling

\begin{tabular}{|c|c|c|c|c|c|c|}
\hline Emission Point & $\begin{array}{c}\text { Major } \\
\text { Emission Unit }\end{array}$ & Sample Type & $\begin{array}{l}\text { Sampling } \\
\text { Frequency }\end{array}$ & $\begin{array}{l}\text { Duration of } \\
\text { Each Sample }\end{array}$ & $\begin{array}{l}\text { Constituents } \\
\text { Analyzed }\end{array}$ & Comments \\
\hline \multicolumn{7}{|c|}{ Hanford Site/300 Area Active Emission Units } \\
\hline EP-318-01-S & No & Particulate & Annual & 2 week & Alpha/Beta & Minor Emission Unit_-ANSI N13.1-1969 \\
\hline EP-325-01-S & Yes & $\begin{array}{c}\text { Particulate } \\
\text { Water Vapor } \\
\text { Gas } \\
\text { Composite }\end{array}$ & Continuous & $\begin{array}{l}2 \text { week } \\
1 \text { month } \\
1 \text { month } \\
6 \text { month }\end{array}$ & $\begin{array}{c}\text { Alpha/Beta } \\
\text { Tritium } \\
\text { Tritium } \\
\text { Specific Nuclides }\end{array}$ & $\begin{array}{l}\text { Major Emission Unit- ANSI N13.1-1999 } \\
\text { Isotopic Analysis on Composites (see Appendix A) }\end{array}$ \\
\hline EP-331-01-V & Yes & $\begin{array}{l}\text { Particulate } \\
\text { Composite }\end{array}$ & Continuous & $\begin{array}{l}2 \text { week } \\
6 \text { month }\end{array}$ & $\begin{array}{l}\text { Alpha/Beta } \\
\text { Specific Nuclides }\end{array}$ & $\begin{array}{l}\text { Major Emission Unit- ANSI N13.1-1969 } \\
\text { Isotopic Analysis on Composites (see Appendix A) }\end{array}$ \\
\hline \multicolumn{7}{|c|}{ PNNL Site Active Emission Units } \\
\hline EP-3410-01-S & Yes & $\begin{array}{l}\text { Particulate } \\
\text { Composite }\end{array}$ & Continuous & $\begin{array}{l}2 \text { weeks } \\
6 \text { months }\end{array}$ & $\begin{array}{l}\text { Alpha/Beta } \\
\text { Specific Nuclides }\end{array}$ & $\begin{array}{l}\text { Major Emission Unit-ANSI N13.1-1999 } \\
\text { Isotopic Analysis on Composites }\end{array}$ \\
\hline EP-3420-01-S & Yes & $\begin{array}{l}\text { Particulate } \\
\text { Composite }\end{array}$ & Continuous & $\begin{array}{l}2 \text { weeks } \\
6 \text { months }\end{array}$ & $\begin{array}{c}\text { Alpha/Beta } \\
\text { Specific Nuclides }\end{array}$ & $\begin{array}{l}\text { Major Emission Unit-ANSI N13.1-1999 } \\
\text { Isotopic Analysis on Composites }\end{array}$ \\
\hline EP-3430-01-S & Yes & $\begin{array}{l}\text { Particulate } \\
\text { Composite }\end{array}$ & Continuous & $\begin{array}{l}2 \text { weeks } \\
6 \text { months }\end{array}$ & $\begin{array}{c}\text { Alpha/Beta } \\
\text { Specific Nuclides }\end{array}$ & $\begin{array}{l}\text { Major Emission Unit-ANSI N13.1-1999 } \\
\text { Isotopic Analysis on Composites }\end{array}$ \\
\hline \multicolumn{7}{|c|}{ Battelle Private Active Emission Units } \\
\hline EP-RTL-10-V & No & Particulate & Quarterly & 2 week & Alpha/Beta & Minor Emission Unit- ANSI N13.1-1969 \\
\hline EP-RTL-11-V & No & Particulate & Quarterly & 2 week & Alpha/Beta & Minor Emission Unit- ANSI N13.1-1969 \\
\hline
\end{tabular}


Table 1.1. (contd)

\begin{tabular}{|c|c|c|c|c|c|c|}
\hline Emission Point & $\begin{array}{c}\text { Major } \\
\text { Emission Unit }\end{array}$ & Sample Type & $\begin{array}{l}\text { Sampling } \\
\text { Frequency }\end{array}$ & $\begin{array}{l}\text { Duration of } \\
\text { Each Sample }\end{array}$ & $\begin{array}{l}\text { Constituents } \\
\text { Analyzed }\end{array}$ & Comments \\
\hline \multicolumn{7}{|c|}{ Fugitive and Non Sampled Emission Units } \\
\hline $\begin{array}{c}300 \text { Area } \\
\text { Diffuse/Fugitive }\end{array}$ & No & N/A & N/A & N/A & N/A & Fugitive, 300 Area Excavation Activities \\
\hline $\mathrm{J}-361$ & No & N/A & N/A & N/A & N/A & Fugitive, 361 Building \\
\hline $\mathrm{J}-3425$ & No & N/A & N/A & N/A & N/A & Fugitive, 3425 Building \\
\hline EP-331-02-S & No & N/A & N/A & N/A & N/A & $\begin{array}{l}\text { Non Sampled; Administrative review determined by } \\
40 \text { CFR 61, Appendix D, } 331 \text { Building. Previously } \\
\text { registered as the Portable Radon Research Facility }\end{array}$ \\
\hline EP-3420-02-S & No & N/A & N/A & N/A & N/A & $\begin{array}{l}\text { Non Sampled, Administrative review determined by } \\
40 \text { CFR 61, Appendix D, } 3420 \text { Building }\end{array}$ \\
\hline EP-3430-02-S & No & N/A & N/A & N/A & N/A & $\begin{array}{c}\text { Non Sampled, Administrative review determined by } \\
40 \text { CFR 61, Appendix D, } 3430 \text { Building }\end{array}$ \\
\hline EP-3430-1606P-S & No & N/A & N/A & N/A & N/A & $\begin{array}{c}\text { Non Sampled, Administrative review determined by } \\
40 \text { CFR 61, Appendix D, } 3430 \text { Building }\end{array}$ \\
\hline EP-3430-1608P-S & No & N/A & N/A & N/A & N/A & $\begin{array}{c}\text { Non Sampled, Administrative review determined by } \\
40 \text { CFR 61, Appendix D, } 3430 \text { Building }\end{array}$ \\
\hline EP-3430-1610P-S & No & N/A & N/A & N/A & N/A & $\begin{array}{c}\text { Non Sampled, Administrative review determined by } \\
40 \text { CFR 61, Appendix D, } 3430 \text { Building }\end{array}$ \\
\hline EP-3430-1612P-S & No & N/A & N/A & N/A & N/A & $\begin{array}{c}\text { Non Sampled, Administrative review determined by } \\
40 \text { CFR 61, Appendix D, } 3430 \text { Building }\end{array}$ \\
\hline EP-3430-1614P-S & No & N/A & N/A & N/A & N/A & $\begin{array}{c}\text { Non Sampled, Administrative review determined by } \\
40 \text { CFR 61, Appendix D, } 3430 \text { Building }\end{array}$ \\
\hline EP-LSLII-01-V & No & N/A & N/A & N/A & N/A & $\begin{array}{l}\text { Non Sampled, Administrative review determined by } \\
40 \text { CFR 61, Appendix D, LSL-II }\end{array}$ \\
\hline EP-LSLII-02-V & No & N/A & N/A & N/A & N/A & $\begin{array}{l}\text { Non Sampled, Administrative review determined by } \\
40 \text { CFR 61, Appendix D, LSL-II }\end{array}$ \\
\hline EP-3020-01-S & No & N/A & N/A & N/A & N/A & Fugitive, EMSL. Previously registered. \\
\hline \multicolumn{7}{|c|}{ Deregistered/Transitioned Emission Units (Historical Data) } \\
\hline EP-320-01-S & No & N/A & N/A & $\mathrm{N} / \mathrm{A}$ & N/A & Emission Unit Transitioned \\
\hline EP-320-02-S & No & N/A & N/A & N/A & N/A & Emission Unit Transitioned \\
\hline EP-320-04-S & No & N/A & N/A & N/A & N/A & Emission Unit Deregistered \\
\hline EP-326-01-S & No & N/A & N/A & N/A & N/A & Emission Unit Transitioned \\
\hline EP-329-01-S & No & N/A & N/A & N/A & N/A & Emission Unit Transitioned \\
\hline
\end{tabular}


Table 1.2. Facility Radiological Air Emission Sampling Systems

\begin{tabular}{|c|c|c|c|c|c|c|c|}
\hline $\begin{array}{c}\text { Emission Unit } \\
\text { Number }\end{array}$ & $\begin{array}{l}\text { Unit } \\
\text { ID }\end{array}$ & Unit Name & $\begin{array}{c}\text { Unit } \\
\text { Description }\end{array}$ & $\begin{array}{c}\text { Release } \\
\text { Height above } \\
\text { Grade (ft) } \\
\end{array}$ & $\begin{array}{c}\text { Effective } \\
\text { Release } \\
\text { Height (ft)* } \\
\end{array}$ & $\begin{array}{c}\text { Nominal } \\
\text { Flow Rate } \\
\left(\mathrm{ft}^{3} / \mathrm{min}\right) \\
\end{array}$ & $\begin{array}{c}\text { Nominal } \\
\text { Temperature } \\
\left({ }^{\circ} \mathbf{F}\right) \\
\end{array}$ \\
\hline \multicolumn{8}{|c|}{ Hanford Site/300 Area Active Emission Units } \\
\hline EP-318-01-S & 318 & Radiological Calibrations Laboratory & Stack & 28.9 & 41 & 500 & 82 \\
\hline EP-325-01-S & 325 & Radiochemical Processing Laboratory & Stack & 88.8 & 268 & 140,000 & 77 \\
\hline EP-331-01-V & 331 & Life Sciences Laboratory & Vent & 62.0 & 163 & 58,000 & 77 \\
\hline \multicolumn{8}{|c|}{ PNNL Site Active Emission Units } \\
\hline EP-3410-01-S & 3410 & Material Science and Technology Laboratory & Stack & 45 & 173.9 & 13,700 & 72 \\
\hline EP-3420-01-S & 3420 & Radiation Detection Laboratory & Stack & 45 & 228 & 39,000 & 72 \\
\hline EP-3430-01-S & 3430 & Ultra-Trace Laboratory & Stack & 45 & 203.1 & 24,600 & 72 \\
\hline \multicolumn{8}{|c|}{ Battelle Private Active Emission Units } \\
\hline EP-RTL-10-V & RTL & Research Technology Laboratory & Vent & 26.0 & 68 & 14,000 & 80 \\
\hline EP-RTL-11-V & RTL & Research Technology Laboratory & Vent & 26.0 & 73 & 17,000 & 78 \\
\hline \multicolumn{8}{|c|}{ Deregistered/Transitioned and Non-Sampled Emission Units } \\
\hline EP-320-01-S & 320 & Analytical and Nuclear Research Laboratory & Stack & 39.7 & 100 & 30,000 & 75 \\
\hline EP-320-02-S & 320 & Analytical and Nuclear Research Laboratory & Stack & 31.8 & 44 & 500 & 83 \\
\hline EP-320-04-S & 320 & Analytical and Nuclear Research Laboratory & Stack & 26.0 & 37 & 500 & 82 \\
\hline EP-326-01-S & 326 & Materials Sciences Laboratory & Stack & 47.7 & 131 & 49,000 & 77 \\
\hline EP-329-01-S & 329 & Chemical Sciences Laboratory & Stack & 62.5 & 156 & 45,000 & 75 \\
\hline EP-331-02-S & 331 & Life Sciences Laboratory & Stack & 42.3 & 73 & 4800 & N/A \\
\hline EP-3420-02-S & 3420 & Radiation Detection Laboratory & Stack & 45.9 & 117 & 61,000 & 72 \\
\hline EP-3430-02-S & 3430 & Ultra-Trace Laboratory & Stack & 45.9 & 112 & 66,500 & 72 \\
\hline EP-3430-606P-S & 3430 & Ultra-Trace Laboratory & N/A & N/A & N/A & N/A & N/A \\
\hline EP-3430-608P-S & 3430 & Ultra-Trace Laboratory & N/A & N/A & N/A & N/A & N/A \\
\hline EP-3430-610P-S & 3430 & Ultra-Trace Laboratory & N/A & N/A & N/A & N/A & N/A \\
\hline EP-3430-612P-S & 3430 & Ultra-Trace Laboratory & N/A & N/A & N/A & N/A & N/A \\
\hline EP-3430-614P-S & 3430 & Ultra-Trace Laboratory & N/A & N/A & N/A & N/A & N/A \\
\hline EP-LSLII-01-V-1 & LSLII & Life Sciences Laboratory II & Vent & 24.4 & 59 & 19,000 & 76 \\
\hline EP-LSLII-01-V-2 & LSLII & Life Sciences Laboratory II & Vent & 24.4 & 63 & 23,000 & 78 \\
\hline EP-LSLII-02-V-1 & LSLII & Life Sciences Laboratory II & Vent & 15.6 & 79 & 63,000 & 74 \\
\hline EP-LSLII-02-V-2 & LSLII & Life Sciences Laboratory II & Vent & 15.6 & 78 & 61,000 & 74 \\
\hline EP-3020-01-S & EMSL & Environmental Molecular Sciences Laboratory & Stack & 53.6 & 99 & 6900 & 78 \\
\hline \multicolumn{8}{|c|}{ * The effective release height is equal to the physical stack height plus the plume rise attributable to momentum and buoyancy. } \\
\hline Conversions: & $\begin{array}{l}1 \text { foot }(\mathrm{ft}) \\
1 \mathrm{ft}^{3} / \mathrm{min}\end{array}$ & $\begin{array}{c}0.3048 \text { meter }(\mathrm{m}) \\
0.0283 \mathrm{~m}^{3} / \mathrm{min}\end{array}$ & & & & & \\
\hline
\end{tabular}



The remainder of this report is divided into sections by emission unit, for which the following data were compiled:

- a photograph of the stack and sample system

- emission sample unit ID

- traverse unit ID

- location of emission unit using Washington Geological Survey 84 Coordinates

- facility/process description

- exhaust unit description

- exhaust unit control technology

- exhaust unit flow rate

- record particulate sample system description

- sample extraction unit

- sample extraction probe

- sample transport line

- vacuum air sample system

- applicable drawings.

\subsection{Background}

In response to EPA plans to revise the emission sampling regulations, PNNL initiated a comprehensive effort to upgrade facility radionuclide emission sampling systems in 1990. The EPA regulations were issued as 40 CFR 61, "National Emission Standard for Hazardous Air Pollutants" (December 15, 1989).

Prior to 2002, PNNL sampling systems were designed to be operated at a nominal sample rate of 2 cubic feet per minute ( $\mathrm{cfm}$ ); that is, the sample probe nozzles were sized to operate isokinetically at a sample rate of $2 \mathrm{cfm}$. Accurate setting of sample rates to achieve isokinetic sampling conditions requires that the exhaust system velocity be measured at the sample extraction location. However, changes in facility ventilation flow rates, degradation of the sampler vacuum supply, or compliance with the American National Standards Institute (ANSI) N13.1-1999 can result in deviation from the original isokinetic design.

Information obtained during sampler inspections and stack velocity measurements were used with the Deposition computer software code (DEPO) to estimate the deposition of particles collected in each sampling system. Since 1990, the sampling systems have been periodically evaluated for sampling error caused by sampling system line losses using DEPO. Table 1.3 summarizes the most current data. 
Table 1.3. Summary of Radionuclide Emission Sampler Efficiencies* (for $1-\mu \mathrm{m}$ particles with $2.25 \sigma_{\mathrm{g}}$ )

\begin{tabular}{|c|c|c|c|c|}
\hline \multirow[b]{2}{*}{$\begin{array}{l}\text { Emission Sample } \\
\text { Unit Number }\end{array}$} & \multirow[b]{2}{*}{$\begin{array}{c}\text { Number of } \\
\text { Nozzles }\end{array}$} & \multicolumn{2}{|c|}{ Flow Range (cfm) } & \multirow[b]{2}{*}{$\begin{array}{c}\text { Penetration Efficiency } \\
\text { Range }(\%)\end{array}$} \\
\hline & & Stack Flow Rate & $\begin{array}{l}\text { Sampler } \\
\text { Flow Rate }\end{array}$ & \\
\hline \multicolumn{5}{|c|}{ Hanford Site/300 Area Active Emission Units } \\
\hline ESP-318-01-S & 2 & 300 to 800 & $1-5$ & 94 to 101 \\
\hline ESP-325-01-S (CAM) & 6 & 120,000 to 150,000 & $5-30$ & 96 to 98 \\
\hline ESP-325-01-S & 1 & 120,000 to 150,000 & $1-5$ & 94 to 112 \\
\hline ESP-331-01-D & 6 & 50,000 to 100,000 & $1-5$ & 95 to 117 \\
\hline \multicolumn{5}{|c|}{ PNNL Site Active Emission Units } \\
\hline EP-3410-01-S & 1 & 10,000 to 25,000 & $1-5$ & 97 to 99 \\
\hline EP-3420-01-S & 1 & 30,000 to 60,000 & $1-5$ & 97 to 99 \\
\hline EP-3430-01-S & 1 & 20,000 to 40,000 & $1-5$ & 96 to 99 \\
\hline \multicolumn{5}{|c|}{ Battelle Private Active Emission Units } \\
\hline ESP-RTL-10-D & 5 & 10,000 to 25,000 & $1-5$ & 93 to 119 \\
\hline ESP-RTL-11-D & 5 & 10,000 to 25,000 & $1-5$ & 93 to 119 \\
\hline \multicolumn{5}{|c|}{ Deregistered/Transitioned and Non-Sampled Emission Units } \\
\hline EP-320-01-S & 6 & 20,000 to 50,000 & $1-5$ & 92 to 108 \\
\hline EP-320-02-S & 2 & 300 to 600 & $1-5$ & 83 to 97 \\
\hline EP-320-04-S & 1 & 300 to 1,200 & $1-5$ & 81 to 101 \\
\hline EP-326-01-S & 6 & 40,000 to 70,000 & $1-5$ & 94 to 110 \\
\hline EP-329-01-S & 6 & 30,000 to 60,000 & $1-5$ & 93 to 110 \\
\hline EP-331-02-S & N/A & 4,800 to 6,200 & N/A & N/A \\
\hline EP-3420-02-S & N/A & 61,200 to 63,400 & N/A & N/A \\
\hline EP-3430-02-S & N/A & 66,500 to 77,400 & N/A & N/A \\
\hline EP-3430-1606P-S & N/A & N/A & N/A & N/A \\
\hline EP-3430-1608P-S & N/A & N/A & N/A & N/A \\
\hline EP-3430-1610P-S & N/A & N/A & N/A & N/A \\
\hline EP-3430-1612P-S & N/A & N/A & N/A & N/A \\
\hline EP-3430-1614P-S & N/A & N/A & N/A & N/A \\
\hline EP-LSLII-01-V-1 & 7 & 10,000 to 25,000 & $1-5$ & 99 to 107 \\
\hline EP-LSLII-01-V-2 & 7 & 10,000 to 25,000 & $1-5$ & 80 to 133 \\
\hline EP-LSLII-02-V-1 & 7 & 40,000 to 100,000 & $1-5$ & 95 to 108 \\
\hline EP-LSLII-02-V-2 & 7 & 50,000 to 100,000 & $1-5$ & 81 to 104 \\
\hline EP-3020-01-S & N/A & N/A & N/A & N/A \\
\hline
\end{tabular}

* Sampler efficiencies are reported for active emission units only.

Note: Sampler transport efficiencies were calculated for the particulate samplers with varying stack and sampler flow rates. The emission sample unit transport efficiencies assumed a particle size of $1 \mu$ with $\sigma_{\mathrm{g}}=2.25$. See project records (EM Rad Air File Plan) for detailed line-loss calculations.

In addition, cyclonic flow measurements were conducted for each sampling system according to 40 CFR 60 Appendix A, Method 1, Section 11.4, Verification of Absence of Cyclonic Flow (1971). Table 1.4 summarizes the results of these measurements. 
Table 1.4. Verification of Absence of Cyclonic Flow Conditions in Stacks and Vents

\begin{tabular}{|c|c|c|c|c|c|}
\hline $\begin{array}{c}\text { Emission } \\
\text { Unit Number }\end{array}$ & Unit Name & $\begin{array}{c}\text { Traverse } \\
\text { Point }\end{array}$ & Date & $\begin{array}{c}\text { Average } \\
\text { Yaw Angle } \\
\text { (degrees) }\end{array}$ & $\begin{array}{c}\text { Acceptable } \\
\text { (Yes/No)* }^{*}\end{array}$ \\
\hline \multicolumn{6}{|c|}{ Hanford Site/300 Area Active Emission Units } \\
\hline EP-318-01-S & Radiological Calibrations Laboratory & TP-318-01-1 & $06 / 22 / 2006$ & 12.2 & Yes \\
\hline EP-325-01-S & Radiochemical Processing Laboratory & TP-325-01-1 & $11 / 20 / 2002$ & 4.0 & Yes \\
\hline EP-331-01-V & Life Sciences Laboratory & TP-331-01-1 & $08 / 02 / 2000$ & 10.7 & Yes \\
\hline \multicolumn{6}{|c|}{ PNNL Site Active Emission Units } \\
\hline EP-3410-01-S & Material Science and Technology Laboratory & TP-3410-01-1 & $07 / 12 / 2010$ & 2.8 & Yes \\
\hline EP-3420-01-S & Radiation Detection Laboratory & TP-3420-01-1 & $07 / 12 / 2010$ & 2.0 & Yes \\
\hline EP-3430-01-S & Ultra-Trace Laboratory & TP-3430-01-1 & $07 / 12 / 2010$ & 2.6 & Yes \\
\hline \multicolumn{6}{|c|}{ Battelle Private Active Emission Units } \\
\hline EP-RTL-10-V & Research Technology Laboratory & TP-RTL-10-1 & 09/20/1999 & 5.9 & Yes \\
\hline EP-RTL-11-V & Research Technology Laboratory & TP-RTL-11-1 & 09/20/1999 & 5.2 & Yes \\
\hline \multicolumn{6}{|c|}{ Deregistered/Transitioned and Non-Sampled Emission Units } \\
\hline EP-320-01-S & Analytical and Nuclear Research Laboratory & TP-320-01-1 & $10 / 12 / 2000$ & 3.4 & Yes \\
\hline EP-320-02-S & Analytical and Nuclear Research Laboratory & TP-320-02-1 & 07/20/1999 & 0.75 & Yes \\
\hline EP-320-04-S & Analytical and Nuclear Research Laboratory & TP-320-04-1 & 07/20/1999 & 1.35 & Yes \\
\hline EP-326-01-S & Materials Sciences Laboratory & TP-326-01-1 & $03 / 30 / 2000$ & 6.05 & Yes \\
\hline EP-329-01-S & Chemical Sciences Laboratory & TP-329-01-1 & $01 / 27 / 2000$ & 3.85 & Yes \\
\hline EP-331-02-S & Life Sciences Laboratory & N/A & N/A & N/A & N/A \\
\hline EP-3420-02-S & Radiation Detection Laboratory & N/A & N/A & N/A & N/A \\
\hline EP-3430-02-S & Ultra-Trace Laboratory & N/A & N/A & N/A & N/A \\
\hline $\begin{array}{l}\text { EP-3430- } \\
1606 P-S\end{array}$ & Ultra-Trace Laboratory & N/A & N/A & N/A & N/A \\
\hline $\begin{array}{l}\text { EP-3430- } \\
\text { 1608P-S }\end{array}$ & Ultra-Trace Laboratory & N/A & N/A & N/A & N/A \\
\hline $\begin{array}{l}\text { EP-3430- } \\
\text { 1610P-S }\end{array}$ & Ultra-Trace Laboratory & N/A & N/A & N/A & N/A \\
\hline $\begin{array}{l}\text { EP-3430- } \\
\text { 1612P-S }\end{array}$ & Ultra-Trace Laboratory & N/A & N/A & N/A & N/A \\
\hline $\begin{array}{l}\text { EP-3430- } \\
\text { 1614P-S }\end{array}$ & Ultra-Trace Laboratory & N/A & N/A & N/A & N/A \\
\hline EP-LSLII-01-1 & Life Sciences Laboratory II & TP-LSLII-01-1 & 9/30/1999 & 13.8 & Yes \\
\hline EP-LSLII-01-2 & Life Sciences Laboratory II & TP-LSLII-01-2 & 9/30/1999 & 7.3 & Yes \\
\hline EP-LSLII-02-1 & Life Sciences Laboratory II & TP-LSLII-02-1 & $5 / 26 / 1999$ & 4.9 & Yes \\
\hline EP-LSLII-02-2 & Life Sciences Laboratory II & TP-LSLII-02-2 & 8/11/1999 & 2.4 & Yes \\
\hline EP-3020-01-S & Environmental Molecular Sciences Laboratory & TP-3020-01-1 & $1 / 12 / 2000$ & 2.1 & Yes \\
\hline
\end{tabular}

In 2002, the EPA amended 40 CFR 61 Subpart H and 40 CFR 61 Appendix B Method 114 to include requirements from ANSI N13.1-1999 for new or modified emission units. Additionally, the WDOH amended the WAC 246-247 to include ANSI N13.1-1999 requirements in 2005. A result of the amended regulations is the requirement to prepare a written technical basis for the radiological air emission sampling and monitoring program. The technical basis must address the sampling objective, graded approach for meeting the objectives, relevant building operating conditions and airborne contaminants, and action levels that signal changing conditions of significance.

A key component of the technical basis is the potential impact category (PIC) assigned to an emission unit. ANSI N13.1-1999 uses PICs to define a graded approach to sampling for airborne 
radioactive materials. The PICs used for illustrative purposes in the standard are based on potential "dose consequences that may occur assuming effluent attenuation or filtration devices present in the effluent stream have no effect" (ANSI N13.1-1999). This is comparable to the definition for potential-to-emit (PTE) used in radiological air emission regulations.

Since 2004, PNNL has been using the suggested PIC definitions provided in ANSI N13.1-1999 with a safety factor of $50 \%$ for the lower end of the PIC 2, 3, and 4 categories. Although PTEs for each emission unit are calculated annually using actual inventory, the PTE used for assigning PICs is the permitted PTE, which is based on maximum estimated inventory and throughput for permitted activities. Continuous radionuclide sampling is conducted on all emission units designated as "major." The criteria found in Pacific Northwest National Laboratory Potential Impact Categories for Radiological Air Emission Monitoring (PNNL 2010a) should be considered when setting sampling requirements. The PNNL defined PIC categories are not reiterated herein.

In 2007, PNNL began construction on the Physical Sciences Facility, which is a complex of five research laboratories and consists of:

- 3410 - Materials Science and Technology Laboratory

- 3420 - Radiation Detection Laboratory

- 3425 - Ultra-Low Background Counting Laboratory

- 3430 - Ultra-Trace Laboratory

- 3440 - Large Detector Laboratory

Of these five laboratories, only the 3410, 3420, and 3430 buildings house processes that use dispersible radioactive materials in quantities sufficient to require continuous sampling.

\subsection{Compliance Requirements}

The primary drivers for the airborne radionuclide emission sampling and monitoring program are as follows:

- 40 CFR 61, Subpart H, "National Emission Standards for Emissions of Radionuclides other than Radon from Department of Energy Facilities" (2002) applies to DOE owned or operated facilities that emit radionuclides other than radon-222 and radon-220 to the air and require 1) evaluating potential radiological air emission sources for impact to the public and environment, 2) sampling release streams, 3) registering certain sources and emissions, 4) filing notices of construction for new and or modified sources, 5) complying with the 10-millirem (mrem) release standard, 6) evaluating best available control technology, 7) reporting emissions, and 8) maintaining a quality assurance program.

- 40 CFR 61, Subpart I, "National Emission Standards for Radionuclide Emissions from Federal Facilities Other Than Nuclear Regulatory Commission Licensees and Not Covered by Subpart H," (2002) applies to facilities owned or operated by any federal agency other than DOE and requires 1) complying with the 10-mrem release standard, 2) reporting emissions, and 3) maintaining a quality assurance program.

- WAC 246-247, "Radiation Protection-Air Emissions" (WAC 2005), provides licensing requirements for 1) monitoring facility radioactive air emissions, 2) evaluating potential radiological air emission sources for impact to the public and environment, 3) sampling 
release streams, 4) filing notices of construction for new and or modified sources, 5) complying with the 10-mrem release standard, 6) evaluating best available control technology, 7) reporting emissions, and 8) maintaining a quality assurance program.

- 40 CFR 70, "State Operating Permit Programs" (2007), provides for maintaining state air operating permit programs, demonstrating emission levels, and complying with permit conditions as applicable.

- WAC 173-401, “Operating Permit Regulation,” program (WAC 2011) requires applying for an air operating permit, demonstrating emission levels, and complying with permit conditions as applicable.

- DOE Order 450.1, "Environmental Protection Program” (DOE 2003), replaced DOE Order 5400.1, requires DOE sites to implement an Environmental Management System (EMS) as part of an Integrated Safety Management System, a continuing cycle of planning, implementing, evaluating, and improving processes and actions undertaken to achieve environmental goals.

- DOE Order 458.1 "Radiation Protection of the Public and the Environment" (DOE 2011), replaced DOE Order 5400.5, establishes requirements to protect the public and the environment against undue risk from radiation. Major portions of this order are not in the PNNL contract.

- DOE 5480.19, "Conduct of Operations Requirements for DOE Facilities” (DOE 2001), establishes requirements for the conduct of operations at DOE facilities to verify acceptable operations, provide for continuing improvements in the operations, and verify the maintenance of acceptable margins of safety.

- DOE/EH-0173T, "Environmental Regulatory Guide for Radiological Effluent Monitoring and Environmental Surveillance" (1991), establishes elements of a radiological effluent monitoring and surveillance program.

Facility airborne radionuclide emission sampling requirements are derived from 40 CFR 61, Subpart H and WAC 246-247. The regulations require:

- Continuous sampling at airborne emission units for which annual emissions could result in a potential effective dose equivalent (EDE) to an off-site individual of $0.1 \mathrm{mrem} / \mathrm{yr}$ or more.

- When continuous sampling is required, all radionuclides that contribute greater than $10 \%$ of the PTE total effective dose equivalent (TEDE) to the MEI, greater than $0.1 \mathrm{mrem} / \mathrm{yr}$ PTE TEDE to the MEI, and greater than $25 \%$ of the TEDE to the MEI after controls for a release point shall be measured.

- Any identified radioisotope with the PTE to meet the requirements of the bullet above shall be reported and, if not measured analytically, evaluated using 40 CFR 61, Appendix D as clarified by WDOH.

Washington State regulations primarily reflect federal regulations but are also allowed to be more stringent than federal regulations. EPA granted partial approval to WDOH's request for program approval and delegation of authority to implement and enforce the Radionuclide NESHAP program in 71 FR 32276-32282 (2006). 
The potential EDE to an off-site individual is based on a projection of the emissions that could result during normal operations and anticipated process upsets, assuming all pollution control equipment (e.g., high efficiency particulate air filter [HEPA]) did not exist. For EPA regulations, the MEI is a member of the public at any offsite point where there is a residence, school, business, or office. For the Washington State regulations, the MEI is any member of the public who abides or resides in an unrestricted area.

Facility emission rates are projected based on radionuclide quantities within each emission unit. Off-site unit dose factors are calculated using the EPA Clean Air Act Assessment Package-1988 (CAP88) computer model. Annual PTE doses are modeled using CAP88-PC for DOE sites, COMPLY for MSL and a location modification factor based on CAP88-PC for private facilities in Richland, WA (e.g., Research Technology Laboratory [RTL]). Table 1.5 summarizes the unabated potential offsite dose and, for major emission units, the nuclides identified in the permit application that could contribute greater than $10 \%$ of the PTE dose to the MEI, or $>0.1 \mathrm{mrem} / \mathrm{yr}$ PTE dose to the MEI, or $>25 \%$ of the dose to the MEI after controls. 
Table 1.5. Facility NESHAP Compliance Summary

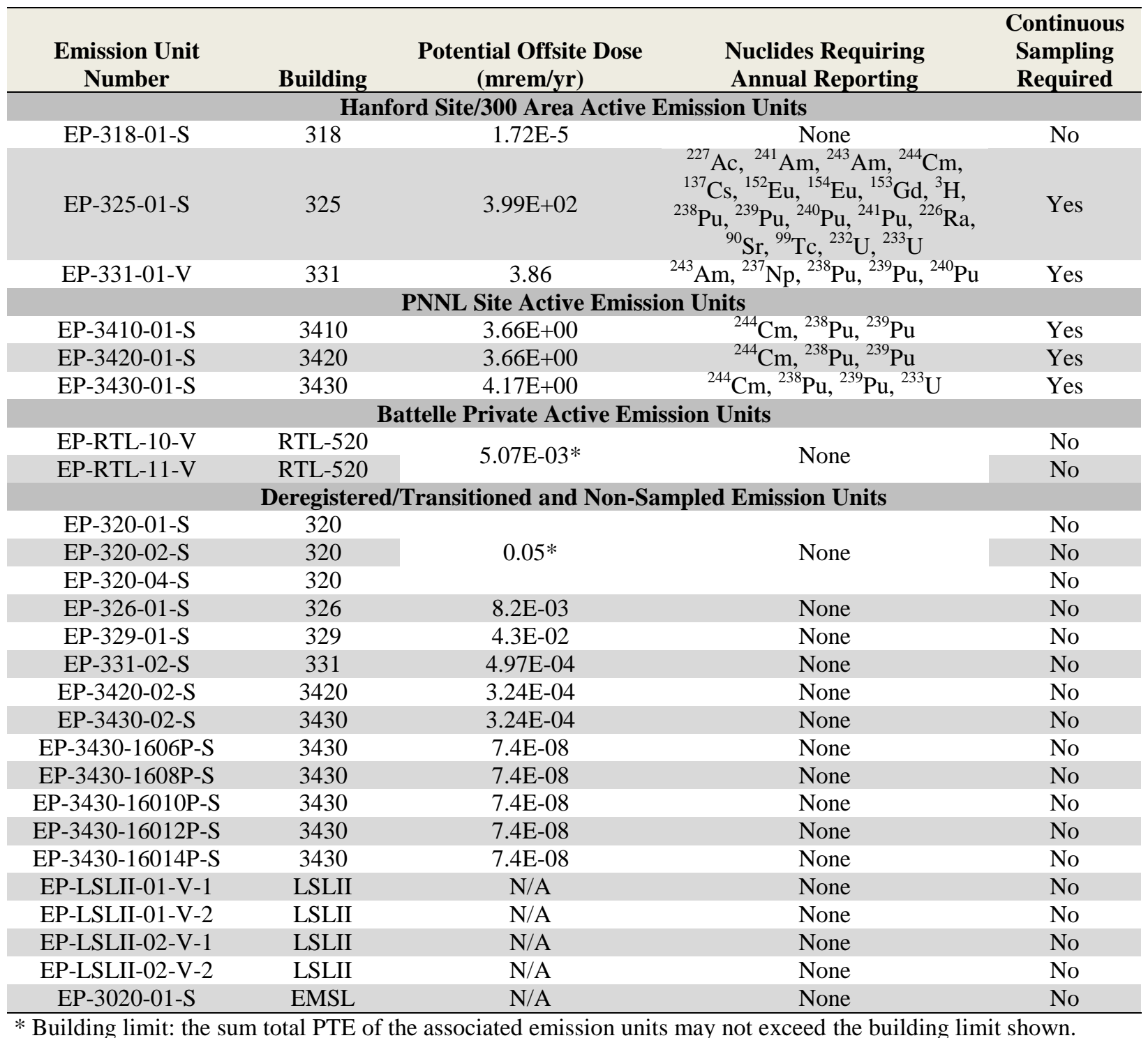




\subsection{Sampling System Design}

Both federal and state regulations incorporate ANSI N13.1for sampling system design requirements. Prior to September 2002, the 1969 method was utilized; after September 2002, federal regulations adopted ANSI N13.1-1999 (ANSI 1999) for new or modified systems. Data on sampler design characteristics were obtained from facility safety analysis reports, engineering drawings, vendor design documents, and system inspections. Since 1991, PNNL's Effluent Management (EM) has been involved with the facility modification process to verify that systems are designed and installed as required and that design drawings are maintained.

\subsection{Stack Velocity and Cyclonic Flow Measurements}

The stack velocity and cyclonic flow conditions at the sample extraction point are measured according to 40 CFR 60, Appendix A, Method 2 (1971). PNNL Facilities \& Operations (F\&O) staff performs these measurements in support of the effluent monitoring task.

The following PNNL procedures were derived from the regulatory guides and are used by the F\&O Air Balance staff:

- EPRP-AIR-016, "PNNL Stack/Duct Velocity Traverse Method"

- EPRP-AIR-017, "Verification of Absence of Cyclonic Flow Conditions in Stacks and Vents"

- EPRP-AIR-019, "Standard and Type-S Pitot Tube Specifications Inspection Procedure."

\subsection{Sampling Program}

\subsubsection{Schedule}

The basic sampling frequency is provided in Table 1.1. The sampling program includes:

- Continuous sampling - The sampler is operated continuously throughout the year. The sample is exchanged approximately every 2 weeks.

- Quarterly sampling-A sample is collected every quarter for a 2-week period.

- Annual sampling - A sample is collected once a year for a 2-week period.

- Special sampling-A sample is collected as needed to follow up on sampler problems or investigate anomalies in sample results.

- Other sampling - A sample may be collected from system cleaning or other activity or study.

\subsubsection{Particulate Sample Collection and Analysis}

Particulate record samples are collected using a 47-mm membrane filter (Gelman Sciences Versapor 3000®-membrane, acrylic copolymer membrane filter) supported by a filter holder. The membrane filter has an estimated retention efficiency of greater than $99 \%$ for $0.3-\mu$ particles (Pall Corporation 2000). 
Two-week particulate record samples are collected on an annual, quarterly, or continuous basis. Sample systems are inspected for proper flow-rate settings and system operation daily, excluding weekends and holidays, during sampling events. Sample systems are enclosed in metal cabinets for protection from inclement weather. See Appendix A for sample analysis and data evaluation requirements.

\subsubsection{Sample Flow Rate Systems}

Stack sample flow rate systems follow guidance provided in ANSI N13.1. Depending on the year the system was put into service or modified, ANSI N13.1-1969 or ANSI N13.1-1999 is utilized. Table 1.1 identifies which version of the ANSI N13.1 standard to which the emission unit is designed and operated. Additional information is provided below and in the appendixes for specific emission units.

For ANSI N13.1-1969 systems, PNNL measures the sample flow rate by a Brooks Instrument GT-1000 (0.586 to 5.86 standard cubic feet per minute [scfm]) rotameter and adjusted using a throttle valve (both located just downstream of the filter holder). A vacuum gauge (0 to 100 in. of water) is installed on the inlet side of the rotameter and used to correct the sample flow for vacuum conditions. Sampler flows are set at or near isokinetic based on stack flow measurements that are performed on an annual basis. The rotameter and vacuum gauge are calibrated and exchanged annually.

For ANSI N13.1-1999 systems, PNNL measures the sample flow rate by using a Masstron (1.0 to 4.0 standard cubic feet per minute $[\mathrm{scfm}]$ ) Flow Transmitter. The radiological air emissions sampling (RAES) system measures both the total stack exhaust mass flow rate and a representative variable sample mass flow rate with the sample flow being extracted from the building exhaust air stack. The sample flow rate is maintained proportionally to the stack air flow rate and operates over the calibrated range of air velocities and temperature with a minimum turndown ratio of 10:1. The RAES system interfaces with the vacuum air sampling system that draws the stack air samples through an extraction nozzle located on the sample probe.

\subsubsection{Tritium Sample Collection and Analysis}

Tritium sample collection is specific to the 325 Building main stack. Tritium sample collection details are provided in the 325 Radiochemical Processing Laboratory (RPL) section of this manual. See Appendix B for sample analysis and data-evaluation requirements. 


\subsection{Procedures}

PNNL's EM group maintains documented technical and operating procedures for all aspects of effluent monitoring. The PNNL standards-based management system How Do I? (HDI) workflow "Procedures, Permits, and Other Work Instructions" (PNNL 2004) contains the requirements for preparation, review, and approval of these procedures. EM procedures incorporate all required elements of the aforementioned subject area.

EM procedures follow the department procedure EPRP-ADMIN-003, "EPRP Work Instruction," requirements and format (PNNL 2010b). Key work processes requiring procedures to conduct radioactive air emission monitoring tasks include:

- prepare notice of construction (NOC) applications

- measure facility exhaust flow rates and conditions

- determine sample system collection efficiencies

- collect samples

- operate the 325 Building continuous air monitor (CAM)

- respond to unplanned/unexpected emission measurements

- inspect emission unit sample lines and instrumentation.

Table 3.1 identifies the EM procedures used in sampling and monitoring PNNL radiological emission units.

Table 3.1. Effluent Management Radiological Air Monitoring/Sampling Procedures

\begin{tabular}{|c|c|}
\hline $\begin{array}{l}\text { Procedure } \\
\text { Number* }\end{array}$ & Procedure Title \\
\hline EPRP-AIR-004 & Chain-of-Custody Procedure \\
\hline EPRP-AIR-005 & Troubleshooting and Repair of Stack Emission Sampling/Monitoring Systems \\
\hline EPRP-AIR-010 & Stack Particulate Sampling Procedure \\
\hline EPRP-AlR-011 & 325 Building Stack Tritium Sampling Procedure \\
\hline EPRP-AlR-013 & Preparing Notice of Construction Applications for Radioactive Air Emissions \\
\hline$\overline{\text { EPRP-AIR-014 }}$ & Line Loss Calculations for Radiological Air Emissions Monitoring \\
\hline$\overline{\text { EPRP-AIR-015 }}$ & Evaluating Rad Air Effluent Sampling Data \\
\hline EPRP-AIR-016 & PNNL Stack/Duct Velocity Traverse Method \\
\hline EPRP-AIR-017 & Verification of Absence of Cyclonic Flow Conditions in Stacks and Vents \\
\hline EPRP-AIR-019 & Standard and Type-S Pitot Tube Specifications Inspection Procedure \\
\hline$\overline{\text { EPRP-AIR-020 }}$ & Videoscope Inspection and Assessment of Stack Sample Lines \\
\hline EPRP-AIR-021 & $\begin{array}{l}\text { Source Response and Calibration Test on the PNNL OS3300 Stack Particulate Radionuclide Monitoring } \\
\text { System at the } 325 \text { Building Main Stack }\end{array}$ \\
\hline EPRP-AIR-022 & $\begin{array}{l}\text { Source Response and Calibration Test on the PNNL OS3700 Tritium Monitoring System for the } 325 \\
\text { Building Main Stack }\end{array}$ \\
\hline EPRP-AIR-023 & 325 Building Stack Radionuclide Sampling and Monitoring Systems Daily Inspection \\
\hline EPRP-AIR-024 & 325 Stack PNNL OS3700 Tritium CAM Alarm Test Procedure \\
\hline EPRP-AIR-025 & RPL Stack PNNL OS3300 Alpha/Beta CAM Filter Exchange \\
\hline EPRP-AIR-026 & Operation of the PNNL OS3300 Stack Particulate Monitoring System at the 325 Building Main Stack \\
\hline$\overline{\text { EPRP-AIR-027 }}$ & Operation of the PNNL OS3700 Tritium Emission Monitoring System at the 325 Building Main Stack \\
\hline$\overline{\text { EPRP-AIR-028 }}$ & PSF Radioactive Air Emissions Sampling (RAES) Systems Filter Exchange and Inspection \\
\hline EM-AIR-TWD-005 & 331 Building Stack Probe Removal and Particulate Deposition Sample Collection \\
\hline \multicolumn{2}{|c|}{$\begin{array}{l}\text { The procedures listed above can be accessed at https://wwwi.pnl.gov/emsd/procedures/xml/procedures.asp\#04 } \\
\text { The access date for the procedure list was } 04 / 09 / 2012 \text {. } \\
\text { *The EPRP procedure designator has historically changed to accommodate the department or division name. It can therefore } \\
\text { sometimes show up as EM, EMS, or EMSD. }\end{array}$} \\
\hline
\end{tabular}




\subsection{Sample System Performance}

Sampler transport efficiencies are calculated for all particulate sample systems with varying stack and sampler flow rates using procedure EPRP-AIR-014, "Line Loss Calculations for Radiological Air Emissions Monitoring." This procedure uses the DEPO software referenced in Nuclear Regulatory Commission (NRC) Regulatory Guide 8.25 (1992) as an acceptable method for calculating the penetration of particles through sampling systems. Results are graphed for each system so that transport efficiencies can be more easily obtained over anticipated potential future stack and sampler flow rates. Copies of the applicable graphs and the line-loss calculations are contained in the EM Rad Air File Plan. Table 1.3 summarizes the results of the total sample system efficiency calculations.

Recommendations to use DEPO to evaluate PNNL stacks are described in an internal letter from John Glissmeyer to Monte Sula dated August 27, 1991 (Glissmeyer 1991). A full text copy of this letter is provided in Appendix C. 


\subsection{Potential Off-Site Dose and Principle Radionuclides}

The potential EDE to an individual is an inventory-based projection of the emissions that could result during normal operations, assuming the emissions are not reduced by installed emission control equipment.

A radionuclide inventory assessment is performed on an annual basis to determine facility PTE (in mrem/yr). This assessment is used to verify compliance with the EPA and WDOH permits and to determine the need for continuous compliance sampling (40 CFR 61, Subpart H). The results of past and current annual NESHAPS assessments are provided through the EM website: https://wwwi.pnl.gov/emsd/em/. 



\subsection{References}

40 CFR 60. Appendix A. 1971. "Standards of Performance for New Stationary Sources, Appendix A: Test Methods." U.S. Code of Federal Regulations. U.S. Environmental Protection Agency.

40 CFR 61. 1989. "National Emissions Standards for Hazardous Air Pollutant.” U.S. Code of Federal Regulations. U.S. Environmental Protection Agency.

40 CFR 61, Appendix B, Method 114. 2002. "Test Methods for Measuring Radionuclide Emissions from Stationary Sources.” U.S. Code of Federal Regulations. U.S. Environmental Protection Agency.

40 CFR 61, Appendix D. 1989. "Methods for Estimating Radionuclide Emissions." U.S. Code of Federal Regulations. U.S. Environmental Protection Agency.

40 CFR 61, Subpart H. 2002. "National Emission Standards for Emissions of Radionuclides Other Than Radon from Department of Energy Facilities." U.S. Code of Federal Regulations. U.S. Environmental Protection Agency.

40 CFR 61, Subpart I. 2002. "National Emission Standards for Radionuclide Emissions from Federal Facilities Other Than Nuclear Regulatory Commission Licensees and Not Covered by Subpart H.” U.S. Code of Federal Regulations. U.S. Environmental Protection Agency.

40 CFR 70. 2007. "State Operating Permit Programs.” U.S. Code of Federal Regulations. U.S. Environmental Protection Agency.

71 FR 32276-32282. June 5, 2006. "Partial Approval of the Clean Air Act, Section 112(1), Delegation of Authority to the Washington State Department of Health." Federal Register. U.S. Environmental Protection Agency.

ANSI-American National Standards Institute. 1970. Guide to Sampling Airborne Radioactive Materials in Nuclear Facilities. ANSI N13.1-1969, Washington, D.C.

ANSI/HPS - American National Standards Institute/Health Physics Society. 1999. Sampling and Monitoring Releases of Airborne Radioactive Substances from the Stacks and Ducts of Nuclear Facilities. ANSI/HPS N13.1-1999, Washington, D.C.

Ballinger MY and TL Gervais. 2011. Assessment of Unabated Facility Emission Potentials for Evaluating Airborne Radionuclide Monitoring Requirements at Pacific Northwest National Laboratory. PNNL-10855, Rev. 5, Pacific Northwest National Laboratory, Richland, WA.

Barfuss BC. 2007. Development of a Tritium Dilution Factor from Measured Laboratory Emissions and Localized Ambient Air Sampling Measurements. Washington State University, Pullman, WA. 
Barnett JM, LA True, and DD Douglas. 2004. Review of Tritium Emissions Sampling and Monitoring from the Hanford Site Radiochemical Processing Laboratory. In Proceedings of the HPS 2004 Midyear Meeting - Air Monitoring and Internal Dosimetry, February 8-11, 2004, Augusta, GA, pp. 199-204, Health Physics Society, McLean, Virginia.

DOE-U.S. Department of Energy. 1990. "General Environmental Protection Program." DOE Order 5400.1, Change 1, Washington, D.C.

DOE-U.S. Department of Energy. 1991. Environmental Regulatory Guide for Radiological Effluent Monitoring and Environmental Surveillance. DOE/EH-0173T, Washington, D.C.

DOE-U.S. Department of Energy. 2001. "Conduct of Operations Requirements for DOE Facilities.” DOE Order 5480.19, Change 2, Washington, D.C.

DOE-U.S. Department of Energy. 2003. "Environmental Protection Program." DOE Order 450.1, Washington, D.C.

DOE-U.S. Department of Energy. 2011. "Radiation Protection of the Public and the Environment." DOE Order 458.1, Change 1, Washington, D.C.

Glissmeyer JA. 1991. "Recommendation of Particle Line-Loss Code.” Letter to MJ Sula. Pacific Northwest National Laboratory, Richland, Washington.

Pall Corporation. 2000. SLS Report No. 9069. Private Communication.

PNNL—Pacific Northwest National Laboratory. 2004. "Procedures, Permits, and Other Work Instructions." HDI, Pacific Northwest National Laboratory, Richland, Washington. Accessed at https://hdi-sa.pnl.gov/standard/74/7400t010.htm.

PNNL—Pacific Northwest National Laboratory. 2010a. Pacific Northwest National Laboratory Potential Impact Categories for Radiological Air Emission Monitoring. PNNL-19904, Rev 3. Richland, WA. Accessed at https://wwwi.pnl.gov/emsd/em/procedures/impactcategories.stm

PNNL—Pacific Northwest National Laboratory. 2010b. "EPRP Work Instruction.” EM/EPRP Procedures. Pacific Northwest National Laboratory, Richland, Washington. Accessed at https://wwwi.pnl.gov/emsd/procedures/xml/details.asp?docNumber=EPRP-ADMIN-003.

NRC-U.S. Nuclear Regulatory Commission. 1992. Air Sampling in the Workplace. NRC Regulatory Guide 8.25, Washington, D.C.

WAC-Washington Administrative Code. 2005. "Radiation Protection-Air Emissions." WAC 246-247, Olympia, WA.

WAC-Washington Administrative Code. 2011. “Operating Permit Regulation.” WAC 173-401, Olympia, WA. 


\section{Appendix A}

\section{Particulate Sample Analysis and Data Evaluation}





\section{Appendix A: Particulate Sample Analysis and Data Evaluation}

The Radiochemical Sciences and Engineering (RS\&EG) group of PNNL's RPL performs particulate sample analyses. All analytical work associated with radionuclide sampling is performed according to required methods per the PNNL statement of work (SOW), "Airborne Radionuclide Emission Sample Analysis." The SOW is prepared to meet the Quality Assurance (QA) Requirements from 40 CFR 61, Appendix B, Method 114 (2002). Procedures for performing analyses are used and maintained by analytical laboratory staff.

After collection, the sample filter is stored for a minimum of 4 days and 10 hours to permit decay of radon and thoron daughter radionuclides. Each sample is individually counted for gross alpha and gross beta activity. The analytical laboratory staff use direct counting methods for total alpha and total beta activity using a solid-state, gas-flow, proportional, alpha-beta, coincidence counter. The counter is calibrated using ${ }^{238} \mathrm{Pu}$ for alpha and ${ }^{90} \mathrm{Sr}$ for beta. Detection levels of $7 \mathrm{pCi} / \mathrm{mL}$ alpha and $140 \mathrm{pCi} / \mathrm{mL}$ beta are required.

In addition to the above individual sample analyses, particulate samples from "major" stacks are combined and analyzed semi-annually as a single "composite" sample for specific radionuclides as determined by the annual inventory assessment. A composite sample consists of 6-months' worth of individual samples (typically January through June and July through December). Radionuclides identified by the assessment (e.g., from RMT) that contribute greater than $10 \%$ of the PTE TEDE to the maximally exposed individual (MEI) before controls, greater than 0.1 mrem/yr PTE TEDE to the MEI before controls, and greater than $25 \%$ of the TEDE to the MEI after controls for a release point are analyzed isotopically. Specific nuclide analysis is accomplished by destructive analysis of the filters. The analytical laboratory documents detection levels for specific isotope analysis performed and includes the appropriate quality control (QC) samples so that reasonable estimates of confidence in the data can be made. QC sample results are used to verify instrument control and detect out-of-control conditions.

The sample results obtained are used to evaluate existing facility emission levels and to calculate annual emission quantities for compliance determination and reporting purposes. Data are evaluated using documented and approved procedures. Data evaluation procedures are based on guidance in DOE/EH-0173T (1991).

Airborne-emission sampling data are reviewed for anomalies and trends. Release data are updated periodically throughout the sampling year (calendar year). At the completion of the calendar year, data are reviewed, and results are finalized. Anomalous data are investigated and documented. Final release quantities include corrections for isokinetic sampling efficiency, sample transport losses, sample self-absorption, decay, counting efficiency, background, and collection media efficiency. 



\section{Appendix B}

Tritium Sample Analysis and Data Evaluation 



\section{Appendix B: Tritium Sample Analysis and Data Evaluation}

The RS\&EG group performs tritium sample analyses. All analytical work associated with the tritium sampling is performed according to required methods per the PNNL SOW, "Airborne Radionuclide Emission Sample Analysis." The SOW is prepared to meet the QA requirements from 40 CFR 61, Appendix B, Method 114 (2002). Procedures for performing analyses are used and maintained by analytical laboratory staff.

Tritium sample analysis consists of removing absorbed water vapor from silica gel columns by vacuum distillation. An aliquot of recovered water is analyzed for tritium content by liquid scintillation spectrometry. Instrument and reagent blanks are analyzed with each batch of samples counted for quality assurance. The detection level for tritium in water, as specified in the $\mathrm{SOW}$, is $180 \mathrm{pCi} / \mathrm{L}$. The PNNL tritium samplers are designed and operated to provide the required sample size. The sensitivity of the measurement is highly dependent on the water loading of the sampler, with analytical sensitivity indirectly proportional to sampler loading. Tritium-emission quantities for the collection period are calculated assuming complete retention of the sample in the collection column and multiplying the quantity of tritium collected in the column by the ratio of the stack flow rate to the sampler flow rate.

Results obtained from tritium sampling are used to evaluate existing facility emission levels and to calculate annual emission quantities for compliance determination and reporting purposes. Data are evaluated using documented and approved procedures. Data evaluation procedures are based on guidance in DOE/EH-0173T (1991).

Tritium emission sampling data are reviewed for anomalies and trends. The tritium released is updated periodically throughout the sampling year (calendar year). At the completion of the calendar year, data are reviewed, and the results are finalized. Anomalous data are investigated and documented. Final release quantities include corrections for counting efficiency, background, and sample-recovery efficiency. Additional information on tritium sampling and analysis is available in Barfuss (2007) and Barnett et al. (2004). 



\section{Appendix C}

\section{Recommendation of Particle Line-Loss Code}





\section{Appendix C: Recommendation of Particle Line-Loss Code}

SWattelle

Pacific Northwest Laboratories

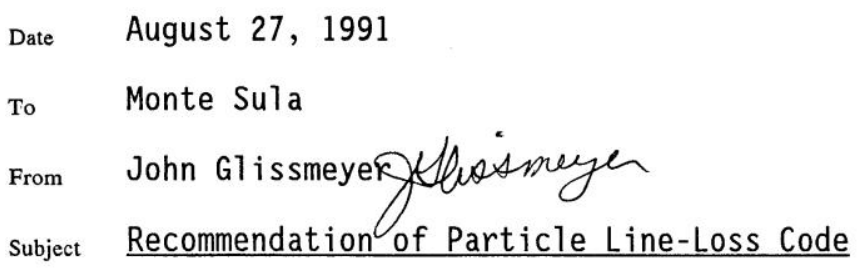

Project NumberM87846

Internal Distribution

J Johnston

SJ Jette

$\mathrm{File} / \mathrm{LB}$

Five usable computerized models were identified. These were:

- EEG as described by Rodgers (1987) and modified to allow broader application and repeat runs.

- PARTPEN developed from the report by Schwendiman and Glissmeyer (1977),

- ARGONNE developed by Novick and described by Schlenger ${ }^{1}$

- TEXAS A \& M described by Anand et. al. (1990), and

- ASTEC developed at Sandia by Yamano and Brockman (1989).

The capabilities of each code were reviewed in detail. All of the codes were similar in that they are combinations of various theoretical or empirical models developed to describe particle deposition due to various phenomena. It is simplistically assumed that the effects of each deposition mechanism are independent and additive. Each deposition mechanism is applied as deemed appropriate for the particle transport conditions under consideration. The various mechanisms and models are not described or evaluated in this summary. That would be worthwhile documenting later. Table la lists the sources of the various models incorporated into each code. (The table references are not included here for brevity.) Table lb shows some of the features of each code.

It was my original intent to select a code based on my review of the merits of the component models. However, having found two tests of simulated air sampling systems, I decided to compare the code predictions against the test cases and base my recommendation thereon. The two test cases were:

- Strom (1972) - where a vertical loop of 2-in. pipe was tested for the transport of various particle sizes and flow rates when the particles were aspirated from a generating chamber. The 1oop consisted of two vertical pipes, two horizontal pipes, and connecting bends.

1 Schlenger, B. J. Memorandum to B. W. Spencer of June 8, 1988. Argonne National Laboratory. 
- McFarland (described in Fan, et. al., 1991) - where a simple air sampler was tested for various particle sizes and flow conditions when the particles were aspirated from a wind tunnel. The piping consisted of a horizontal probe and pipe, a vertical and inclined section and two bends. The nozzle was aligned both parallel and perpendicular to the flow in the wind tunnel.

Table la shows that neither the PARTPEN, nor ARGONNE codes include the capability for accounting for particle bias caused by isokinesis. The isokinesis results from the EEG code were incorporated into those codes to complete the analysis for the McFarland test case. Isokinesis was not an issue for the Strom test case. The Sandia code (ASTEC) included the capability for analyzing isokinesis only when the nozzle was axial, or parallel, to the flow. Hence, results for the perpendicular orientation are missing. The EEG results could have been incorporated in this instance too, and should be investigated later; however, it did not seem appropriate at the time to use two isokinesis approaches in the same code and thereby use different versions in certain instances.

Table 2 lists the particle penetration data and predictions for the two test cases combined. Together with Jim Johnston (a statistician in the Analytical Sciences Department, Applied Physics Center) we decided to judge which model best fits the test case data according to four criteria: 1) the minimum standard deviation of the differences between the experimental data and the code predictions; 2) the minimum average difference between experiment and code prediction; 3 ) the linear regression with the slope nearest one; and 4) the linear regression with the intercept nearest zero.

We were encouraged when there seemed to be one or two clear preferences in the two test cases taken separately. Unfortunately, the preferences were different for the two test cases. Furthermore, a clear preference disappeared when the two test cases were combined.

Table 3 lists the criteria statistics (and others) for the Strom test cases. For the Strom case, the EEG code appears best overa11. The standard deviation of the differences and the maximum absolute difference were smallest. The regression analysis shows that the EEG values have the slope closest to one and the constant (intercept) closest to zero. The second place PARTPEN code has a better (larger) R-Square (correlation), a smaller average absolute difference, but a definitely biased slope and intercept. These results can also be observed in the Figure 1 plot of the data. 


\begin{tabular}{|c|c|c|c|c|c|c|}
\hline \multirow{3}{*}{$\begin{array}{l}\frac{5}{0} \\
\frac{0}{5} \\
\frac{0}{0}\end{array}$} & 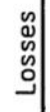 & & & 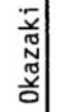 & & $\begin{array}{l}\overline{\widetilde{J}} \\
\widetilde{N} \\
\tilde{\sigma}\end{array}$ \\
\hline & $\stackrel{3}{=}$ & & 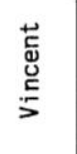 & 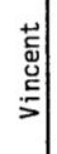 & & \\
\hline & $\underset{x}{x}$ & & 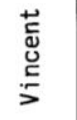 & 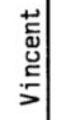 & & 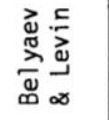 \\
\hline \multirow{2}{*}{ 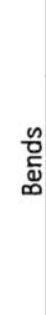 } & 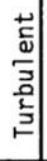 & 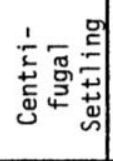 & $\begin{array}{l}\infty \\
\Xi \\
\vdots\end{array}$ & $\begin{array}{l}\overline{\tilde{\omega}} \\
\overline{\mathrm{E}} \\
\mathrm{\Phi}\end{array}$ & 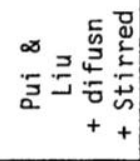 & 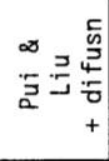 \\
\hline & | & & & & 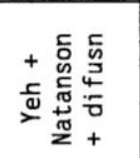 & 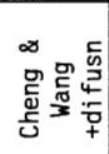 \\
\hline \multirow{2}{*}{ 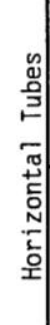 } & 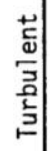 & 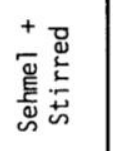 & 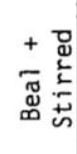 & & 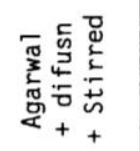 & 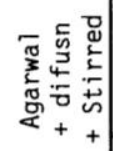 \\
\hline & : & & & $\begin{array}{l}c \\
0 \\
\stackrel{0}{n} \\
\stackrel{\pi}{2}\end{array}$ & 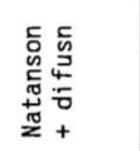 & 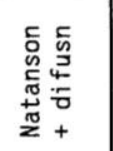 \\
\hline \multirow{2}{*}{ 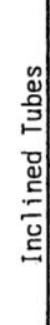 } & $\begin{array}{l}\text { 苟 } \\
\frac{0}{3} \\
\frac{5}{5} \\
\vdots\end{array}$ & & 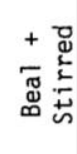 & & 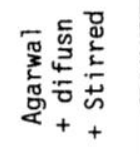 & 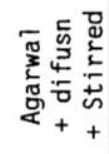 \\
\hline & : & & & 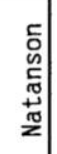 & 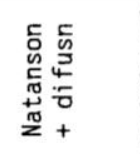 & 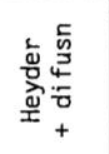 \\
\hline \multirow{2}{*}{ 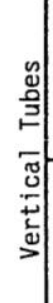 } & 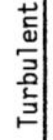 & 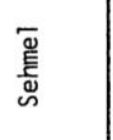 & '్ָ & $\begin{array}{l}-\overline{0} \\
\frac{\pi}{3} \\
0 \\
0\end{array}$ & 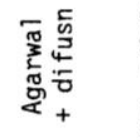 & 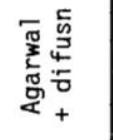 \\
\hline & 畜 & & & & 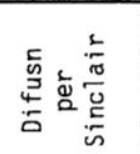 & 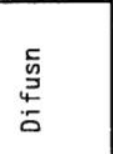 \\
\hline & $\begin{array}{l}\overline{0} \\
\frac{0}{2}\end{array}$ & 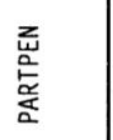 & 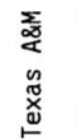 & 㞻 & 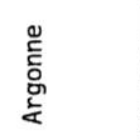 & 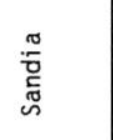 \\
\hline
\end{tabular}

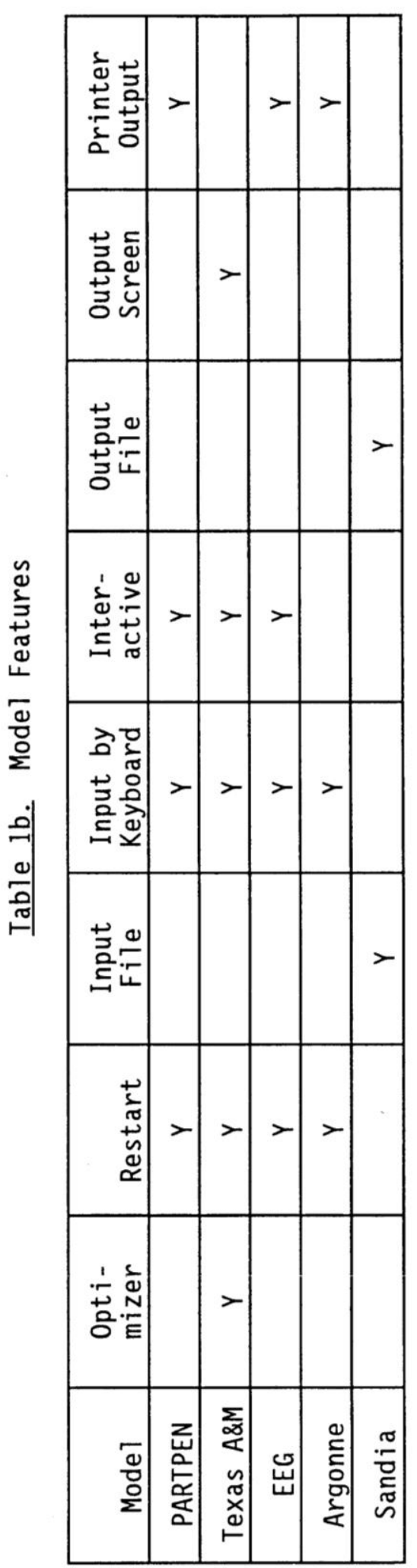


Table 2. Experimental Data and Code Predictions of Particle \% Penetration Part.

Flow diam.
lpm micron Data $\underline{\text { EEG Partpen }} \underline{\text { Argonne }} \underline{\text { Texas }} \underline{\text { Sandia }}$

Strom's test case:

$\begin{array}{rrrrrrrr}19.65 & 2.1 & 95.4 & 96.6 & 96.7 & 96.3 & 95.5 & 97 \\ & 4.7 & 87.1 & 85.1 & 84.3 & 83.7 & 80.32 & 86.5 \\ & 8 & 59.3 & 59.5 & 61.1 & 58.3 & 53.43 & 65.4 \\ 34.35 & 15 & 11.3 & 4.7 & 17.6 & 4.8 & 11.08 & 16.7 \\ & 2.1 & 100.5 & 97.8 & 97.2 & 95.4 & 95.48 & 95.2 \\ & 4.7 & 95.2 & 90.2 & 86.7 & 80.0 & 80.12 & 79.2 \\ 61.31 & 8 & 70.5 & 67 & 66 & 52.1 & 52.65 & 50.6 \\ & 15 & 13.8 & 16.5 & 23.1 & 8.8 & 9.55 & 7.8 \\ & 2.1 & 101 & 98.5 & 96.5 & 93.7 & 93.95 & 93.6 \\ & 4.7 & 90.6 & 88.9 & 83.6 & 73.0 & 73.53 & 72.1 \\ & 8 & 54.7 & 61.5 & 59.3 & 37.5 & 39.14 & 35.7 \\ & 15 & 10.6 & 7 & 15.6 & 1.1 & 0.89 & 7.8\end{array}$

\begin{tabular}{|c|c|c|c|c|c|c|c|}
\hline $\mathrm{McFa}$ & $d^{\prime} s$ & case: & & & & & \\
\hline 70 & 3 & 100 & 98.8 & 97.7 & 96.0 & 98.14 & 97 \\
\hline Axial & 4.38 & 98 & 97.7 & 96.3 & 93.0 & 96.15 & \\
\hline & 6.41 & 93 & 95.7 & 92.3 & 85.7 & 92.04 & 88 \\
\hline & 9.36 & 83.5 & 89.3 & 86.4 & 73.6 & 83.74 & 76.7 \\
\hline & 13.7 & 68 & 76.7 & 74.1 & 52.8 & 68.08 & 57.2 \\
\hline & 20 & 31 & 54.9 & 53.4 & 25.4 & 43.04 & 30 \\
\hline 130 & 3 & 97 & 98.9 & 97.4 & 94.9 & 96.79 & 95.2 \\
\hline Axial & 4.38 & 93 & 97.9 & 95.6 & 90.5 & 93.6 & 90.3 \\
\hline & 6.41 & 87 & 93.7 & 90.8 & 81.0 & 86.37 & 80.6 \\
\hline & 9.36 & 73.5 & 84.9 & 80.8 & 63.1 & 73.02 & 3.2 \\
\hline & 13.7 & 46 & 67.7 & 65.0 & 37.4 & 50 & 6.7 \\
\hline & 20 & 8 & 38.8 & 41.0 & 10.9 & 17.48 & $10 ?$ \\
\hline 70 & 3 & 96 & 95.5 & 94.8 & 93.1 & 9496 & \\
\hline Perp. & 4.38 & 92 & 91.1 & 89.5 & 86.4 & 89.73 & \\
\hline & 6.41 & 82 & 82.7 & 80.1 & 74.3 & 79.74 & \\
\hline & 9.36 & 63.5 & 66.7 & 64.4 & 54.8 & 62.9 & \\
\hline & 13.7 & 31.5 & 44.1 & 42.8 & 30.5 & 39.51 & \\
\hline & 20 & 5 & 20.9 & 20.2 & 9.6 & 16.62 & \\
\hline 130 & & 95 & 96.9 & 95.4 & 93.0 & 94.8 & \\
\hline Perp. & 4.38 & 92.5 & 93.6 & 90.8 & 85.9 & 89.36 & \\
\hline & 6.41 & 86 & 85.4 & 82.5 & 73.6 & 78.84 & \\
\hline & 9.36 & 72 & 70.3 & 67.2 & 52.5 & 60.72 & \\
\hline & 13.7 & 38 & 47.1 & 45.2 & 26.0 & 34.98 & \\
\hline & 20 & & 20.2 & 21.5 & 5.7 & 9.2 & \\
\hline
\end{tabular}


Table 3. Comparisons of Goodness of Fit Criteria for Strom's Data Versus Predictive Models

$\begin{array}{lrrrrr} & \text { EEG } & \text { Partpen } & \text { Argonne } & \text { Texas } & \text { Sandia } \\ \text { No. Data Points } & 12 & 12 & 12 & 12 & 12 \\ & & & & & \\ \text { Differences } & & & & & \\ \quad \text { Average } & -1.392 & -0.192 & -8.777 & -8.697 & -6.867 \\ \text { sd(diff.) } & 3.643 & 5.699 & 6.750 & 6.322 & 9.465 \\ \text { t=Ave/sd(Ave) } & -1.323 & -0.116 & -4.504 & -4.765 & -2.513 \\ \text { Max |diff| } & 6.8 & 9.3 & 18.36 & 17.85 & 19.9 \\ & & & & & \\ \text { Regression } & 1.815 & -9.290 & 10.325 & 8.311 & 6.408 \\ \text { Constant } & 0.9934 & 1.1445 & 0.9729 & 1.0067 & 1.0078 \\ \text { Slope } & 98.97 & 99.05 & 96.54 & 96.90 & 93.05 \\ \text { R-Sq } \% & 0.206 & -4.086 & 0.46 & 0.119 & 0.089 \\ \text { t for slope=1 } & & & & & \end{array}$

$\bar{A}$-value of 2.201 is significant at the $95 \%$ confidence level for 11 degrees of freedom.

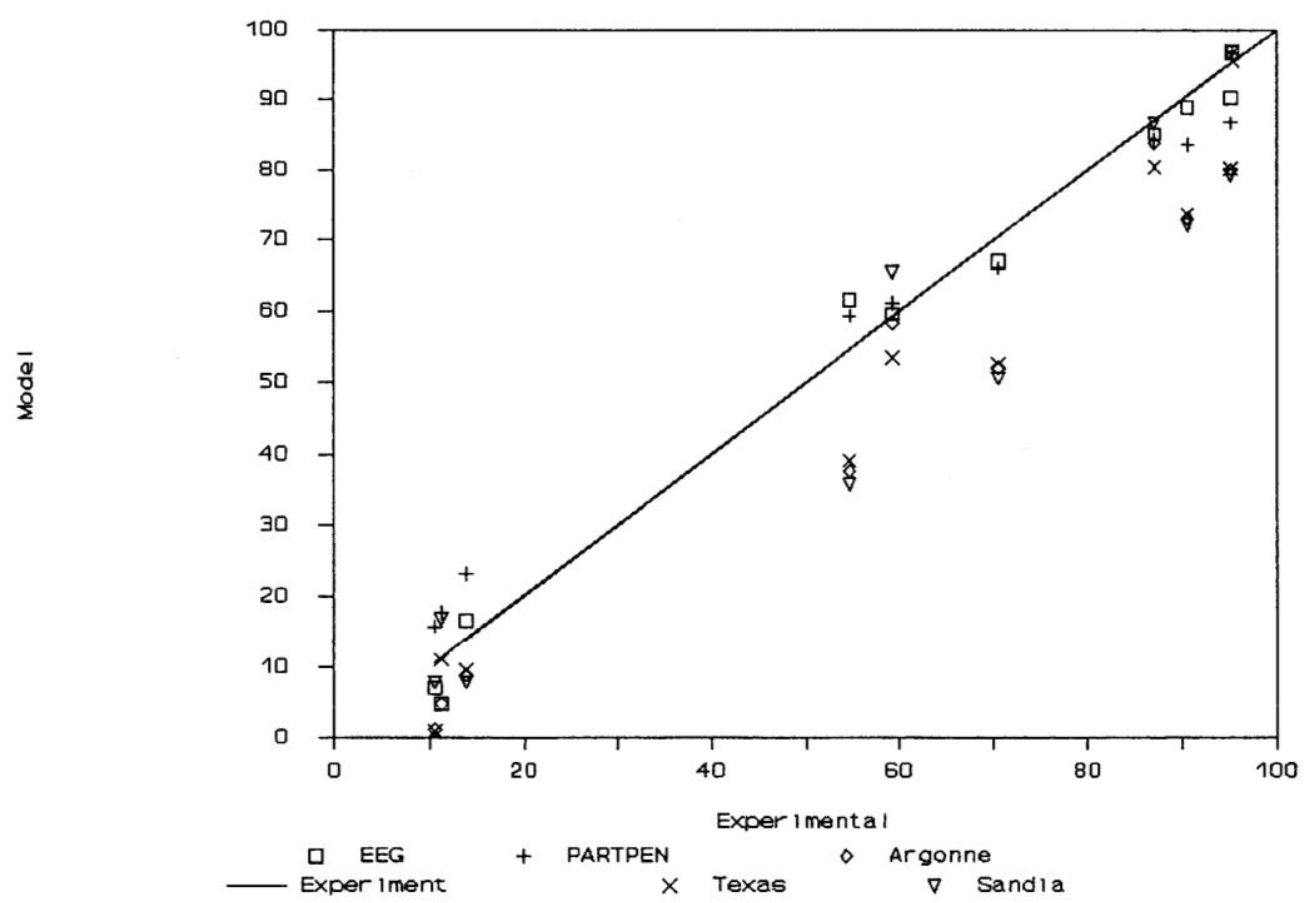

Figure 1 Comparison of Model vs Experimental Data For Strom's Test Case 
Table 4 lists the criteria statistics for the McFarland test case. For the McFarland test, none of the codes has as good an agreement with the data as in the Strom case. By criteria 1, 3 and 4 the Sandia code looks best, but that is only based on half as many data points as the rest of the analysis. The Texas $A$ \& $M$ code looks next best with the best minimum average difference. However, the regression slope is significantly different from unity and the intercept is large. If the Sandia code is eliminated, the Argonne code looks best in the regression based criteria and the Texas A \& M code in the difference based criteria. These results can also be observed by examining the Figure 3 plot of the experimental vs model data.

Table 4. Comparisons of Goodness of Fit Criteria for McFarland's Data Versus Predictive Models

$\begin{array}{lrrrrr} & \text { EEG } & \text { Partpen } & \text { Argonne } & \text { Texas } & \text { Sandia } \\ \text { No. Data Points } & 24 & 24 & 24 & 24 & 12 \\ & & & & & \\ \text { Differences } & & & & & \\ \quad \text { Average } & 6.57 & 4.69 & -6.14 & 0.38 & -4.91 \\ \quad \text { sd(diff.) } & 8.8081 & 9.369 & 5.5496 & 5.3758 & 4.0407 \\ \text { t=Ave/sd(Ave) } & 3.656 & 2.453 & -5.421 & 0.346 & -4.279 \\ \quad \text { Max |diff| } & 30.78 & 33.02 & 19.49 & 11.62 & 10.8 \\ \text { Regression } & & & & & \\ \quad \text { Constant } & -26.093 & -26.449 & 4.126 & -8.458 & 3.757 \\ \quad \text { Slope } & 1.251 & 1.286 & 1.032 & 1.115 & 1.017 \\ \quad \text { R-Sq \% } & 96.18 & 95.71 & 97.04 & 98.16 & 98.25 \\ \text { t for slope=1 } & 4.715 & 4.934 & 0.833 & 3.531 & 0.393\end{array}$

A t-value of 2.201 is significant at the $95 \%$ confidence level for 11 degrees of freedom; for 22 degrees of freedom the critical t-value is 2.074 .

The choice would be easier if we could disregard one or the other test case. The McFarland case covers a wider set of conditions, including parallel and perpendicular sampling and a slightly broader set of particle sizes. The data reporting in both cases was less than ideal - the data had to be read from idealized plots. As far as technique goes, neither case can be eliminated.

Table 5 shows the analysis statistics for both test cases combined together. This analysis does not produce a clear "Best" code that explains the data over all the experimental conditions. The Texas A \& M code seems to show the least mean difference, but the standard deviations are too 1 arge to prove that the means significantly differ from each other. The Texas A \& M code seems to have the smallest intercept and a slope that ranks third closest 


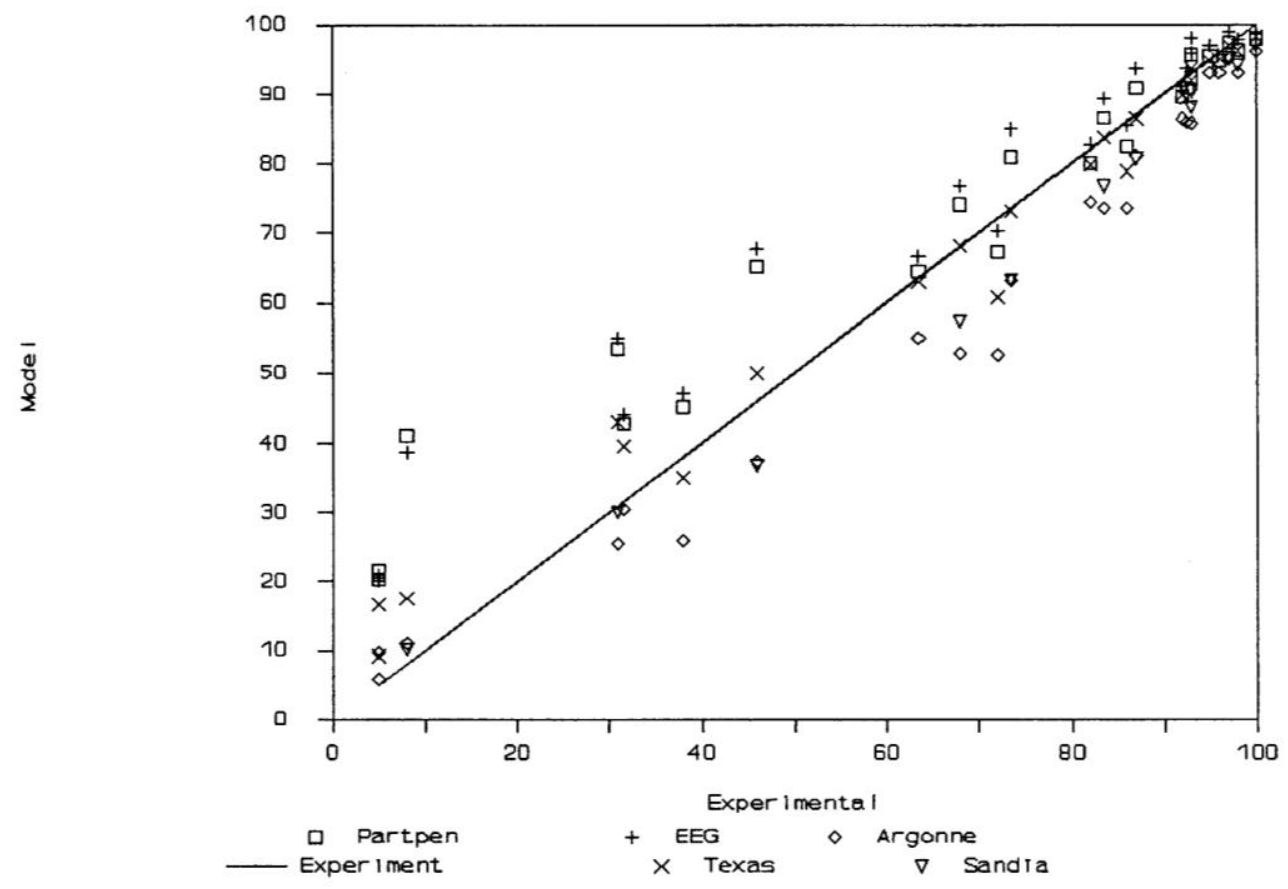

Figure 2 Comparison of Model vs Experimental Data for McFarland's Test Case

to one at only 1.04. The errors associated with these statistics would not support a conclusion of significant difference, the result is only suggestive. Figures $3-7$ show the plots of each model vs all test case data.

This leaves the final conclusion to other factors. The regression analysis in Table 5 suggests that as group, the Texas A \& M, Sandia and Argonne codes have better intercepts and slopes. Out of this group, the Argonne code is by far the least convenient to use. (A run is required for each particle size and segment, requiring manual calculations of the final result.) The advantages of the Texas A \& M code are: 1) it is the most user friendly, 2) it is interactive, 3) it has an operating manual, 4) it is the most polished product, and 5) it is the best documented. It is the recommended code for the PNL application for now. If laminar flow becomes of interest and non-axial sampling is not a concern, then the Sandia code is more complete. Either of the codes could be modified to complete the range of phenomena included; however, the current copies in my possession are only executable. It may be worthwhile to write a new code combining the strengths 
Table 5. Comparisons of Goodness of Fit Criteria for All Data Versus Predictive Models

$\begin{array}{lrrrrr} & \text { EEG } & \text { Partpen } & \text { Argonne } & \text { Texas } & \text { Sandia } \\ \text { No. of Data Points } & 36 & 36 & 36 & 36 & 24 \\ & & & & & \\ \text { Differences } & & & & & \\ \quad \text { Mean difference } & 4.341 & 3.520 & -6.999 & -2.529 & -5.887 \\ \quad \text { Standard Dev. } & 8.524 & 8.831 & 6.038 & 7.177 & 7.169 \\ \text { t=ave/sd(ave) } & 3.055 & 2.392 & -6.956 & -2.114 & -4.023 \\ \text { Max |diff| } & 30.781 & 33.022 & 19.488 & 17.850 & 19.900 \\ & & & & & \\ \text { Regression } & & & & & \\ \text { Intercept } & -11.064 & -18.069 & 6.6859 & -0.1436 & 5.4731 \\ \text { Slope } & 1.094 & 1.205 & 1.005 & 1.041 & 1.007 \\ \text { R Squared \% } & 93.95 & 95.93 & 96.62 & 95.37 & 95.13 \\ \text { t for slope = 1 } & 1.968 & 4.589 & 0.161 & 1.047 & 0.134 \\ \text { Std Err of S1ope } & 0.0476 & 0.0447 & 0.0322 & 0.0393 & 0.0485\end{array}$

of both. It would also be worthwhile to similarly evaluate the PARSLE code under development at WHC.

Notes on this effort were recorded in Lab Book 54090 . Model run streams are on file in my office. 


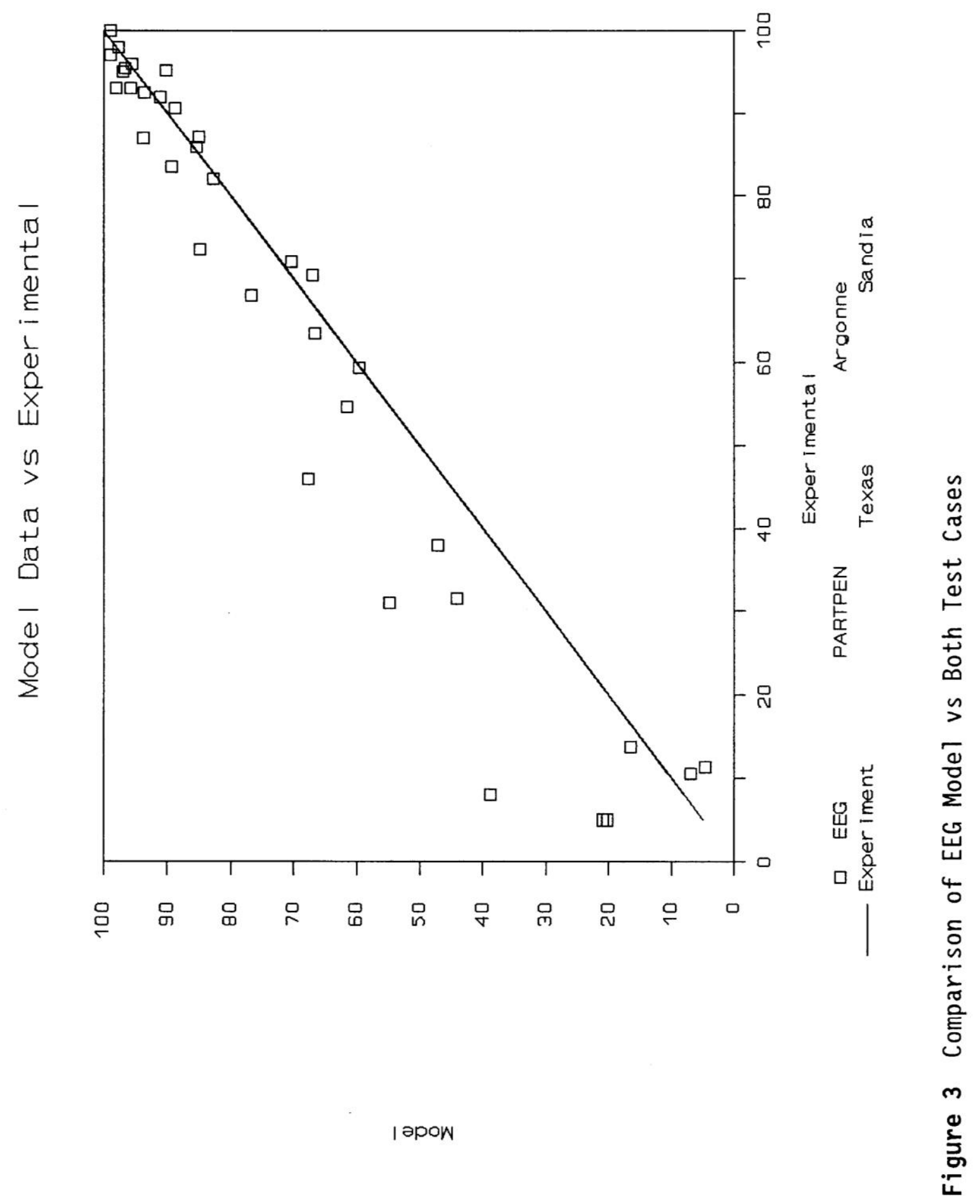




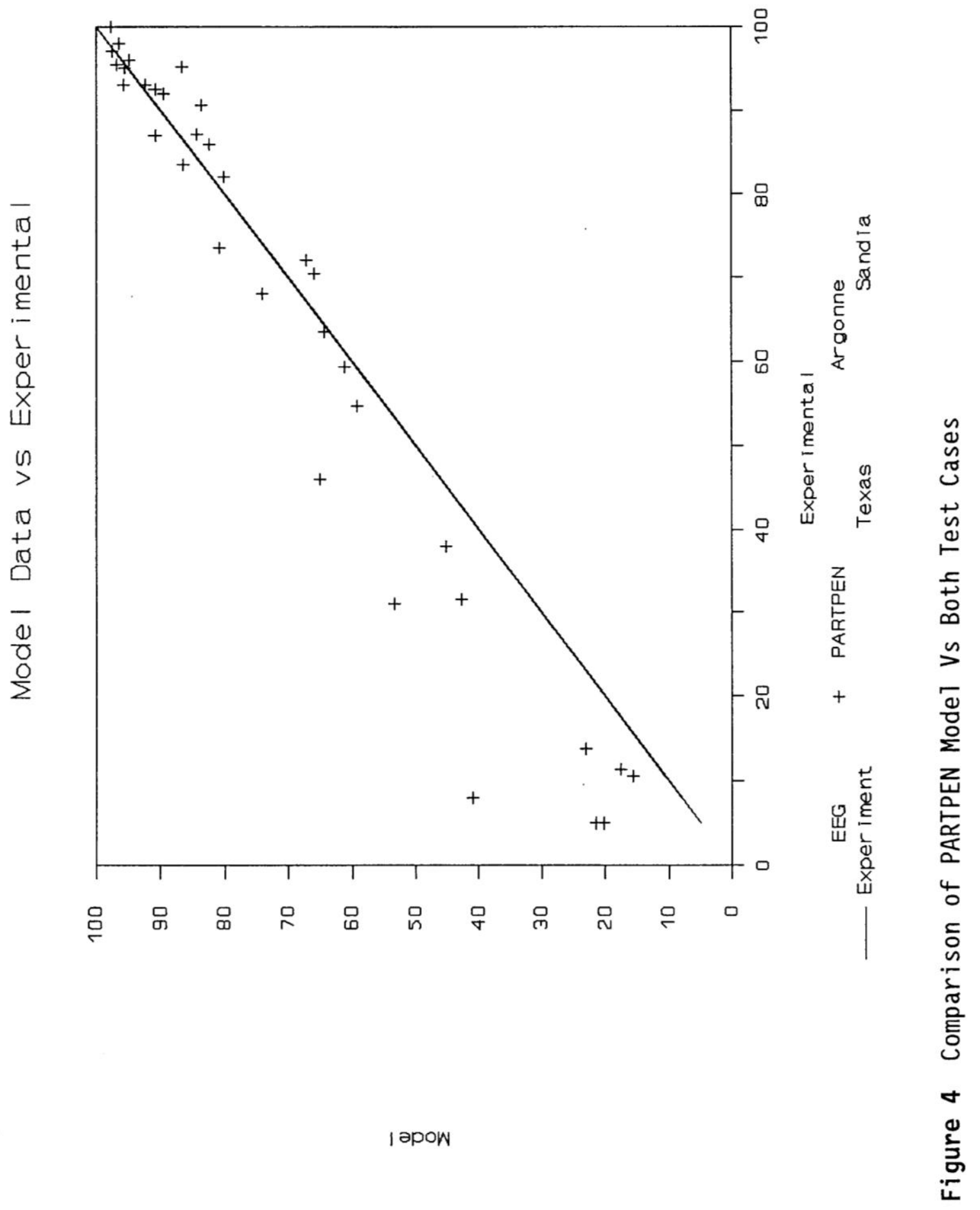

C. 10 


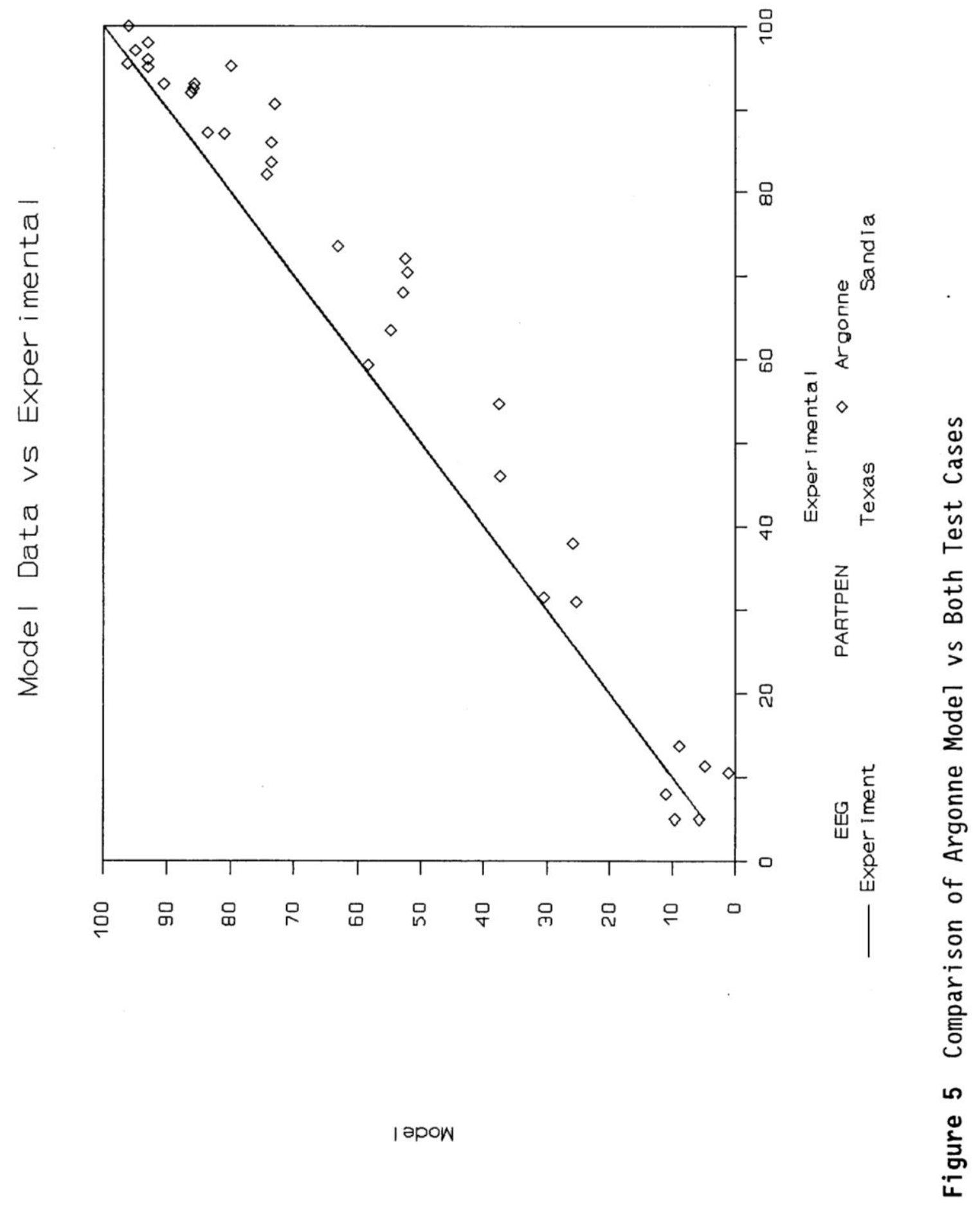

C. 11 


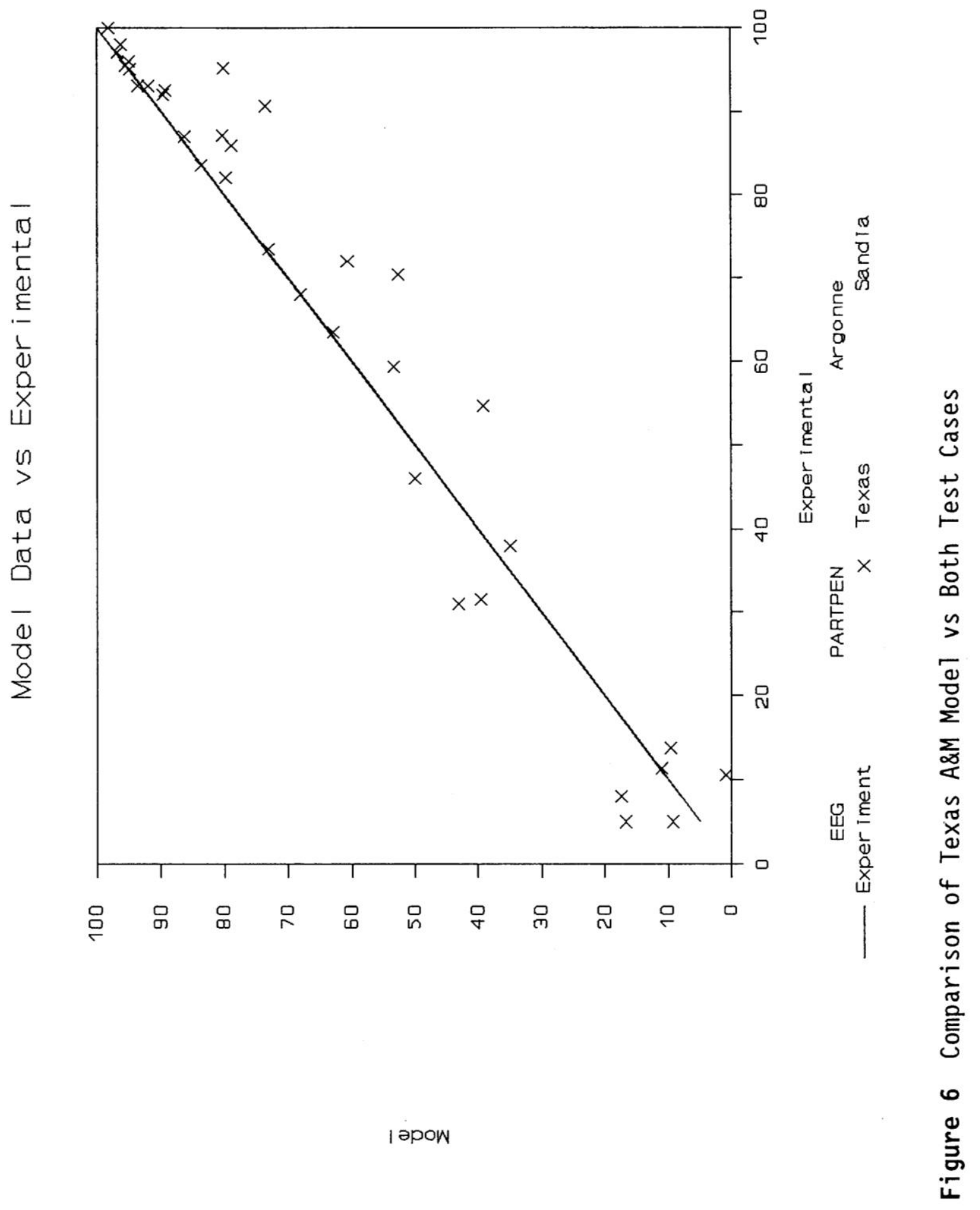

C. 12 


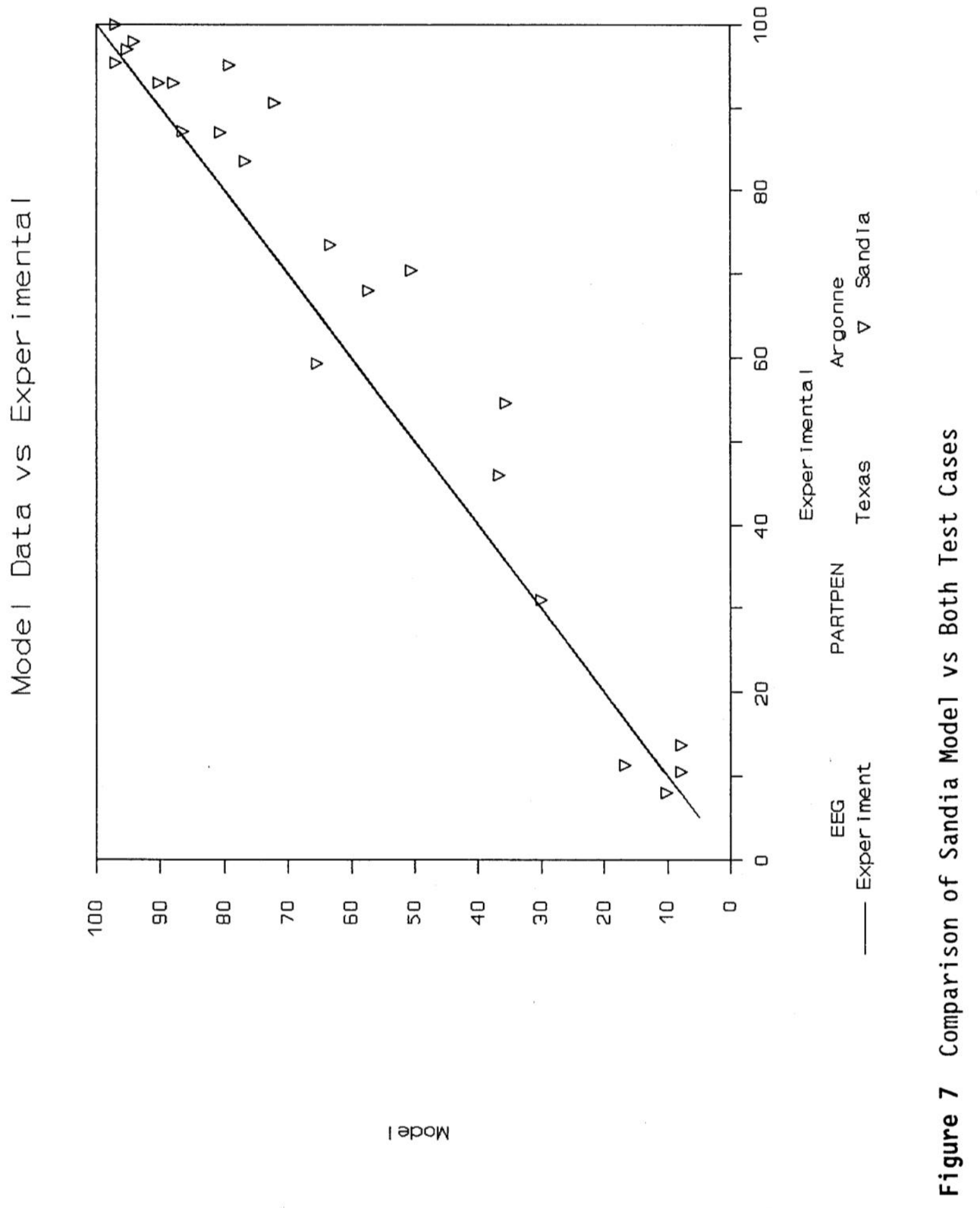

C. 13 


\section{REFERENCES}

Anand, N. K., A. R. McFarland, F. Wong, and K. D. Kim. 1990. Optimization of Aerosol Penetration Through Transport Lines. Aerosol Technology Laboratory Report 6441/01/19/90/NKA, Texas A\&M Research Foundation, College Station, TX. Prepared for the U. S. Nuclear Regulatory Commission, Washington DC, under Contract No. NRC-04-89-353.

Fan, B., F. Wong, N. K. Anand, and A. R. McFarland. 1991. Optimization of Aerosol Penetration Through Transport Lines. Aerosol Technology Laboratory Report 6441/01/31/91/NKA, Texas A\&M Research Foundation, College Station, TX. Prepared for the U. S. Nuclear Regulatory Commission, Washington DC, under Contract No. NRC-04-89-353.

Rodgers, J. C. 1987. Exhaust Stack Monitoring Issues At The Waste Isolation Pilot Plant. EEG-37, Environmental Evaluation Group, New Mexico Institute of Mining and Technology, State of New Mexico, Albuquerque NM.

Schwendiman, L. C., and J. A. Glissmeyer. 1976. "An Analysis Format and Evaluation Method for Effluent Particle Sampling Systems in Nuclear Facilities." In Proceedings of the 14th ERDA Air Cleaning Conference, ed. M. W. First, Harvard Air Cleaning Laboratory, Harvard School of Public Health, CONF-760822, pp. 507-527. Boston, Massachusetts, August 2-4, 1976, Sun Valley, Idaho.

Strom, L. 1972. "Transmission efficiency of aerosol Sampling Lines." In Atmospheric environment Vol. 6, pp. 133-142.

Yamano, N. and J. E. Brockman. 1989. Aerosol sampling and Transport Efficiency Calculation (ASTEC) and Application to Surtsey/DCH Aerosol Sampling System, Code Version 1.0: Code Description and User's Manual. NUREG/CR-5252, SAND88-1447, Sandia National Laboratories, Albuquerque, NM. 


\section{Appendix D}

Hanford Site/300 Area Stack Sampler Systems 



\section{Appendix D: Hanford Site/300 Area Stack Sampler Systems}

Appendix D contains a description of the buildings, exhaust units, control technologies, and sample extraction details for each facility emission unit. Additionally, applicable stack-samplerconfiguration drawings, figures, and photographs are provided for the following DOE emission units: EP-318-01-S, EP-325-01-S, and EP-331-01-V.

\section{Emission Unit EP-318-01-S: Radiological Calibration Laboratory}

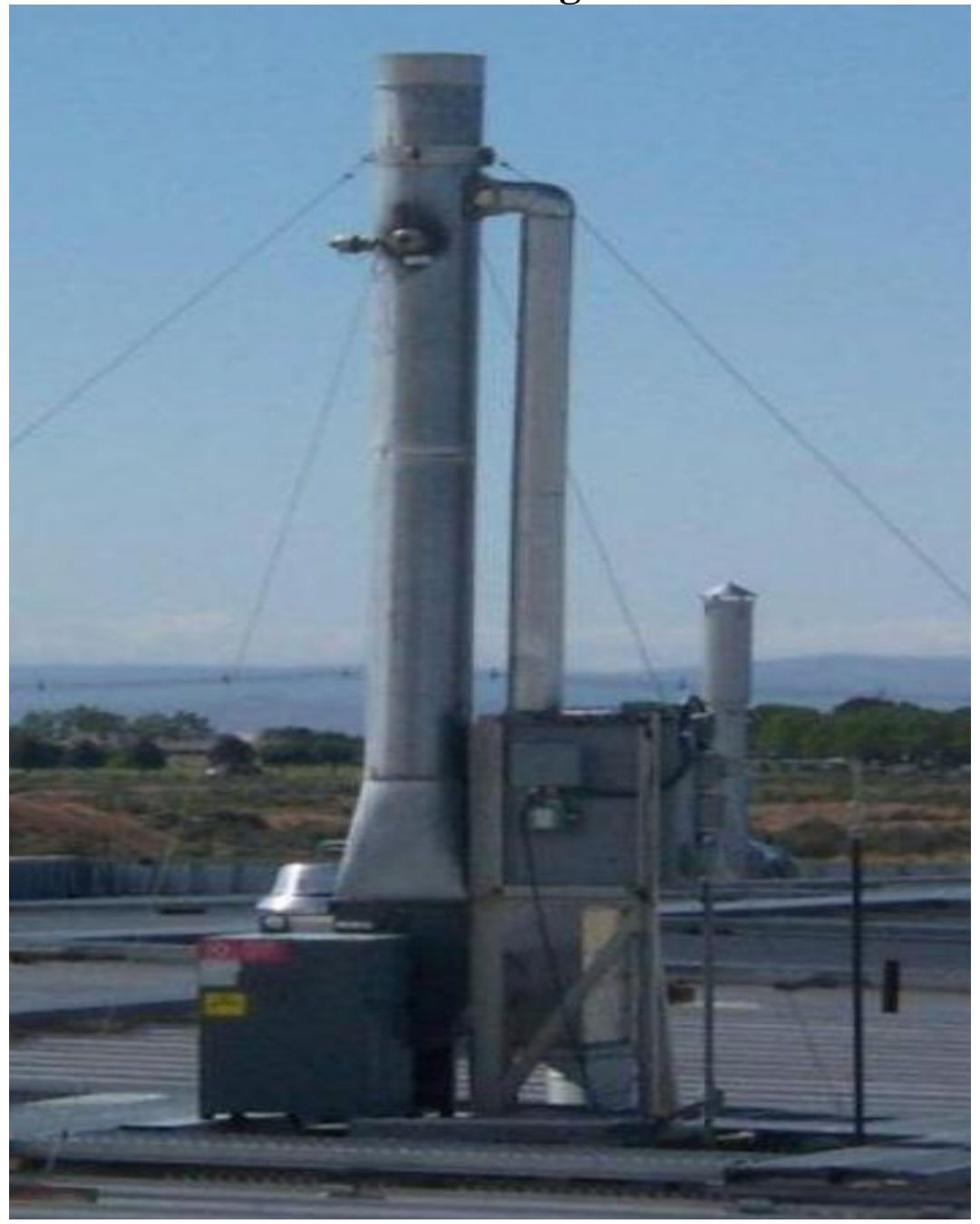

Emission Unit ID:

EP-318-01-S

Emission Sample Unit ID:

ESP-318-01-S

Traverse Point ID:

TP-318-01-1

Washington Geological Survey 84 Coordinates:

Latitude: 46.366 degrees

Longitude: 119.278 degrees 


\section{$\underline{\text { Facility/Process Description }}$}

The Radiological Calibrations Laboratory (318 Building) provides technical services and testing for a large variety of radiological instrumentation and dosimetry. Testing includes neutron, photon, and beta exposure facilities through the use of Radiation Generating Devices (RGDs) and other radiological sources as well as the ability to emulate a variety of environmental conditions. Such testing directly supports EHS\&S systems, product line strategic intent of assisting the government and individual customers to comply with exposure limits by providing precise testing conditions. Nondestructive Assay (NDA) and NSD activities are also conducted in the facility.

\section{$\underline{\text { Exhaust Unit Description }}$}

A small fraction of the air in the building is discharged via a filtered emission unit. The air discharges through a fume hood located in room 126. The exhaust from this unit goes through a HEPA filter prior to discharging from the stack located on the roof of the 318 Building. The stack height is $14 \mathrm{ft}$ from the top of the roof to the point of discharge, and is $28.4 \mathrm{ft}$ above grade. The stack has a diameter of $0.82 \mathrm{ft}$ (9.84 in.), with a cross sectional area of $0.53 \mathrm{ft}^{2}$.

\section{Exhaust Unit Control Technology}

The following simplified drawing shows the effluent pathway and the installed control technology for the 318 Building emission unit:

Figure D.1 318-01-S Building Effluent Pathway

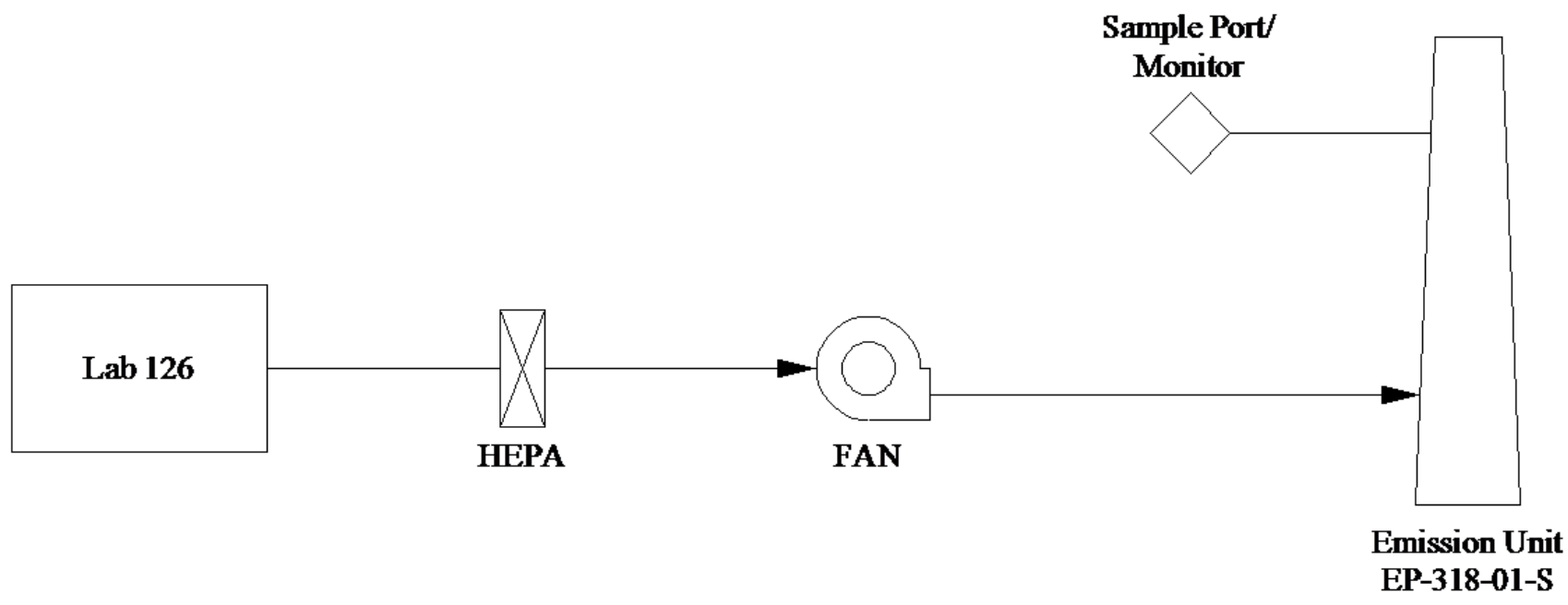

\section{$\underline{\text { Exhaust Unit Flow Rate and Temperature }}$}

Exhaust flow rates and temperature are determined annually using EM procedure EPRP-AIR016. This procedure was developed based on the requirements in 40 CFR 60, Appendix A, Method 2. The following tables provide historical flow rate and temperature measurements: 
Table D.1 318-01-S Building Exhaust Unit Flow Rate

\begin{tabular}{|c|c|}
\hline Date Measured & Flow Rate (CFM) \\
\hline $04 / 20 / 00$ & 480 \\
\hline $06 / 14 / 01$ & 413 \\
\hline $06 / 25 / 02$ & 484 \\
\hline $07 / 29 / 03$ & 484 \\
\hline $06 / 24 / 04$ & 583 \\
\hline $06 / 21 / 05$ & 616 \\
\hline $06 / 22 / 06$ & 586 \\
\hline $06 / 19 / 07$ & 567 \\
\hline $06 / 12 / 08$ & 435 \\
\hline $06 / 23 / 09$ & 531 \\
\hline $06 / 02 / 10$ & 539 \\
\hline $06 / 23 / 11$ & 569 \\
\hline Average $\pm 1 \sigma$ & $520 \pm 64$ \\
\hline
\end{tabular}

Table D.2 318-01-S Building Exhaust Unit Temperature

\begin{tabular}{|c|c|}
\hline Date Measured & Average Temperature $\left({ }^{\circ} \mathbf{F}\right)$ \\
\hline $06 / 22 / 06$ & 80 \\
\hline $06 / 19 / 07$ & 83 \\
\hline $06 / 12 / 08$ & 83 \\
\hline $06 / 23 / 09$ & 74 \\
\hline $06 / 02 / 10$ & 72 \\
\hline $06 / 23 / 11$ & 80 \\
\hline Average $\pm 1 \sigma$ & $79 \pm 4.6$ \\
\hline
\end{tabular}

\section{$\underline{\text { Record Particulate Sample System Description }}$}

Emission unit EP-318-01-S record particulate sampling system operates in conformance with 40 CFR 61, Subpart H and the ANSI N13.1-1969 standard requirements. The sampling unit is located on the roof top of the 318 Building. The stack sample extraction line begins about $12.3 \mathrm{ft}$ above the roof top.

The sample probe is positioned $7.3 \mathrm{ft}$ from the nearest flow disturbance and $1.75 \mathrm{ft}$ from the top of the stack, and sample nozzles are located at the geometric center of equal annular areas. The sample probe is constructed of stainless steel and manufactured by Air Monitoring Corporation. The sample nozzles are tapered and feed a common 1.12 in ID manifold running horizontally across the stack. The manifold extends outside the stack 0.75 in. before making a 90 degree, 6 -in. radius of curvature bend downward and uniting with the sample transport line. The sample housing is located on the roof.

The sample transport line is constructed of $1.12 \mathrm{in.} \mathrm{ID} \mathrm{stainless} \mathrm{steel} \mathrm{tubing.} \mathrm{The} \mathrm{line} \mathrm{extends}$ downward and terminates in a cabinet on the roof containing the collection filter, rotameter, and sample flow rate adjustment valve. The sample line upstream of the collector is insulated, heat traced, and electrically grounded. The rotameter is changed out annually and calibrated; the heat tape and grounding is inspected per internal preventative maintenance measures. 


\section{Vacuum Air Sample System}

Vacuum is supplied to the sample system by a single Rietschle carbon vane pump located in the basement equipment room. This system is powered by normal and emergency power.

\section{Sample Collection}

Samples are collected using an isokinetic sampling probe mounted in the exhaust stack. The record particulate sampling system was constructed in conformance with ANSI N13.1-1969 requirements. The sample probe has two nozzles, with each nozzle sampling an equal annular space within the stack. The probe in the stack is located to meet the 8:2 (downstream:upstream) duct-diameter placement recommendation from ANSI N13.1-1969. The sampling system components (Brooks GT1000 flowmeter and vacuum gauge) are calibrated annually. Inspections of the sampling system are performed prior to initiating a sampling event and every day (excluding holidays and weekends) during sample collection.

\section{$\underline{\text { Battelle Drawings }}$}

Stack Sampler Configuration EP-318-01-S; Rev. 0

Stack Sampler Configuration EP-318-01-S; Rev. 1 HEPA Filter Installation Plan, Section and Notes; Rev. 0 $\underline{\text { Number }}$

H-3-307241

H-3-307824-1

H-3-309863-1

Electronic access to these drawings is available.

\section{$\underline{\text { Air Monitor Corp. Drawings }}$}

Flo-Sampler General Arrangement \#1; Rev. 1

Sample Probe Top Assembly; Rev. 0

Iso-Sampling Threaded Nozzle; Rev. 0

Iso-Sampling Manifold; Rev. 0

Iso-Sampling Manifold; Rev. 0

Mounting Plate, Fitting and End Plug; Rev. 0

\section{$\underline{\text { Number }}$}

W32208AA

W32208BA

W32208BB

W32208BC

W32208BD

W32208BE

Drawings provided by the vendor are not available electronically at this time. 


\section{Emission Unit EP-325-01-S: Radiochemical Processing Laboratory}

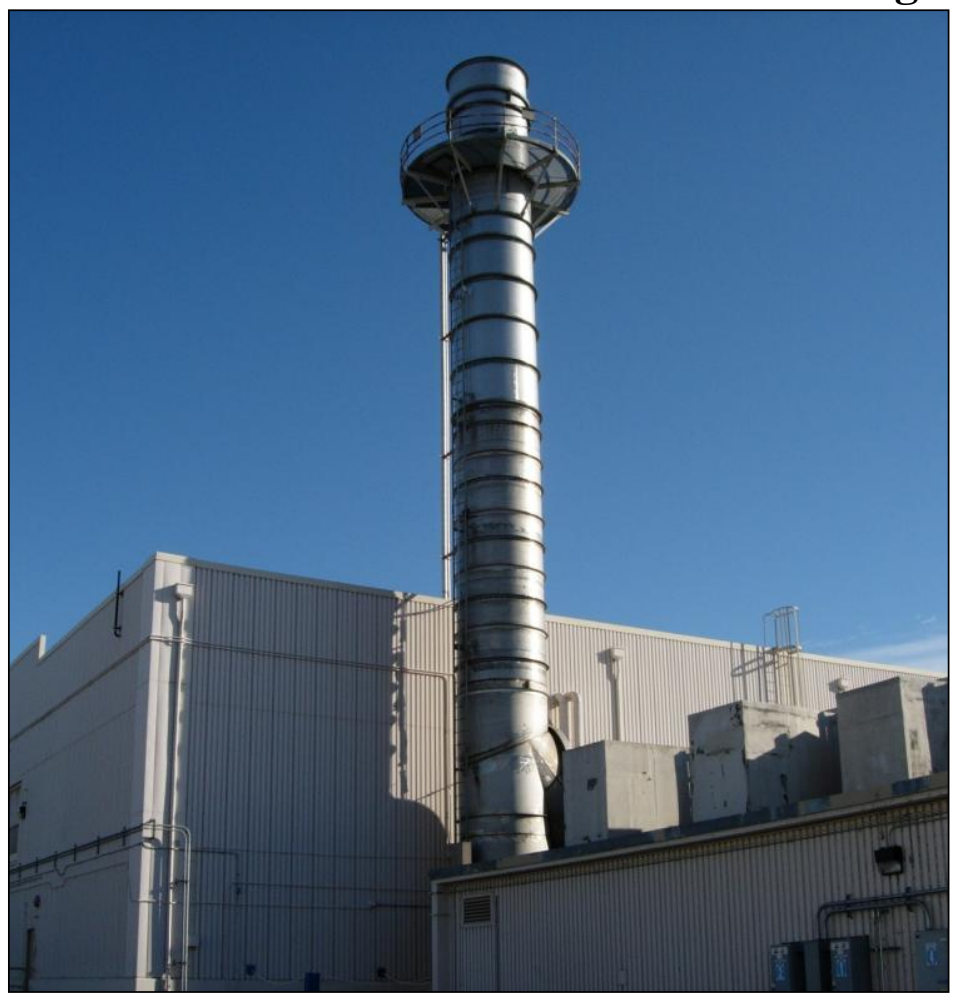

Emission Unit ID:

EP-325-01-S

Emission Sample Unit ID:

ESP-325-01-S

Traverse Point ID:

TP-325-01-1

Washington Geological Survey 84 Coordinates:

Latitude: 46.369 degrees

Longitude: 119.279 degrees

\section{Facility/Process Description}

The RPL (325 Building) has the capability of developing and testing radiochemical technologies, and characterizing radiochemical and spent nuclear fuel samples. Full service analytical and metallurgical capabilities for radiochemical waste processes are also used. RPL also provides basic and applied research and technical support for geostatistical analysis, testing and development of simulants and glass materials for both radioactive and non-radioactive waste conditions. The special capabilities include four hot cells and two shielded storage units in which process development and analytical work can be performed.

\section{Exhaust Unit Description}

Air exhausts through EP-325-01-S from areas inside of the 325 Building where radionuclides are handled and used, which include fume hoods, glove boxes, hot cells and other work spaces. The exhaust stream passes through two stages of HEPA filters located upstream of the exhaust fans. 
The stack is located on the northwest corner of the 325 Building. The stack is $88.83 \mathrm{ft}$ tall from the existing grade. The stack is 96 in. in diameter and has a cross-sectional area of $50.3 \mathrm{ft}^{2}$.

\section{Exhaust Unit Control Technology}

The following simplified drawing shows the effluent pathway and the installed control technology for the 325 Building emission unit:

Figure D.2 325-01-S Building Effluent Pathway

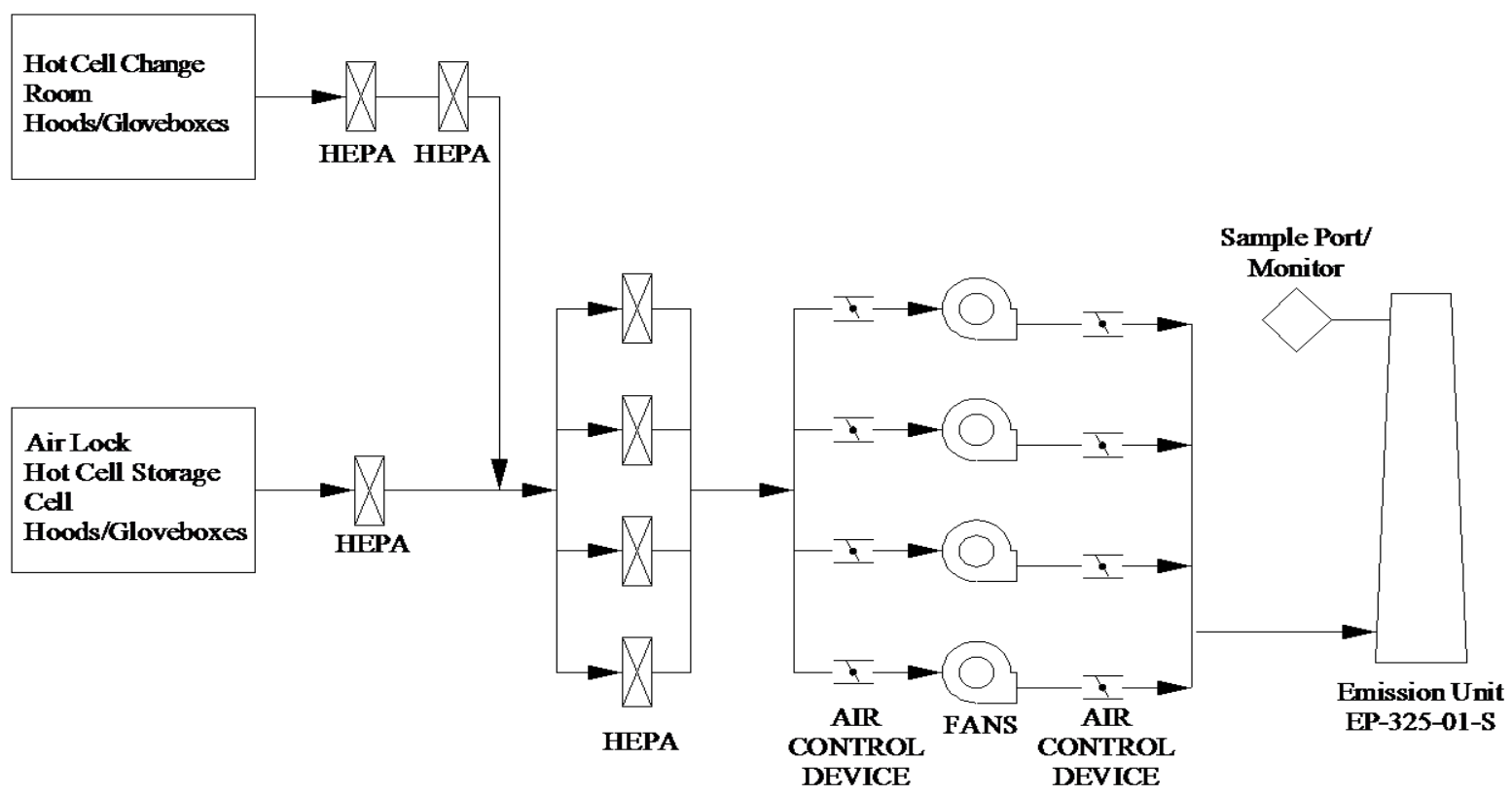

\section{$\underline{\text { Exhaust Unit Flow Rate and Temperature }}$}

Exhaust flow rates and temperature are determined quarterly using EM procedure EPRP-AIR016. This procedure was developed based on the requirements in 40 CFR 60, Appendix A, Method 2. The following tables provide historical flow rate and temperature measurements: 
Table D.3 325-01-S Building Exhaust Unit Flow Rate

\begin{tabular}{|c|c|}
\hline Date Measured & Flow Rate (CFM) \\
\hline $03 / 03 / 01$ & 133,000 \\
\hline $05 / 03 / 01$ & 141,600 \\
\hline $08 / 27 / 01$ & 138,800 \\
\hline $12 / 05 / 01$ & 137,600 \\
\hline $02 / 25 / 02$ & 141,800 \\
\hline $05 / 09 / 02$ & 144,400 \\
\hline $08 / 21 / 02$ & 142,300 \\
\hline $11 / 20 / 02$ & 145,100 \\
\hline $02 / 19 / 03$ & 145,400 \\
\hline $06 / 26 / 03$ & 142,100 \\
\hline $10 / 22 / 03$ & 145,100 \\
\hline $12 / 22 / 03$ & 140,800 \\
\hline $02 / 19 / 04$ & 142,900 \\
\hline $05 / 20 / 04$ & 143,100 \\
\hline $08 / 12 / 04$ & 144,100 \\
\hline $11 / 16 / 04$ & 134,800 \\
\hline $02 / 22 / 05$ & 142,300 \\
\hline $05 / 12 / 05$ & 142,900 \\
\hline $08 / 16 / 05$ & 143,900 \\
\hline $11 / 09 / 05$ & 143,100 \\
\hline $03 / 01 / 06$ & 139,100 \\
\hline $05 / 02 / 06$ & 143,100 \\
\hline
\end{tabular}

\begin{tabular}{|c|c|}
\hline Date Measured & Flow Rate (CFM) \\
\hline $08 / 09 / 06$ & 139,100 \\
\hline $11 / 21 / 06$ & 142,100 \\
\hline $02 / 21 / 07$ & 143,400 \\
\hline $05 / 24 / 07$ & 141,600 \\
\hline $08 / 15 / 07$ & 140,100 \\
\hline $11 / 14 / 07$ & 138,100 \\
\hline $02 / 27 / 08$ & 139,300 \\
\hline $06 / 04 / 08$ & 140,100 \\
\hline $8 / 27 / 08$ & 141,800 \\
\hline $11 / 20 / 08$ & 140,800 \\
\hline $03 / 03 / 09$ & 137,600 \\
\hline $05 / 20 / 09$ & 142,300 \\
\hline $08 / 31 / 09$ & 140,300 \\
\hline $11 / 24 / 09$ & 140,300 \\
\hline $02 / 25 / 10$ & 138,800 \\
\hline $05 / 25 / 10$ & 139,100 \\
\hline $09 / 23 / 10$ & 138,800 \\
\hline $12 / 13 / 10$ & 128,000 \\
\hline $02 / 28 / 11$ & 129,800 \\
\hline $05 / 31 / 11$ & 138,300 \\
\hline $08 / 27 / 11$ & 140,100 \\
\hline Average $\pm 1 \sigma$ & $140,400 \pm 3,700$ \\
\hline
\end{tabular}

Table D.4 325-01-S Building Exhaust Unit Temperature

\begin{tabular}{|c|c|}
\hline Date Measured & Average Temperature $\left({ }^{\circ} \mathbf{F}\right)$ \\
\hline $03 / 01 / 06$ & 76 \\
\hline $05 / 02 / 06$ & 79 \\
\hline $08 / 09 / 06$ & 79 \\
\hline $11 / 21 / 06$ & 69 \\
\hline $02 / 21 / 07$ & 76 \\
\hline $05 / 24 / 07$ & 80 \\
\hline $08 / 15 / 07$ & 80 \\
\hline $11 / 14 / 07$ & 76 \\
\hline $02 / 27 / 08$ & 78 \\
\hline $06 / 04 / 08$ & 80 \\
\hline $8 / 27 / 08$ & 77 \\
\hline $11 / 20 / 08$ & 75 \\
\hline
\end{tabular}

\begin{tabular}{|c|c|}
\hline Date Measured & Average Temperature $\left({ }^{\circ} \mathbf{F}\right)$ \\
\hline $03 / 03 / 09$ & 78 \\
\hline $05 / 20 / 09$ & 81 \\
\hline $08 / 31 / 09$ & 79 \\
\hline $11 / 24 / 09$ & 73 \\
\hline $02 / 25 / 10$ & 78 \\
\hline $05 / 25 / 10$ & 76 \\
\hline $09 / 23 / 10$ & 77 \\
\hline $12 / 13 / 10$ & 75 \\
\hline $02 / 28 / 11$ & 46 \\
\hline $5 / 31 / 11$ & 75 \\
\hline $08 / 27 / 11$ & 91 \\
\hline Average $\pm 1 \sigma$ & $76 \pm 7.7$ \\
\hline
\end{tabular}

\section{Record Particulate Sample System Description}

Emission unit EP-325-01-S record particulate sampling system operates in conformance with 40 CFR 61, Subpart H and the ANSI N13.1-1999 standard requirements. The sampling unit is located in room 916 of the 325 Building. Continuous sampling is conducted for particulates, and samples are collected using a shrouded probe mounted in the center $2 / 3^{\text {rds }}$ of the exhaust stack.

A stainless steel, single shrouded sample probe supplied by Air Monitor Corporation is used to extract a representative sample from the center $2 / 3^{\text {rds }}$ of the duct. The sample probe is 16.88 -in. 
long and is positioned in line to the direction of flow before it makes a 90 degree, 5 -in. radius of curvature bend perpendicular to the stack and intersects the stack sidewall 48-in. away. It is positioned $55.9 \mathrm{ft}$ from the nearest flow disturbance and $8 \mathrm{ft}$ from the top of the stack; it is located $80.83 \mathrm{ft}$ above ground level. The single nozzle inlet has a $1.12 \mathrm{in}$. ID.

The sample transport line is constructed of $1.12 \mathrm{in.} \mathrm{ID} \mathrm{stainless} \mathrm{steel} \mathrm{tubing.} \mathrm{After} \mathrm{connecting} \mathrm{to}$ the shrouded probe the sample line makes a bend of 5 degrees with a 5-in. radius of curvature before, it makes a 90 degree, 15 -in. radius of curvature bend downward. The line extends downward and terminates in room 916 which contains the collection filter and multi-point mass flow transmitter. The sample line upstream of the roof penetration is insulated, heat taped, and electrically grounded. The heat tape and grounding is inspected per internal preventative maintenance measures. An annual pressure test is conducted to ensure that no leaks formed during the previous year.

\section{Vacuum Air Sample System}

Stack emission record samples and continuous air monitoring are withdrawn from the stack and through the sample systems by means of the building vacuum air sampling system located in the basement of the 325 Building. This system has redundant vacuum pumps that are powered by normal and emergency power. Preventive maintenance of the vacuum air sampling system is performed in accordance with a documented preventive maintenance program.

\section{Sample Collection}

\section{Particulate Sample Collection}

Particulate samples are collected using a 47-mm supported membrane filter (Gelman Sciences Versapor-Membrane, acrylic copolymer membrane filter) mounted in a modified sample holder. The membrane filter has estimated retention efficiency for $0.3 \mu$ particles of greater than $99 \%$.

Continuous sampling will be conducted for particulates, and samples will be collected using a shrouded probe located in the center $2 / 3^{\text {rds }}$ of the exhaust stack. The sampling system is designed and constructed in accordance with ANSI N13.1-1999. The radiological air emissions sampling will operate under variable flow rates and temperature conditions. Samples of particulate matter will be collected on membrane filters. The confirmatory demonstration of compliance will be performed against previously proven testing data of similar design. The sampling system components will be calibrated annually. Inspections of the sampling system will be performed before initiating sampling event and daily (excluding holidays and weekends) during sample collection.

\section{Tritium Sample Collection}

Tritium samples are drawn through the same sample probe and transport line as the record particulate samples. The six-nozzle probe assembly was designed to position the nozzles to be representative of the stack cross section. The sample line temperature is maintained above that of the stack gas to prevent losses due to condensation forming in the sample line. 
Tritium as water vapor (HTO) and tritium gas (HT) is sampled continuously using a two-stage sampling system located in the 325 Building, Room 916 . The sample is drawn downstream of the record particulate sampling system and uses the same sample extraction and transport system as the particulate sampler. See Stack Sampling/Monitoring System Flow Diagram Drawing \#H-3-70531. The tritium sample extraction unit, tritium sample extraction probe, tritium sample transport line, and vacuum air sample system are the same as the particulate sampling data.

The record particulate sample collector acts as a pre-filter for the tritium sample stream, and the flow is measured using a calibrated rotameter. The sub-sample flow rate to the tritium sampler is a nominal $200 \mathrm{~mL} / \mathrm{min}$.

Upstream of the first tritium collection unit, a nitrogen-hydrogen carrier gas $\left(3 \% \mathrm{H}_{2}\right.$ in $\left.\mathrm{N}_{2}\right)$ is added to the tritium sample stream via a tee in the sample line. The tee in the sample line is just upstream of the carrier gas rotameter SM-9-RM. It then enters the first 3-stage tritium collection unit where silica gel is used to absorb water vapor from the gas stream. On exit from the first stage, the now dry sample stream is heated to $>180^{\circ} \mathrm{C}$ in the presence of a palladium catalyst to convert free hydrogen (HT and TT) to water vapor. The sample stream is then cooled to less than $40^{\circ} \mathrm{C}$ and passed through the second 2-stage silica gel collector to absorb out the water vapor generated from the catalytic oxidation of free hydrogen (see picture below of tritium sample collection system).

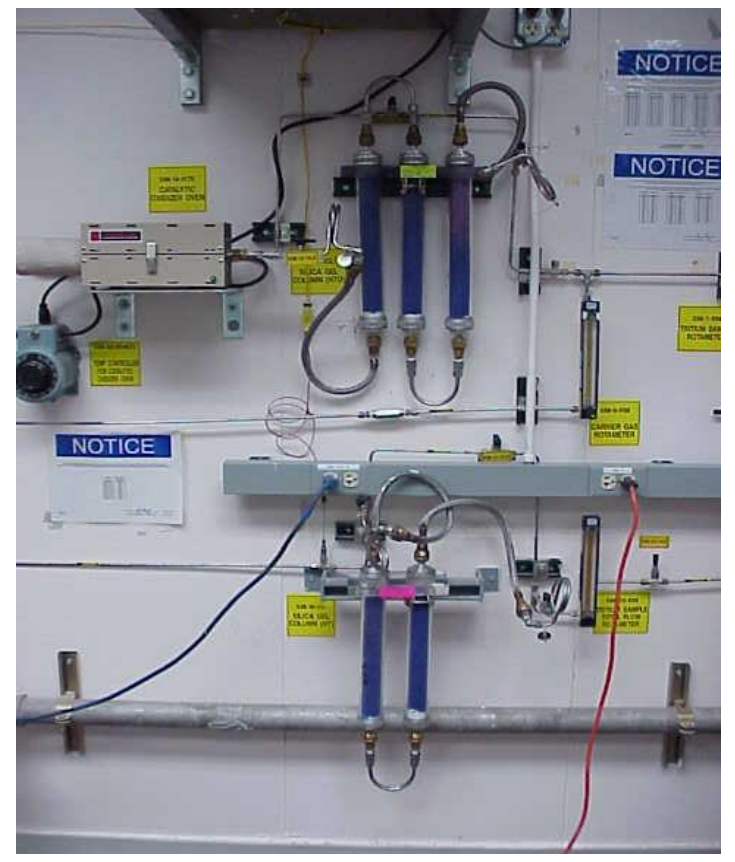

Samples are exchanged about monthly or until the silica gel cartridge loading sampling system meets or exceeds $2 / 3$ loading (based on color change), whichever comes first. Following the sampling collection, the samples are delivered to the analytical laboratory for analysis of the tritium content. The sample system is inspected each workday, excluding weekends and holidays, for proper flow-rate settings and system operation. 
Thermocouples and associated digital temperature displays are either calibrated in place or replaced with calibrated spares on an annual basis. PNNL Maintenance Services performs these per group-specific procedures.

Rotameters that measure sample and carrier gas flows are exchanged with calibrated spares on an annual basis. A Battelle-approved calibration laboratory performs calibration on these instruments.

See Appendix B for analysis and data evaluation requirements for tritium samples collected from this major emission unit.

\section{Continuous Air Monitoring Particulate Sample Collection}

The 325 Stack Particulate CAM system for emission unit EP-325-01-S is operated in conformance with 40 CFR 61, Subpart H and ANSI N13.1-1999 requirements. See Stack Sampler Configuration Drawing H-3-307232.

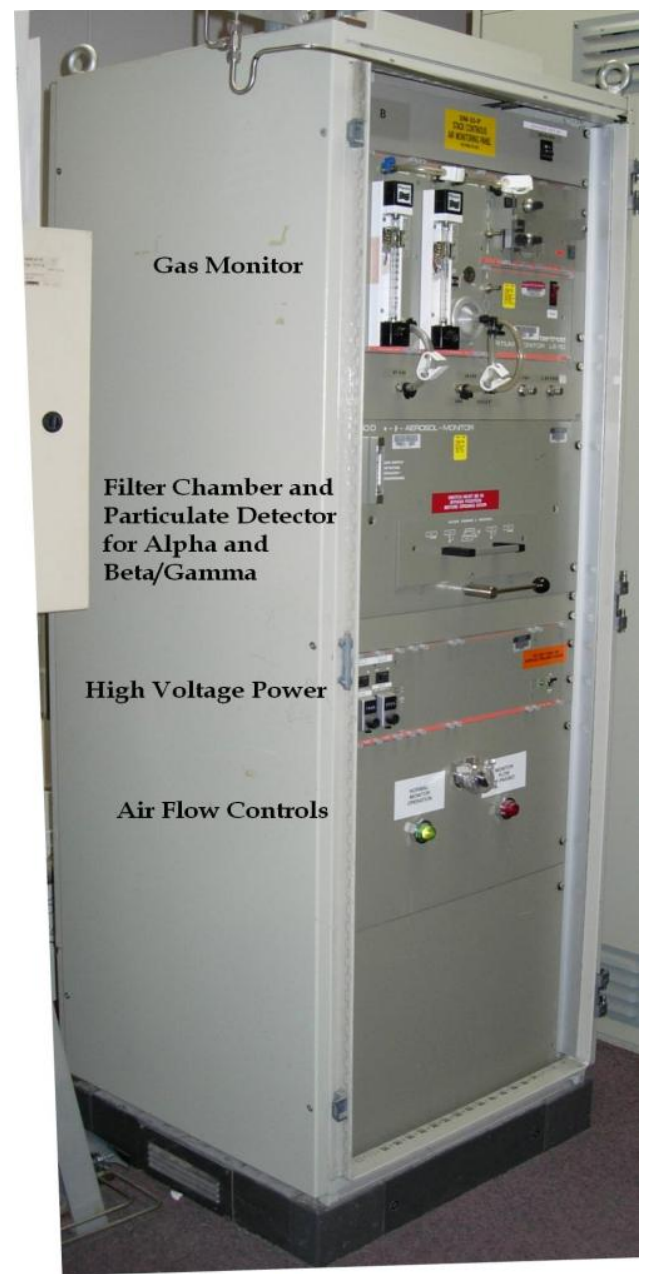

Stack air is continuously monitored for radioactivity associated with particulate matter by an EG\&G-Berthold LB150D alpha-beta-pseudocoincident monitor. The monitor uses an 8 in. diameter glass-fiber filter to collect airborne particles from the stack. The filter is mounted 
against a sandwich arrangement of gas-flow proportional radiation detectors to count the alpha, beta, and gamma emissions as particles accumulate on the filter.

The monitoring system accounts for the presence of radioactive material associated with the decay products of naturally occurring radon isotopes by means of a timing gate to identify simultaneous alpha and beta emissions occurring on the filter. Referred to as the alpha-betapseudocoincidence-difference method, it uses the nearly simultaneous (pseudocoincident) alphabeta decay transitions in the ${ }^{220} \mathrm{Rn}$ and ${ }^{222} \mathrm{Rn}$ decay chains as a means of distinguishing naturally occurring radionuclides from artificial radionuclides deposited on the sample filter. Three gasflow proportional counters in a sandwich configuration independently count the number of alpha, beta, and gamma emissions on the sample collection filter. In addition, alpha and beta emissions that are detected pseudocoincidentally are also counted. The number of pseudocoincident events times a scaling factor is subtracted from the total alpha and beta counts to yield the net event detections attributed to sources other than radon isotopes.

Local and remote annunciators provide indications of high particulate radionuclide emissions as well as monitor component failures.

The sample is extracted from the stack about $80.83 \mathrm{ft}$ above ground level. The sample probe is positioned $55 \mathrm{ft}, 11.25$ in. (7.0 equivalent diameters) downstream of a flow disturbance and $8 \mathrm{ft}$ (1.0 equivalent diameter) from the top of the stack. During the modification to upgrade the stack, it was found that the original existing stack design would not support the extension of the stack to meet the 8:2 (downstream: upstream) duct-diameter placement recommendation from ANSI N13.1 (1999). However, this design does comply with the alternative 2:0.5 criteria.

A stainless steel, six-nozzle probe manufactured by Kurz Instruments, Inc. is used to extract the sample. Each nozzle inlet has a 0.494 in. ID. The nozzles feed into a 1.87 in. ID sample manifold that spans the stack cross-section. See vendor-supplied drawings for details: 1497D7004, 1497C3301, 1497C2504, and 1497C2505.

The sample transport line is constructed of 2.83 in. ID stainless steel tubing. The line makes a 90 degree, 15 in. radius of curvature bend downward upon exiting the stack and makes a 15 in. radius bend to horizontal before entering into the EG\&G Bertholdt alpha/beta CAM, which is located in the 325 Building, Room 916. The sample line upstream of where it penetrates the building roof is insulated, heat traced, and electrically grounded. The sample line temperature is maintained above that of the stack gas to prevent condensation from forming in the sample line.

A particulate sample is collected on an 8 in. glass fiber filter housed in the alpha/beta CAM. Schleicher \& Schuell manufacture the media. The sample flow rate is measured by a Brooks Instrument GT-1000 (3.21 to $32.15 \mathrm{scfm}$ ) rotameter and adjusted using a throttle valve (both located just downstream of the CAM outlet). A vacuum gauge (0 to 100 in. of water) is installed on the inlet side of the rotameter and used to correct the sample flow for vacuum conditions. A one-month particulate sample is collected continuously to measure in real time the actual emissions from the facility. Monitor flows are set at or near isokinetic based on stack flow measurements that are performed quarterly. From January 1998 to present, the isokinetic sample 
flow rate ranged from 21.9 to $22.3 \mathrm{scfm}$. The monitoring system is inspected each workday (excluding weekends and holidays) for proper flow-rate settings and system operation.

The rotameter and vacuum gauge are exchanged on an annual basis with calibrated spares. A Battelle-approved calibration laboratory performs calibration on these instruments. Electronic calibration of the alpha/beta CAM is conducted annually or when failures or modifications of the system occur. PNNL Maintenance Services performs these calibrations per group-specific procedures.

Radiological calibration of the alpha/beta CAM is performed on an annual basis or when failures or modifications of the system occur. PNNL Radcon Instrumentation Services performs these calibrations per group-specific procedures.

Particulate monitor alarm setpoints are addressed in the current version of the "Adjustment To Alpha CAM Alarm Setpoint” document. See EM File Plan or contact EM staff to access documentation.

\section{CAM Tritium Sample Collection}

The 325 Stack Tritium CAM system for emission unit EP-325-01-S is operated in conformance with DOE/EH- 0173T, "Environmental Regulatory Guide for Radiological Effluent Monitoring and Environmental Surveillance" requirements.

Stack air is continuously monitored for tritium by an EG\&G-Berthold LB110 tritium detector and a PNNL OS3700 software tritium analyzer. The LB110 is a windowless, flow-through proportional detector with pulse rise-time discrimination. The discriminator divides individual ionization events into short rise-time events and long rise-time events. Short rise-time events are counted as tritium, while long rise-time events are currently calibrated to ${ }^{85} \mathrm{Kr}$.

The data from the discriminator are fed to the PNNL OS3700 software analyzer unit via coaxial cables. The analyzer is used to allow for subtracting background, accumulating pulse events, and converting those events to concentration. The analyzer also provides the output for the video display along with a web-based tool designed to provide real-time remote access to the data via the PNNL network services.

P-10 gas is mixed with the sample stream in a 4:1 ratio and passed through the detector. The $\mathrm{P}-10$ gas is used to maximize sensitivity and minimize interference from other decays.

Local and remote annunciators provide indications of high tritium emissions, monitor component failures, and sample and P-10 flow transients lasting more than 60 seconds.

The sample is extracted from the stack about $80.83 \mathrm{ft}$ above ground level. The sample probe is positioned $55 \mathrm{ft}$ 11.25-in. (7.0 equivalent diameters) downstream of a flow disturbance and $8 \mathrm{ft}$ (1.0 equivalent diameter) from the top of the stack. During the modification to upgrade the stack, it was found that the original existing stack design would not support the extension of the stack to meet the 8:2 (downstream: upstream) duct-diameter placement recommendation from ANSI N13.1-1999. However, this design does comply with the alternative 2:0.5 criteria. 
A stainless steel, six-nozzle probe manufactured by Kurz Instruments, Inc. is used to extract the sample. Each nozzle inlet has a 0.494 in. ID. The nozzles feed into a $1.87 \mathrm{in}$. ID sample manifold that spans the stack cross-section. See vendor-supplied drawings for details: 1497D7004, 1497C3301, 1497C2504, and 1497C2505.

The sample transport line is constructed of 2.83 in. ID stainless steel tubing. The line makes a 90 degree, $15 \mathrm{in}$. radius of curvature bend downward upon exiting the stack and a $15 \mathrm{in}$. radius bend to horizontal before entering into the EG\&G Bertholdt alpha/beta CAM. The CAM is also located in the 325 Building, Room 916. The tritium CAM draws a sample just downstream from the alpha/beta CAM filter media. The sample line upstream of where it penetrates the building roof is insulated, heat traced, and electrically grounded. The sample line temperature is maintained above that of the stack gas to prevent condensation from forming in the sample line.

A sample is drawn by means of a membrane pump internal to the CAM from a point downstream of the alpha/beta CAM filter media. The sample and counting gas (P-10) flow are measured separately and kept constant by a control circuit. The measurement is performed by means of floating body flow-through meters using photoelectronic positioning scanning. A needle valve operated by a stepper motor serves as the control element. A sample is collected on a continuous basis to measure in real time the actual emissions from the facility. The sample line upstream of where it penetrates the building roof is insulated, heat traced, and electrically grounded. The sample line temperature is maintained above that of the stack gas to prevent losses caused by condensation forming in the sample line.

Electronic calibration of the tritium CAM is performed on an annual basis or when failures or modifications of the system occur. PNNL Maintenance Services performs these calibrations per group-specific procedures.

Radiological calibration of the tritium CAM is performed on an annual basis or when failures or modifications of the system occur. PNNL Radcon Instrumentation Services performs these calibrations per group-specific procedures.

Tritium monitor alarm setpoints are addressed in the current version of the "Tritium Monitor Alarm Setpoint Revision Radiochemical Processing Facility Exhaust Stack" document. See EM File Plan or contact EM staff to access documentation.

\section{$\underline{\text { Battelle Drawings }}$}

Stack Sampler Configuration EP-325-01-S; Rev. 1 Vacuum Air Sampling One-Line Diagram; Rev. 3 Stack Sampling/Monitoring System Flow Diagram; Rev. 5 325 Stack Monitor Mechanical Installation; Rev. 0

Electronic access to these drawings is available.

\section{$\underline{\text { Number }}$}

H-3-307232

H-3-307547

H-3-70531

H-3-310850 


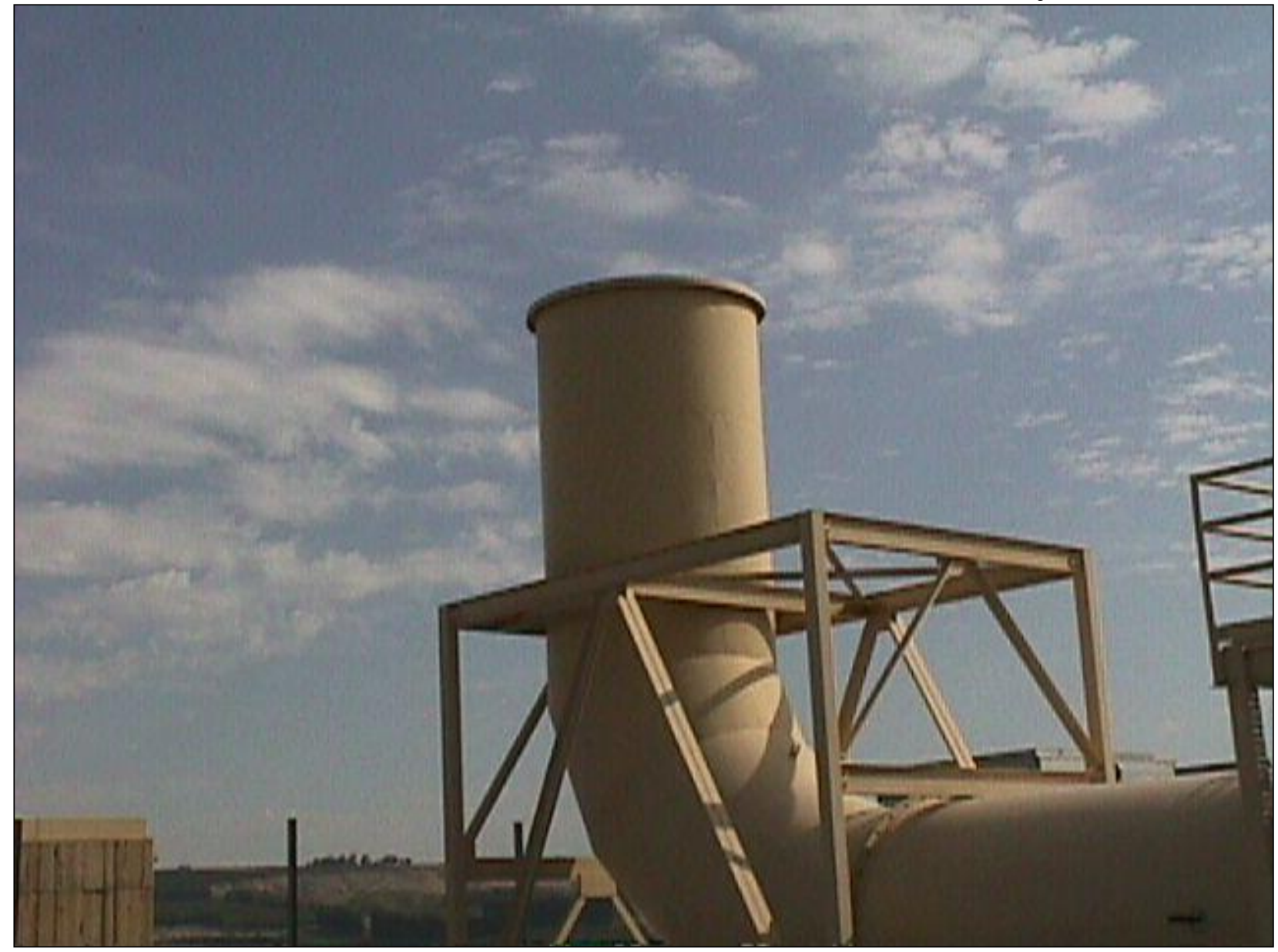

Emission Unit ID:

EP-331-01-V

Emission Sample Unit ID:

ESP-331-01-V

Traverse Point ID:

TP-331-01-1

Washington Geological Survey 84 Coordinates:

Latitude: 46.365 degrees

Longitude: 119.271 degrees

\section{Facility/Process Description}

The Life Sciences Laboratory I (331 Building) provides research in health risks associated with internal and external radiation exposures, experimental studies to understand the microbial process in the range of ecosystems, focusing on potential interaction with Hanford sediment legacy waste and other subsurface issues. Other areas of research capabilities include characterizing and monitoring of aquatic and terrestrial ecosystems, with a focus on impacts of water use practices on fisheries and wildlife. Current projects in the area of basic and applied research of geostatistical analysis include sampling and monitoring designs, and spatial and temporal data analysis. Development of detection systems and analytical processes for the discovery/identification of signatures (chemical, explosive, biological, optical). 


\section{Exhaust Unit Description}

Air exhausts through EP-331-01-V from areas inside of the 331 Building where radionuclides are handled and used, which include fume hoods and other work spaces. The exhaust stream passes through HEPA filters located upstream of the exhaust fans. The stack extents $24.75 \mathrm{ft}$ above the roof top and is $62 \mathrm{ft}$ above the existing grade south of the 331 Building. The stack diameter is $78 \mathrm{in}$. and has a cross-sectional area of $33.2 \mathrm{ft}^{2}$.

\section{Exhaust Unit Control Technology}

The following simplified drawing shows the effluent pathway and the installed control technology for the 331 Building emission unit:

Figure D.3 331-01-V Building Effluent Pathway

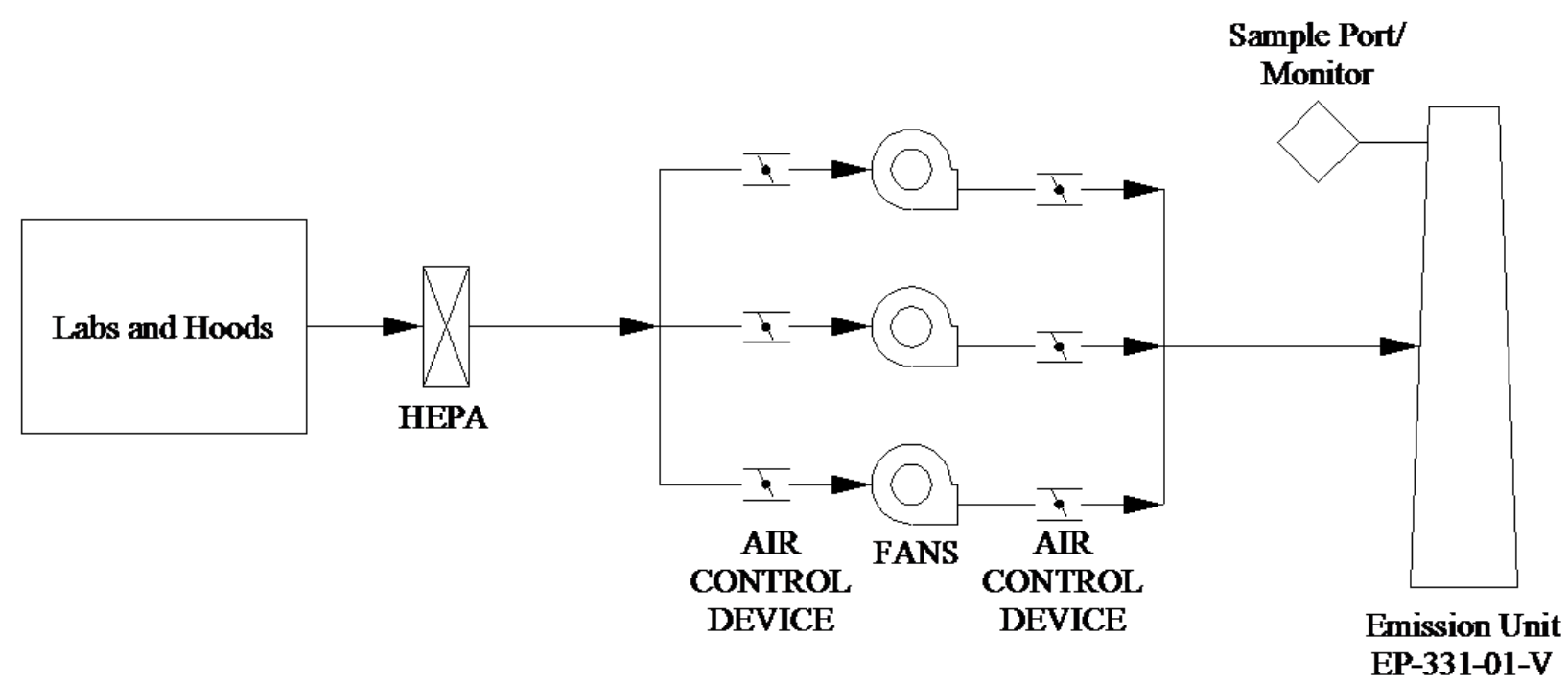

\section{$\underline{\text { Exhaust Unit Flow Rate and Temperature }}$}

Exhaust flow rates are determined quarterly using EM procedure EPRP-AIR-016, which was developed based on the requirements in 40 CFR 60, Appendix A, Method 2. The following table provides historical flow-rate measurements: 
Table D.5 331-01-V Building Exhaust Unit Flow Rate

\begin{tabular}{|c|c|}
\hline Date Measured & Flow Rate (CFM) \\
\hline $02 / 18 / 00$ & 71,712 \\
\hline $05 / 25 / 00$ & 68,757 \\
\hline $08 / 16 / 00$ & 66,134 \\
\hline $11 / 15 / 00$ & 64,900 \\
\hline $03 / 27 / 01$ & 60,400 \\
\hline $06 / 14 / 01$ & 57,800 \\
\hline $10 / 18 / 01$ & 61,400 \\
\hline $12 / 17 / 01$ & 62,900 \\
\hline $03 / 27 / 02$ & 60,800 \\
\hline $06 / 25 / 02$ & 62,600 \\
\hline $09 / 27 / 02$ & 61,100 \\
\hline $12 / 13 / 02$ & 60,300 \\
\hline $03 / 13 / 03$ & 63,400 \\
\hline $05 / 15 / 03$ & 61,100 \\
\hline $08 / 21 / 03$ & 55,900 \\
\hline $12 / 23 / 03$ & 54,600 \\
\hline $03 / 31 / 04$ & 52,100 \\
\hline $06 / 16 / 04$ & 51,100 \\
\hline $09 / 22 / 04$ & 52,600 \\
\hline $12 / 02 / 04$ & 54,300 \\
\hline $03 / 17 / 05$ & 56,600 \\
\hline $06 / 21 / 05$ & 55,900 \\
\hline $10 / 03 / 05$ & 58,400 \\
\hline $12 / 29 / 05$ & 51,100 \\
\hline
\end{tabular}

\begin{tabular}{|c|c|}
\hline Date Measured & Flow Rate (CFM) \\
\hline $03 / 22 / 06$ & 53,300 \\
\hline $06 / 22 / 06$ & 52,100 \\
\hline $09 / 26 / 06$ & 54,000 \\
\hline $12 / 27 / 06$ & 51,000 \\
\hline $03 / 22 / 07$ & 52,300 \\
\hline $06 / 27 / 07$ & 51,600 \\
\hline $09 / 28 / 07$ & 51,600 \\
\hline $12 / 04 / 07$ & 52,100 \\
\hline $02 / 28 / 08$ & 50,500 \\
\hline $06 / 25 / 08$ & 52,800 \\
\hline $09 / 25 / 08$ & 52,800 \\
\hline $12 / 23 / 08$ & 52,300 \\
\hline $03 / 03 / 09$ & 53,300 \\
\hline $06 / 09 / 09$ & 52,800 \\
\hline $09 / 30 / 09$ & 49,800 \\
\hline $12 / 18 / 09$ & 51,500 \\
\hline $03 / 31 / 10$ & 44,500 \\
\hline $06 / 30 / 10$ & 56,900 \\
\hline $09 / 20 / 10$ & 59,600 \\
\hline $12 / 17 / 10$ & 51,500 \\
\hline $03 / 22 / 11$ & 63,200 \\
\hline $06 / 23 / 11$ & 64,700 \\
\hline $09 / 01 / 11$ & 63,100 \\
\hline $12 / 14 / 11$ & 61,800 \\
\hline Average $\pm 1 \sigma$ & $56,800 \pm 5,800$ \\
\hline
\end{tabular}

Table D.6 331-01-V Building Exhaust Unit Temperature

\begin{tabular}{|c|c|}
\hline Date Measured & Average Temperature $\left({ }^{\circ} \mathbf{F}\right)$ \\
\hline $03 / 22 / 06$ & 77 \\
\hline $06 / 22 / 06$ & 78 \\
\hline $09 / 26 / 06$ & 79 \\
\hline $12 / 27 / 06$ & 74 \\
\hline $03 / 22 / 07$ & 77 \\
\hline $06 / 27 / 07$ & 78 \\
\hline $09 / 28 / 07$ & 77 \\
\hline $12 / 04 / 07$ & 77 \\
\hline $02 / 28 / 08$ & 76 \\
\hline $06 / 25 / 08$ & 78 \\
\hline $09 / 25 / 08$ & 78 \\
\hline $12 / 23 / 08$ & 74 \\
\hline
\end{tabular}

\begin{tabular}{|c|c|}
\hline Date Measured & Average Temperature $\left({ }^{\circ} \mathbf{F}\right)$ \\
\hline $03 / 03 / 09$ & 75 \\
\hline $06 / 09 / 09$ & 76 \\
\hline $09 / 30 / 09$ & 75 \\
\hline $12 / 18 / 09$ & 73 \\
\hline $03 / 31 / 10$ & 72 \\
\hline $06 / 30 / 10$ & 74 \\
\hline $09 / 20 / 10$ & 75 \\
\hline $12 / 17 / 10$ & 75 \\
\hline $03 / 22 / 11$ & 73 \\
\hline $06 / 23 / 11$ & 72 \\
\hline $09 / 01 / 11$ & 79 \\
\hline $12 / 14 / 11$ & 73 \\
\hline Average $\pm 1 \sigma$ & $76 \pm 2.2$ \\
\hline
\end{tabular}

\section{Record Particulate Sample System Description}

The record particulate sampling system for emission unit EP-331-01-V is operated in conformance with 40 CFR 61, Subpart H and ANSI N13.1-1969 requirements. See Stack Sampler Configuration Drawing H-3-307236.

The sample is extracted from a section of horizontal duct located on the roof of the 331 Building. The sample probe is positioned about $52 \mathrm{ft}$ ( 8.0 equivalent diameters) downstream of a flow 
disturbance and $14 \mathrm{ft}, 11 \mathrm{in.} \mathrm{(2.3} \mathrm{equivalent} \mathrm{diameters)} \mathrm{to} \mathrm{a} \mathrm{downstream} \mathrm{disturbance} \mathrm{where} \mathrm{the}$ duct makes a $10 \mathrm{ft}$ radius bend upwards. The sample extraction point position meets the 8:2 (downstream:upstream) duct-diameter placement recommendation from ANSI N13.1-1969.

A stainless steel, six-nozzle probe manufactured by Air Monitor Corporation is used to extract the sample. Each nozzle inlet has a 0.237 in. ID. The six sample nozzles feed into a 1.12 in. ID manifold that extends horizontally across the center of the duct. See vendor-supplied drawings for details: W20628DA and W20628EA.

The sample transport line is constructed of 1.25 in. stainless steel tubing. The line extends outside of the duct approximately $2.375 \mathrm{ft}$ before terminating in a waterproof cabinet containing the collection filter, rotameter, and sample flow rate adjustment valve. The sample line is insulated, heat traced, and electrically grounded. The sample line temperature is maintained above that of the stack gas to prevent condensation from forming in the sample line.

\section{Vacuum Air Sample System}

Stack emission samples are withdrawn from the stack and through the sample system by means of the building vacuum air sampling system located in the second floor equipment room of the 331 Building. This system has redundant blowers that are powered by normal and emergency power. See Vacuum Air Sampling One-Line Diagram Drawing H-3-307559-1 for details.

\section{Sample Collection}

The record particulate sampling system was constructed in conformance with ANSI N13.1-1969 requirements. Samples are collected using a sample probe that has six nozzles, with each nozzle sampling an equal annular space within the stack. The probe in the stack is located to meet the 8:2 (downstream: upstream) duct-diameter placement recommendation from ANSI N13.1-1969. The sampling system components (rotameter and vacuum gauge) are calibrated annually. Inspections of the sampling system are performed prior to initiating a sampling event and every day (excluding holidays and weekends) during sample collection.

\section{Battelle Drawings}

Stack Sampler Configuration EP-331-01-V; Rev. 2

Vacuum Air Sampling One-Line Diagram; Rev. 3

Electronic access to these drawings is available.

\section{Number}

H-3-307236-1

H-3-307559-1

\section{$\underline{\text { Air Monitor Corp. Drawings }}$}

Flo-Sampler Probe Assembly; Rev. 2 Iso-Sampling Threaded Nozzle; Rev. 1
Number

W20628DA

W20628EA

Other drawings are provided by the vendor and are not available electronically at this time. 



\section{Appendix E}

\section{PNNL Site Stack Sampler Systems}





\section{Appendix E: PNNL Site Stack Sampler Systems}

Appendix E contains a description of the buildings, exhaust units, control technologies, and sample extraction details for each facility emission unit. Additionally, applicable stack-samplerconfiguration drawings, figures, and photographs are provided for the following emission units: EP-3410-01-S, EP-3420-01-S, and EP-3430-01-S.

\section{Emission Unit EP-3410-01-S: Materials Science and Technology}

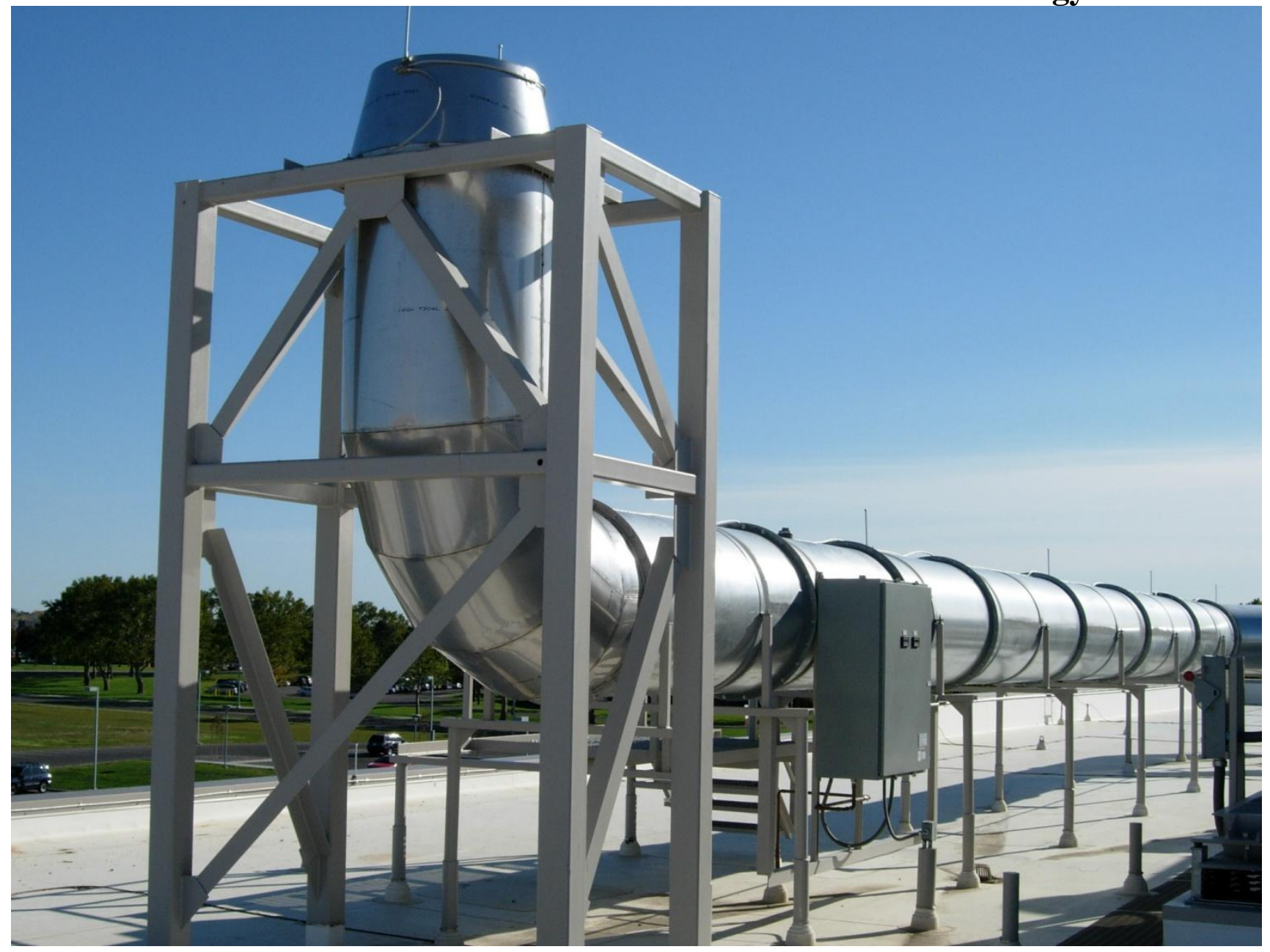

Emission Unit ID:

EP-3410-01-S

Emission Sample Unit ID:

ESP-3410-01-S

Traverse Point ID:

TP-3410-01-1

Washington Geological Survey 84 Coordinates:

Latitude: 46.350 degrees

Longitude: 119.271 degrees 


\section{Facility/Process Description}

The 3410 Building contains research laboratories that evaluate the performance of materials for applications in high temperature, corrosive, and/or radiation environments. Capabilities include radiation materials science to evaluate the aging and degradation of materials in nuclear systems and to develop radiation-resistant structural materials for advanced fission and fusion reactors; synthesis, characterization, and performance of irradiated and un-irradiated materials for applications at temperatures where properties begin to change; investigations of fundamental mechanism of materials corrosion and stress corrosion cracking in nuclear reactor environments; and computational materials science for radiation effects modeling to understand and predict materials behavior.

\section{Exhaust Unit Description}

The design of the 3410 building specifies that all radiological areas (i.e., Rooms 1400, 1401, $1402,1403,1404,1405,1407,1601,1602,1603,1605,1607,1714$, and the 1280E and 1280B corridors) exhaust through a single emission unit: EP-3410-01-S. Single-stage high-efficiency particulate air (HEPA) filters control radiological exhaust using one of two variable air flow exhaust fans operating at any one time. The stack height is $44 \mathrm{ft} 11 \mathrm{in}$. above the existing groundlevel grade. The stack is $40 \mathrm{in}$. in diameter and has a cross-sectional area of $8.73 \mathrm{ft}^{2}$, while the discharge point has a diameter of $32 \mathrm{in}$.

\section{Exhaust Unit Control Technology}

The following simplified drawing shows the effluent pathway and the installed control technology for the 3410 Building emission unit:

Figure E.1 3410-01-S Building Effluent Pathway

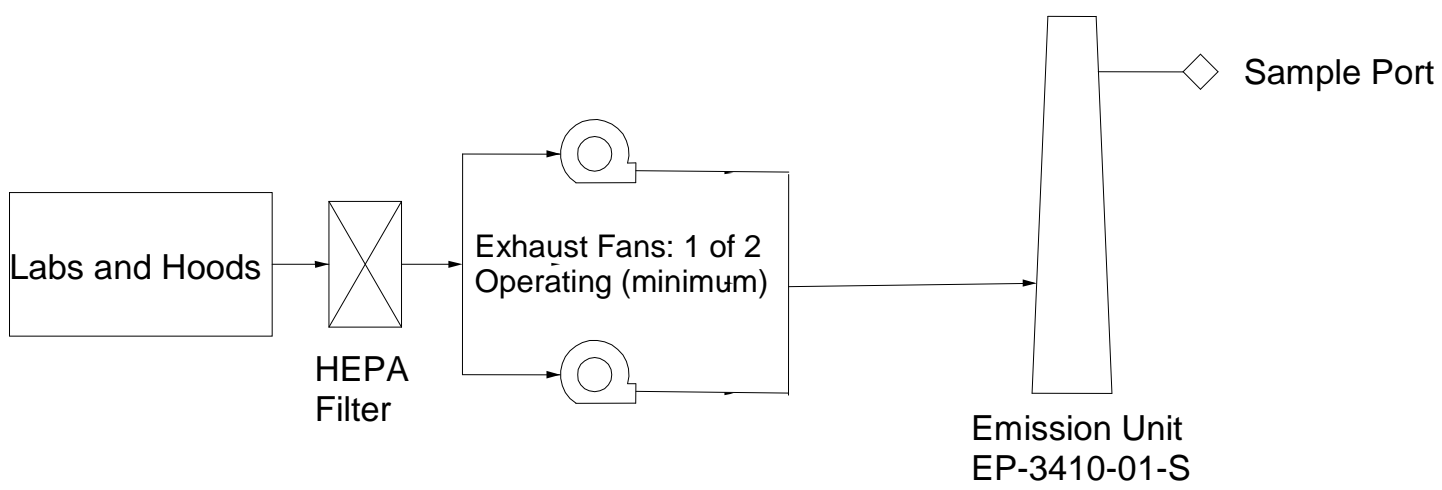

\section{Exhaust Unit Flow Rate}

Exhaust flow rates are determined using EM procedure EPRP-AIR-016, which was developed based on the requirements in 40 CFR 60, Appendix A, Method 2. Since this is a new emission unit, only the exhaust unit flow rate and temperature for 2011 is available. 
Table E.1 3410-01-S Building Exhaust Unit Flow Rate

\begin{tabular}{|c|c|}
\hline Date Measured & Flow Rate (CFM) \\
\hline $07 / 26 / 11$ & 19,200 \\
\hline
\end{tabular}

Table E.2 3410-01-S Building Exhaust Unit Temperature

\begin{tabular}{|c|c|}
\hline Date Measured & Temperature $\left({ }^{\mathbf{0}} \mathbf{F}\right)$ \\
\hline $07 / 26 / 11$ & 85 \\
\hline
\end{tabular}

\section{Record Particulate Sample System Description}

The record particulate sampling system for emission unit EP-3410-01-S operates in conformance with 40 CFR 61, Subpart H and ANSI N13.1-1999 requirements. See Stack Sampler Configuration Drawing H-3-312451.

A record particulate sampling system samples the exhaust from emission unit EP-3410-01-S in conformance with 40 CFR 61, Subpart H. A shrouded probe mounted in the center $2 / 3^{\text {rds }}$ of the exhaust stack conducts continuous sampling for particulates and samples.

A stainless steel, shrouded probe supplied by Air Monitor Corporation is used to extract the sample. The single nozzle inlet has a 1.225 in. ID. The sample nozzle is tapered and feed into a 1.125 in. ID transport line that is run on a horizontal plane across the stack. See vendor-supplied drawing (W68683AD) for details.

The sample transport line is constructed of $1.12 \mathrm{in.} \mathrm{ID} \mathrm{stainless} \mathrm{steel} \mathrm{tubing.} \mathrm{The} \mathrm{line} \mathrm{extends}$ 0.49 in. outside of the duct and terminates in a heated cabinet containing the sample collection filter, flowmeters, and adjustment valves. The sample line temperature is maintained above that of the stack gas to prevent condensation from forming in the sample line.

\section{$\underline{\text { Vacuum Air Sample System }}$}

A single Airtech Inc. regenerative pump located in the $2^{\text {nd }}$ floor equipment room supplies the vacuum to the sample system. This system is powered by normal power.

\section{$\underline{\text { Sample Collection }}$}

A shrouded probe mounted in the center $2 / 3^{\text {rds }}$ of the exhaust stack conducts continuous sampling for particulates and samples. The sampling system is designed and constructed in accordance with ANSI N13.1-1999. The radiological air emissions sampling operates under variable volume and temperature conditions. Membrane filters collect samples of particulate matter. The confirmatory demonstration of compliance is performed against previously proven testing data of similar design. The sampling system components are calibrated annually. Sampling system inspections are performed before initiating sampling event and daily (excluding holidays and weekends) during sample collection. 
$\underline{\text { Battelle Drawings }}$

Mechanical MEP Section

Plumbing Vacuum Air Diagram

Electronic access to these drawings is available.

\section{$\underline{\text { Air Monitor Corp. Drawings }}$}

Flow \& Sampler Probes General Arrangement
Number

H-3-312451

H-3-312546

Number

W68683AD

Other drawings are provided by the vendor and are not available electronically at this time. 


\section{Emission Unit EP-3420-01-S: Radiation Detection Building}

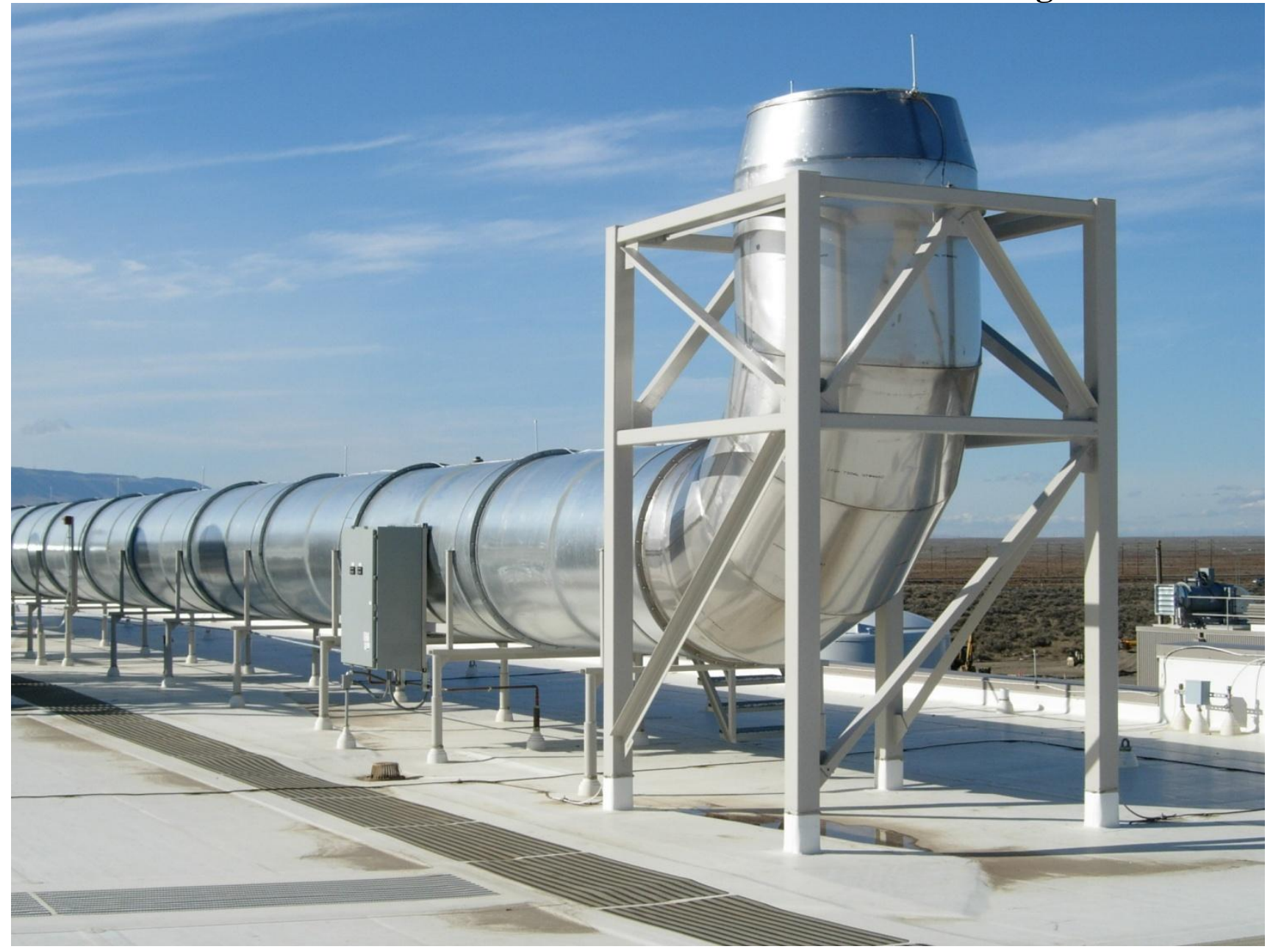

Emission Unit ID:

Emission Sample Unit ID:

Traverse Point ID:
EP-3420-01-S

ESP-3420-01-S

TP-3420-01-1

Washington Geological Survey 84 Coordinates:

Latitude: 46.353 degrees

Longitude: 119.276 degrees

\section{Facility/Process Description}

The 3420 Building contains research laboratories that perform a wide variety of radionuclide measurements. Capabilities used or under development would include state-of-the-art analytical chemistry, radiation physics, light detection, particle detection, chromatography, scintillation materials, sorbents materials, and field-deployable forensics instrumentation. Applications for these capabilities range from fundamental science, such as neutrino mass detection, to applied systems for prevention of nuclear proliferation and radiation portal monitoring. 


\section{Exhaust Unit Description}

The design of the 3420 building specifies that all radiological areas (i.e., Rooms 1601, 1603, 1607, 1607A, 1700, 1701, 1702, 1703, 1703A, 1703B, 1703C, 1704, 1705, 1706, 1707, 1709, 1709A, 1709B, 1800, and the 1280F corridor) exhaust through a single emission unit: EP-342001-S. Single-stage HEPA filters control radiological exhaust using two of three variable air flow exhaust fans operating at any one time. The stack height is $45 \mathrm{ft} 5 \mathrm{in}$. above the existing groundlevel grade. The stack is $62 \mathrm{in}$. in diameter and has a cross-sectional area of $20.97 \mathrm{ft}^{2}$, while the discharge point has a diameter of 52 in.

\section{Exhaust Unit Control Technology}

The following simplified drawing shows the effluent pathway and the installed control technology for the 3420 Building emission unit:

Figure E.2 3420-01-S Building Effluent Pathway

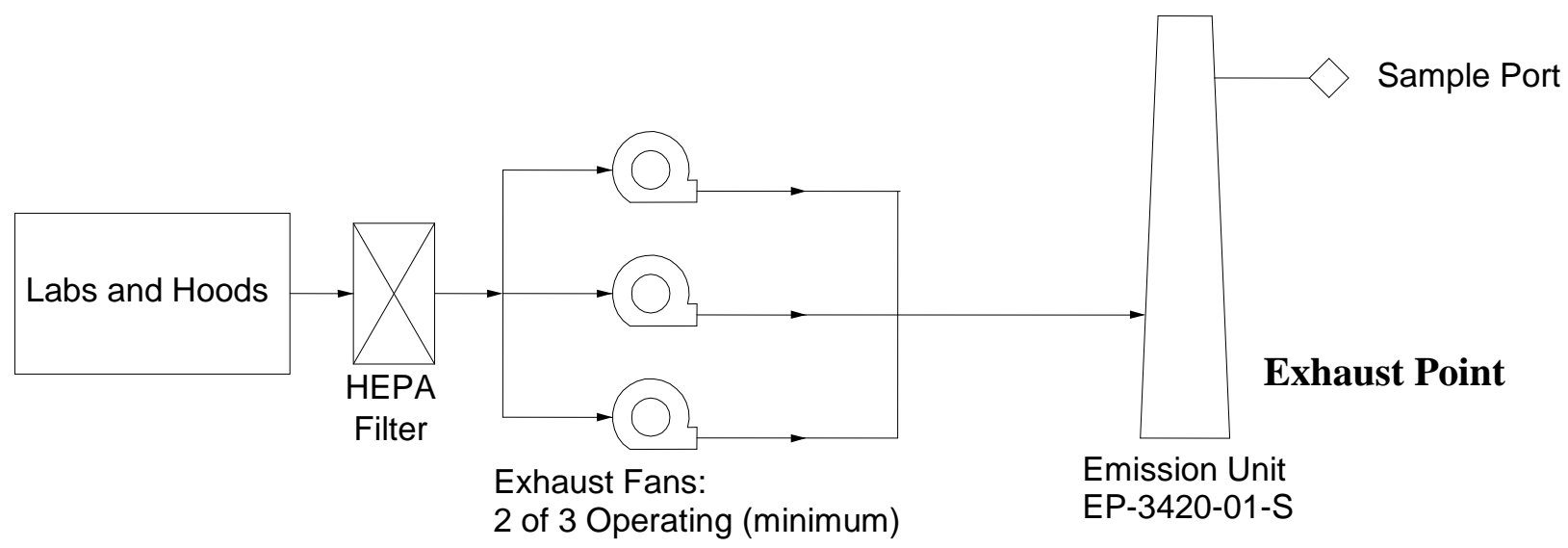

\section{Exhaust Unit Flow Rate}

Exhaust flow rates are determined using EM procedure EPRP-AIR-016, which was developed based on the requirements in 40 CFR 60, Appendix A, Method 2. Since this is a new emission unit, only the exhaust unit flow rate and temperature for 2011 is available.

Table E.3 3420-01-S Building Exhaust Unit Flow Rate

\begin{tabular}{|c|c|}
\hline Date Measured & Flow Rate (CFM) \\
\hline $07 / 28 / 11$ & 36,700 \\
\hline
\end{tabular}

Table E.4 3420-01-S Building Exhaust Unit Temperature

\begin{tabular}{|c|c|}
\hline Date Measured & Temperature $\left({ }^{\circ} \mathbf{F}\right)$ \\
\hline $07 / 28 / 11$ & 76 \\
\hline
\end{tabular}




\section{$\underline{\text { Record Particulate Sample System Description }}$}

The record particulate sampling system for emission unit EP-3420-01-S is operated in conformance with 40 CFR 61, Subpart H and ANSI N13.1-1999 requirements. See Stack Sampler Configuration Drawing H-3-312964.

A record particulate sampling system samples the exhaust from emission unit EP-3420-01-S in conformance with 40 CFR 61 , Subpart $\mathrm{H}$. A shrouded probe mounted in the center $2 / 3^{\text {rds }}$ of the exhaust stack conducts continuous sampling for particulates.

A stainless steel, shrouded probe supplied by Air Monitor Corporation is used to extract the sample. The single nozzle inlet has a $1.225 \mathrm{in}$. ID. The sample nozzle is tapered and feed into a 1.125 in. ID transport line that is run on a horizontal plane across the stack. See vendor-supplied drawing for details: W68683AD.

The sample transport line is constructed of $1.12 \mathrm{in.} \mathrm{ID} \mathrm{stainless} \mathrm{steel} \mathrm{tubing.} \mathrm{The} \mathrm{line} \mathrm{extends}$ 0.49 in. outside of the duct and terminates in a heated cabinet containing the sample collection filter, flowmeters, and adjustment valves. The sample line temperature is maintained above that of the stack gas to prevent condensation from forming in the sample line.

\section{Vacuum Air Sample System}

A single Airtech Inc. regenerative pump located in the $2^{\text {nd }}$ floor equipment room supplies the vacuum to the sample system. This system is powered by normal power.

\section{$\underline{\text { Sample Collection }}$}

A shrouded probe mounted in the center $2 / 3^{\text {rds }}$ of the exhaust stack conducts continuous sampling for particulates. The sampling system is designed and constructed in accordance with ANSI N13.11999. The radiological air emissions sampling operates under variable volume and temperature conditions. Membrane filters collect samples of particulate matter. The confirmatory demonstration of compliance is performed against previously proven testing data of similar design. The sampling system components are calibrated annually. Sampling system inspections are performed before initiating sampling event and daily (excluding holidays and weekends) during sample collection.

\section{Battelle Drawings}

Mechanical MEP Section

Plumbing Vacuum Air Diagram

Electronic access to these drawings is available.
Number

H-3-312964

H-3-313069

\section{$\underline{\text { Air Monitor Corp. Drawings }}$}

Flow \& Sampler Probes General Arrangement
Number

W68683AD 
Other drawings are provided by the vendor and are not available electronically at this time. 


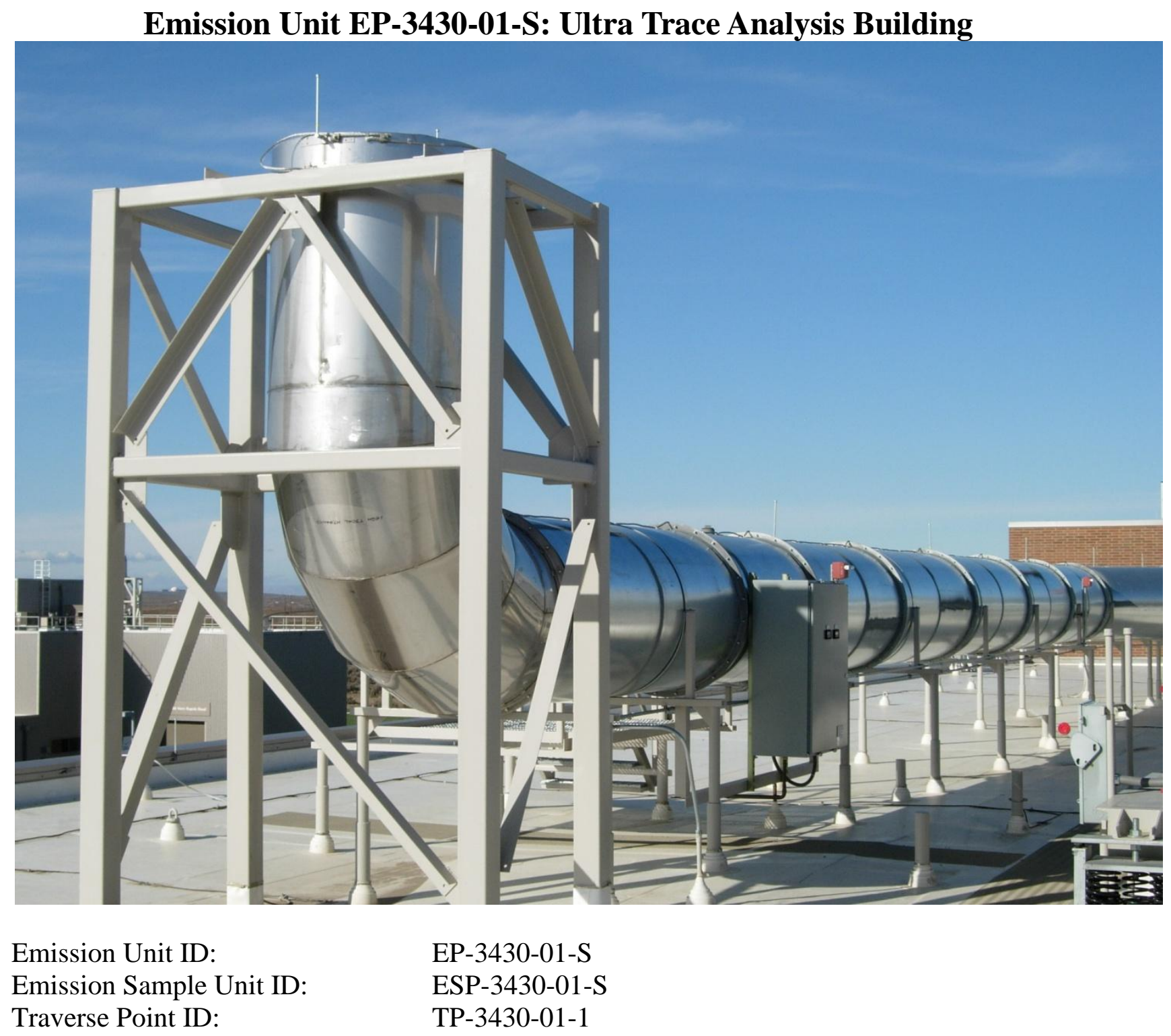

Washington Geological Survey 84 Coordinates:

Latitude: 46.352 degrees

Longitude: 119.278 degrees

\section{$\underline{\text { Facility/Process Description }}$}

The 3430 Building provides ultra-trace radio-analytical capabilities for nuclear forensics in support of critical national needs, such as international treaty verification. These capabilities include highly sensitive analytical systems, such as mass spectrometers, optical microscopes, and electron microscopes to provide isotopic analyses and ultra-low-level radionuclide detection in a wide variety of sample matrices. 


\section{Exhaust Unit Description}

The design of the 3430 building specifies that all radiological areas (i.e., Rooms 1292, 1295, $1300,1302,1304,1306,1308,1310,1501,1503,1505,1507,1507 \mathrm{~A}, 1507 \mathrm{~B}$, and the 1280E corridor) exhaust through a single emission unit: EP-3430-01-S. Single-stage HEPA filters control radiological exhaust using one of two variable air flow exhaust fans operating at any one time. The stack height is $43 \mathrm{ft} 11 \mathrm{in}$. above the existing ground-level grade. The stack is $44 \mathrm{in}$. in diameter and has a cross-sectional area of $10.6 \mathrm{ft}^{2}$.

\section{Exhaust Unit Control Technology}

The following simplified drawing shows the effluent pathway and the installed control technology for the 3430 Building emission unit:

Figure E.3 3430-01-S Building Effluent Pathway

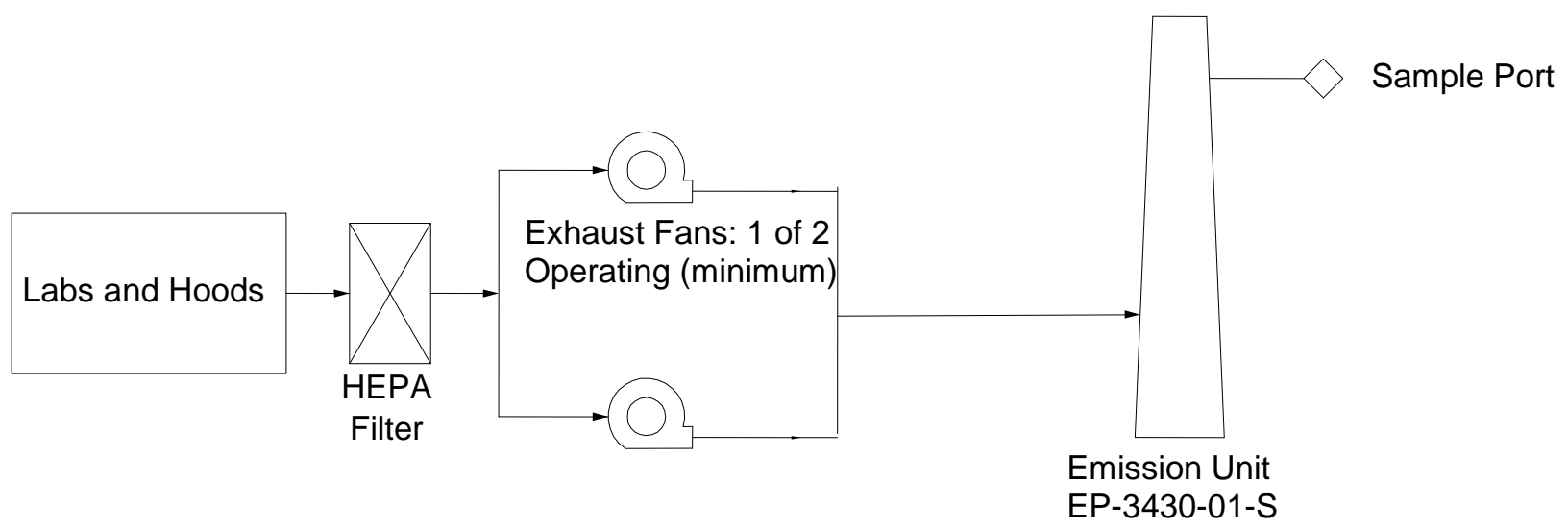

\section{Exhaust Unit Flow Rate}

Exhaust flow rates are determined using EM procedure EPRP-AIR-016, which was developed based on the requirements in 40 CFR 60, Appendix A, Method 2. Since this is a new emission unit, only the exhaust unit flow rate and temperature for 2011 is available.

Table E.5 3430-01-S Building Exhaust Unit Flow Rate

\begin{tabular}{|c|c|}
\hline Date Measured & Flow Rate (CFM) \\
\hline $07 / 28 / 11$ & 31,800 \\
\hline
\end{tabular}

Table E.6 3430-01-S Building Exhaust Unit Temperature

\begin{tabular}{|c|c|}
\hline Date Measured & Temperature $\left({ }^{\mathbf{}} \mathbf{F}\right)$ \\
\hline $07 / 28 / 11$ & 74 \\
\hline
\end{tabular}




\section{$\underline{\text { Record Particulate Sample System Description }}$}

The record particulate sampling system for emission unit EP-3430-01-S is operated in conformance with 40 CFR 61, Subpart H and ANSI N13.1-1999 requirements. See Stack Sampler Configuration Drawing H-3-313813.

A record particulate sampling system samples the exhaust from emission unit EP-3430-01-S for radioactive particulates in conformance with 40 CFR 61, Subpart $\mathrm{H}$. A shrouded probe mounted in the center $2 / 3^{\text {rds }}$ of the exhaust stack conducts continuous sampling for particulates.

A stainless steel, shrouded probe supplied by Air Monitor Corporation is used to extract the sample. The single nozzle inlet has a $1.225 \mathrm{in}$. ID. The sample nozzle is tapered and feed into a 1.125 in. ID transport line that is run on a horizontal plane across the stack. See vendor-supplied drawing for details: W68683AD.

The sample transport line is constructed of $1.12 \mathrm{in}$. ID stainless steel tubing. The line extends 0.49 in outside of the duct and terminates in a heated cabinet containing the sample collection filter, flowmeters, and adjustment valves. The sample line temperature is maintained above that of the stack gas to prevent condensation from forming in the sample line.

\section{Vacuum Air Sample System}

A single Airtech Inc. regenerative pump located in the $2^{\text {nd }}$ floor equipment room supplies the vacuum to the sample system. This system is powered by normal power.

\section{$\underline{\text { Sample Collection }}$}

A shrouded probe mounted in the center $2 / 3^{\text {rds }}$ of the exhaust stack conducts continuous sampling for particulates. The sampling system is designed and constructed in accordance with ANSI N13.1-1999. The radiological air emissions sampling operates under variable volume and temperature conditions. Membrane filters collect samples of particulate matter. The confirmatory demonstration of compliance is performed against previously proven testing data of similar design. The sampling system components are calibrated annually. Sampling system inspections are performed before initiating sampling event and daily (excluding holidays and weekends) during sample collection.

\section{Battelle Drawings}

Mechanical MEP Section

Plumbing Vacuum Air Diagram

Electronic access to these drawings is available.

\section{Number}

H-3-312964

H-3-313069

\section{$\underline{\text { Air Monitor Corp. Drawings }}$}

Flow \& Sampler Probes General Arrangement
Number

W68683AD

Other drawings are provided by the vendor and are not available electronically at this time. 



\section{Appendix F}

\section{Battelle Private Stack Sampler Systems}





\section{Appendix F: Battelle Private Stack Sampler Systems}

Appendix F contains a description of the buildings, exhaust units, control technologies, and sample extraction information for Battelle Private emission units in Richland North Complex. Additionally, applicable stack sampler configuration drawings, figures, and photographs are provided for the following Battelle Private emission units: EP-RTL-10-V and EP-RTL-11-V.

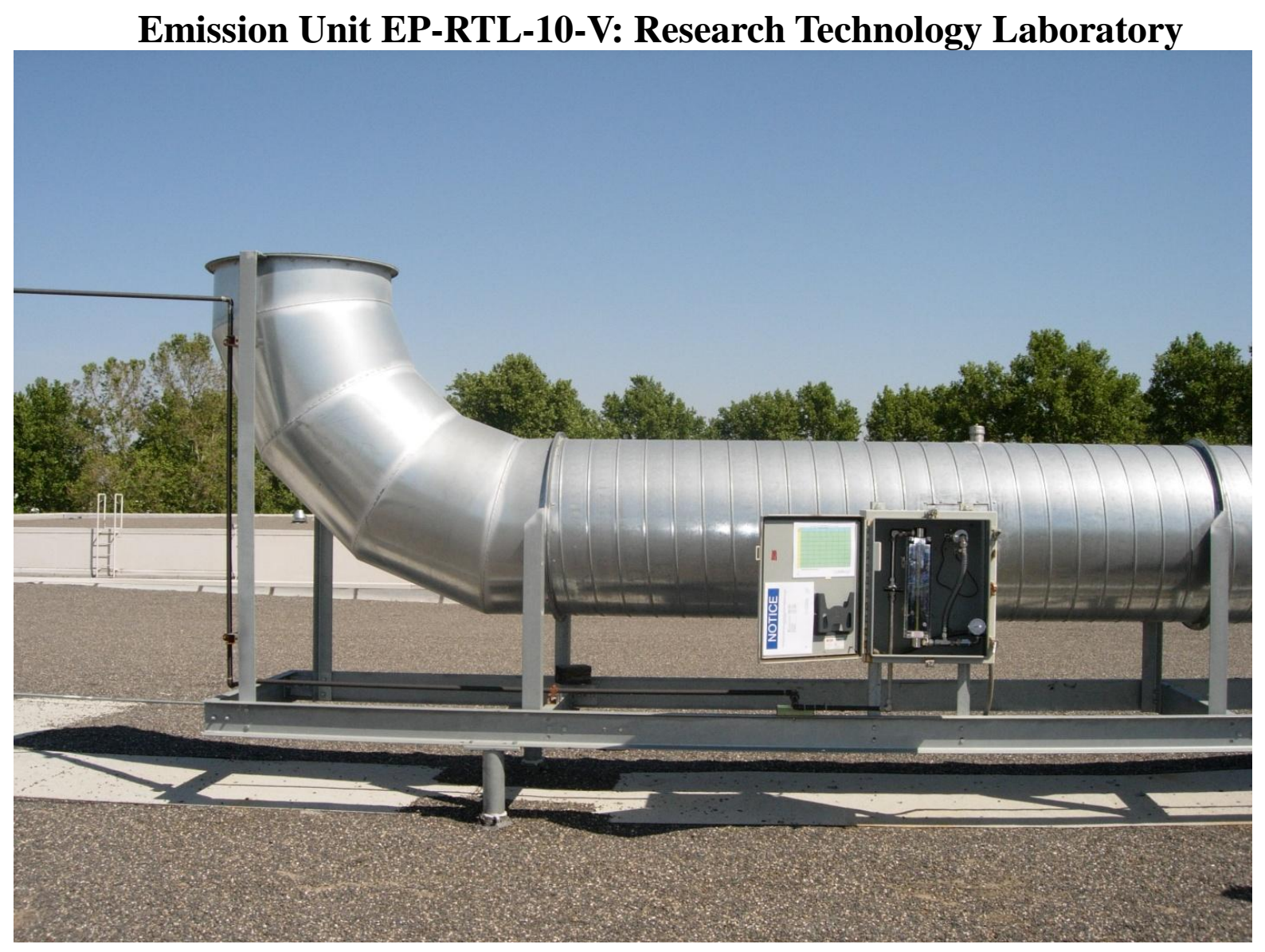

Emission Unit ID:

EP-RTL-10-V

Emission Sample Unit ID:

ESP-RTL-10-D

Traverse Point ID:

TP-RTL-10-1

The RTL-520 Building is located in the Richland North Complex on the corner of $3^{\text {rd }}$ Street and George Washington Way.

Washington Geological Survey 84 Coordinates:

Latitude: 46.337 degrees

Longitude: 119.274 degrees 


\section{$\underline{\text { Facility/Process Description }}$}

The RTL-520 Building and associated support buildings provide laboratory, office, and storage space in support of R\&D activities. The building currently houses staff from three directorates: Environmental Technology (ETD), Energy Science and Technology (ESTD), and Fundamental Science (FSD).

ETD research includes chemical toxicology, health physics, dosimetry, radiological engineering, atmospheric science and modeling, health risk assessment, and soil and groundwater contamination. ETD develops comprehensive environmental monitoring programs, and conducts studies on various cleaning processes and using supporting analytical equipment to define progress.

The ESTD conducts R\&D in coatings and coating technologies including polymer web coatings, sputtering coatings, large-optics coatings, e-beam evaporation coatings, and electospark coatings. Other ESTD capabilities are hydrothermal powder processing and microfabrication, which includes laser micromachining, electrochemical machining, and electrodeposition.

The FSD performs original research directed at understanding reactions that occur at the solidliquid interface of geologic materials. These include interfacial reactions controlling contaminant concentrations in soils and groundwater, linked geochemical-microbiological processes such as electron transfer reactions, and isotope geochemistry. FSD also develops advanced selective laser ionization methods for detecting metal and inorganic materials at ultra-trace levels.

\section{Exhaust Unit Description}

EP-RTL-10-V is centrally located on the east end of the RTL-520 Building roof. All exhaust gas passes through at least one HEPA filter before discharge to the environment. The discharge point measures $26 \mathrm{ft}, 0.5 \mathrm{in}$. above the existing ground level grade. The duct is $31.9 \mathrm{in}$. in diameter and has a cross-sectional area of $5.6 \mathrm{ft}^{2}$.

\section{Exhaust Unit Control Technology}

The following simplified drawing shows the effluent pathway and the installed control technology for the RTL-520, EP-RTL-10-V, emission unit: 
Figure F.1 RTL-10-V Effluent Pathway

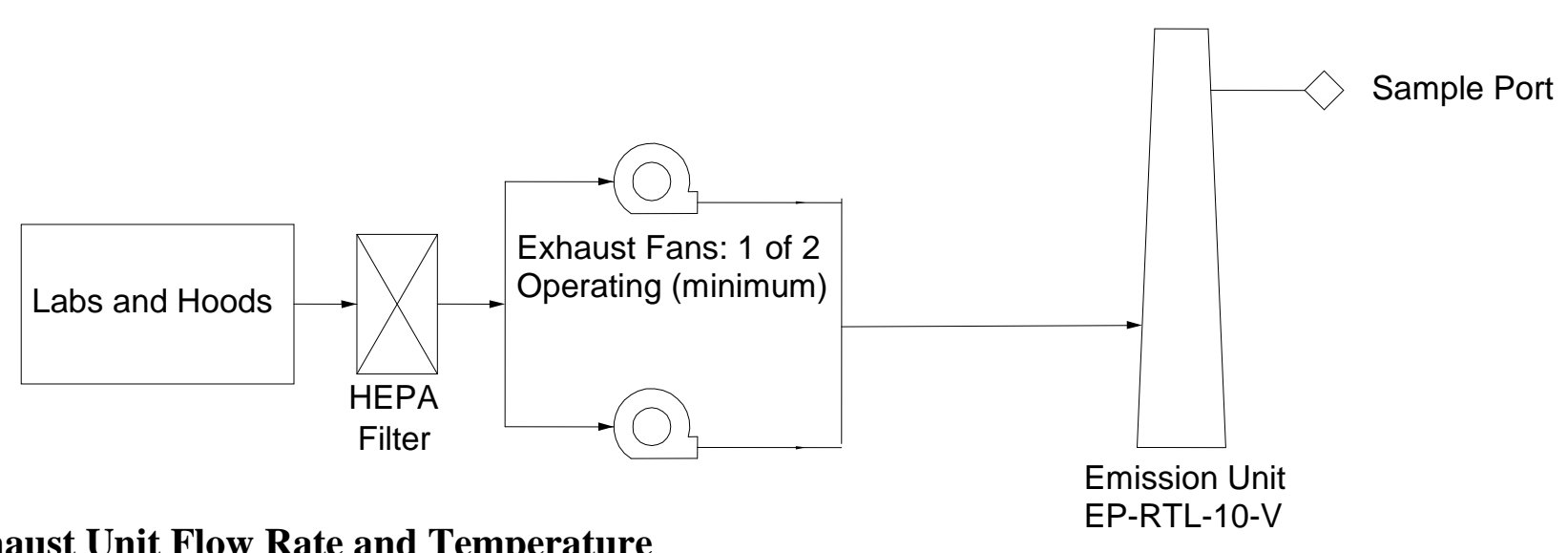

\section{Exhaust Unit Flow Rate and Temperature}

EP-RTL-10-V

Exhaust flow rates and temperature are determined annually using EM procedure EPRP-AIR016, which was developed based on the requirements in 40 CFR 60, Appendix A, Method 2. The following tables provide historical flow rate and temperature measurements:

Table F.1 RTL-10-V Exhaust Unit Flow Rate

\begin{tabular}{|c|c|}
\hline Date Measured & Flow Rate (CFM) \\
\hline $04 / 12 / 00$ & 14,941 \\
\hline $04 / 19 / 01$ & 14,000 \\
\hline $04 / 05 / 02$ & 15,600 \\
\hline $04 / 11 / 03$ & 14,800 \\
\hline $04 / 16 / 04$ & 14,300 \\
\hline $04 / 12 / 05$ & 13,300 \\
\hline $04 / 28 / 06$ & 13,600 \\
\hline $04 / 19 / 07$ & 13,400 \\
\hline $04 / 10 / 08$ & 13,700 \\
\hline $04 / 15 / 09$ & 13,700 \\
\hline $04 / 27 / 10$ & 13,300 \\
\hline $04 / 07 / 11$ & 13,700 \\
\hline Average $\pm 1 \sigma$ & $14,000 \pm 730$ \\
\hline
\end{tabular}

Table F.2 RTL-10-V Exhaust Unit Temperature

\begin{tabular}{|c|c|}
\hline Date Measured & Average Temperature $\left({ }^{\circ} \mathbf{F}\right)$ \\
\hline $04 / 28 / 06$ & 83 \\
\hline $04 / 19 / 07$ & 76 \\
\hline $04 / 10 / 08$ & 76 \\
\hline $04 / 15 / 09$ & 78 \\
\hline $04 / 27 / 10$ & 74 \\
\hline $04 / 07 / 11$ & 77 \\
\hline Average $\pm 1 \sigma$ & $77 \pm 3.1$ \\
\hline
\end{tabular}




\section{$\underline{\text { Record Particulate Sample System Description }}$}

The record particulate sampling system for emission unit EP-RTL-10-V is operated in conformance with 40 CFR 61, Subpart I and ANSI N13.1-1969 requirements. See Stack Sampler Configuration Drawing R-M-2004-1.

The record sample probe is positioned in the horizontal duct $23 \mathrm{ft}, 11.4 \mathrm{in}$. (9.01 equivalent diameters) downstream of the nearest flow disturbance and $5 \mathrm{ft}, 5.38$ in. (2.05 equivalent diameters) upstream from the nearest flow disturbance. The sample extraction point position meets the 8:2 (downstream: upstream) duct-diameter placement recommendation from ANSI N13.1-1969.

A stainless steel, five-nozzle probe manufactured by Air Monitor Corporation is used to extract the sample from the duct. Each nozzle inlet has a 0.185 in. inside diameter (ID). The five sample nozzles are tapered and feed into a common $1.12 \mathrm{in.} \mathrm{ID} \mathrm{manifold} \mathrm{that} \mathrm{extends} \mathrm{horizontally} \mathrm{across}$ the center of the duct. See vendor-supplied drawings for details: W36670AA, W36670BA, W36670BB, W36670BC, and W36670BD.

The sample transport line is constructed of $1.12 \mathrm{in.} \mathrm{ID} \mathrm{stainless} \mathrm{steel} \mathrm{tubing.} \mathrm{The} \mathrm{sample}$ transport line extends 10 in. outside of the duct and terminates in a cabinet containing the collection filter, rotameter, and sample flow rate adjustment valve. The sample line upstream of the collector is insulated, heat traced, and electrically grounded. The sample line temperature is maintained above that of the stack gas to prevent condensation from forming in the sample line.

\section{Vacuum Air Sample System}

Stack emission samples are withdrawn from the stack and through the sample system by means of the building vacuum air sampling system located in East Service Corridor of the RTL-520 Building. This system has redundant carbon vane vacuum pumps that are powered by normal and emergency power.

\section{Sample Collection}

Particulate samples will be collected using an isokinetic sampling probe mounted in the exhaust dust in accordance with ANSI N13.1-1969. Components are calibrated annually. Inspections of the sampling system are performed prior to initiating a sampling event and every day (excluding holidays and weekends) during sample collection.

\section{Battelle Drawings}

Mechanical Exhaust Fan Demolition Plan; Rev.0

Mechanical Exhaust Fan Plan; Rev.2

Mechanical Exhaust Fan Section and Details; Rev.0

Stack Sampler Configuration EP-RTL-10-V; Rev.1

Air Sample Station Instrument Cabinet Assembly; Rev.8

Stack Sample Filter Holder Inlet; Rev.1

Stack Sample Filter Holder Outlet; Rev.0

\section{Number}

R-M-1947-1

R-M-1947-2

R-M-1947-3

R-M-2004-1

H-3-70282-1

H-3-70447-1

H-3-70570-1

Electronic access to these drawings is available. 
$\underline{\text { Air Monitor Corporation Drawings }}$

SAMPLR-probe Threaded Nozzle; Rev.0

SAMPLR-probe Top Assembly; Rev. 1

SAMPLR-probe Sample Manifold; Rev. 0

SAMPLR-probe Mounting Plate \& Gasket; Rev. 1

SAMPLR-probe Radiused End Plug; Rev. 0 $\underline{\text { Number }}$

W36670AA

W36670BA

W36670BB

W36670BC

W36670BD

Other drawings are vendor provided and not electronically available at this time. 


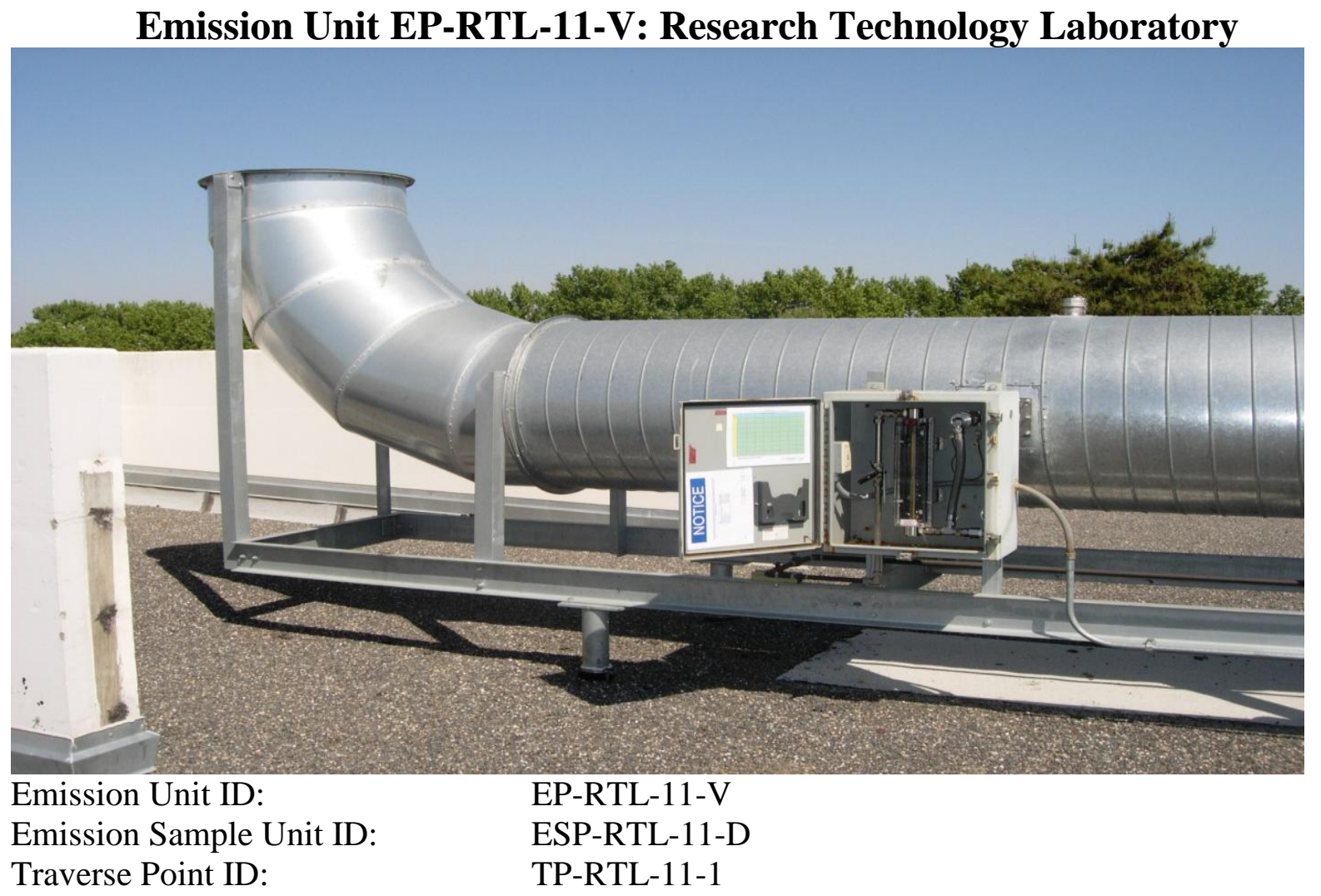

The RTL-520 Building is located in the Richland North Complex on the corner of $3^{\text {rd }}$ Street and George Washington Way.

Washington Geological Survey 84 Coordinates:

Latitude: 46.337 degrees

Longitude: 119.275 degrees

\section{Facility/Process Description}

The RTL-520 Building and associated support buildings provide laboratory, office, and storage space in support of research and development activities. The building currently houses staff from three directorates: ETD, ESTD, and FSD

ETD research includes chemical toxicology, health physics, dosimetry, radiological engineering, atmospheric science and modeling, health risk assessment, and soil and groundwater contamination. ETD develops comprehensive environmental monitoring programs, and conducts studies on various cleaning processes and using supporting analytical equipment to define progress.

The ESTD conducts R\&D in coatings and coating technologies including polymer web coatings, sputtering coatings, large-optics coatings, e-beam evaporation coatings, and electospark coatings. Other ESTD capabilities are hydrothermal powder processing and microfabrication, which includes laser micromachining, electrochemical machining, and electrodeposition. 
The FSD performs original research directed at understanding reactions that occur at the solidliquid interface of geologic materials. These include interfacial reactions controlling contaminant concentrations in soils and groundwater, linked geochemical-microbiological processes such as electron transfer reactions, and isotope geochemistry. FSD also develops advanced selective laser ionization methods for detecting metal and inorganic materials at ultra-trace levels.

\section{$\underline{\text { Exhaust Unit Description }}$}

EP-RTL-10-V is centrally located on the east end of the RTL-520 Building roof. All exhaust gas passes through at least one HEPA filter before discharge to the environment. The discharge point measures $26 \mathrm{ft}, 0.5 \mathrm{in}$. above the existing ground level grade. The duct is $31.9 \mathrm{in}$. in diameter and has a cross-sectional area of $5.6 \mathrm{ft}^{2}$.

\section{Exhaust Unit Control Technology}

The following simplified drawing shows the effluent pathway and the installed control technology for the RTL-520, EP-RTL-11-V, emission unit:

Figure F.2 RTL-11-V Effluent Pathway

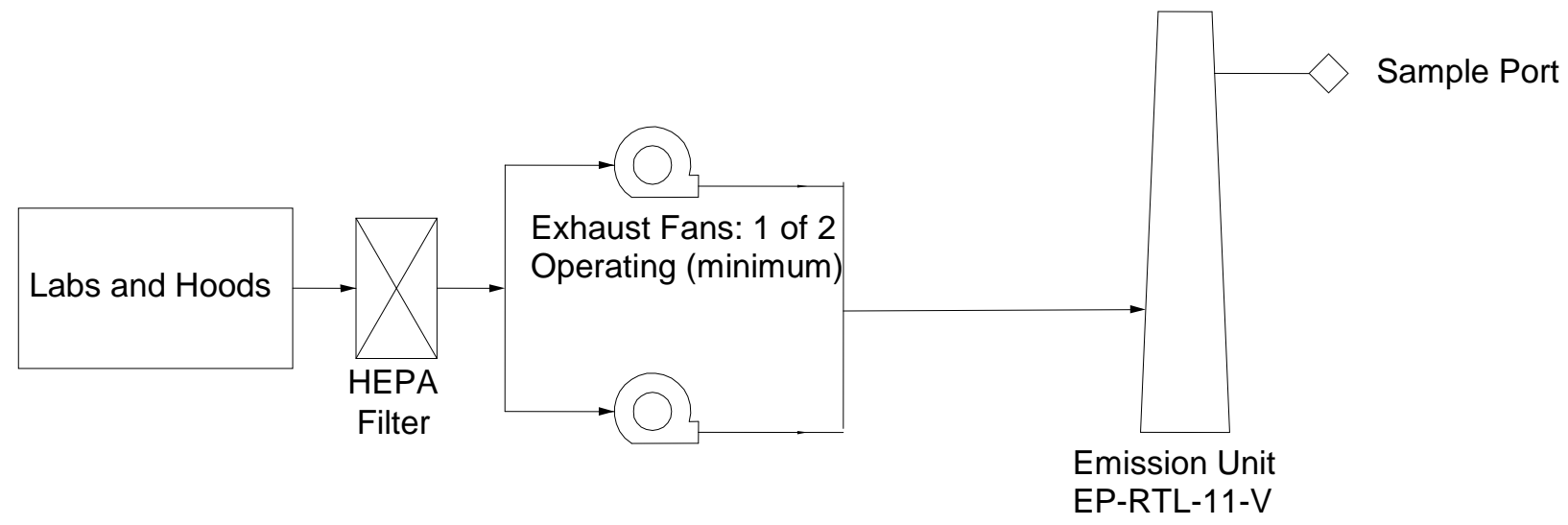

\section{Exhaust Unit Flow Rate and Temperature}

Exhaust flow rates and temperature are determined annually using EM procedure EPRP-AIR016, which was developed based on the requirements in 40 CFR 60, Appendix A, Method 2. The following tables provide historical flow rate and temperature measurements: 
Table F.3 RTL-11-V Exhaust Unit Flow Rate

\begin{tabular}{|c|c|}
\hline Date Measured & Flow Rate (CFM) \\
\hline $04 / 12 / 00$ & 17,643 \\
\hline $04 / 19 / 01$ & 16,900 \\
\hline $04 / 05 / 02$ & 17,400 \\
\hline $04 / 11 / 03$ & 16,100 \\
\hline $04 / 16 / 04$ & 17,100 \\
\hline $04 / 12 / 05$ & 17,800 \\
\hline $04 / 28 / 06$ & 17,500 \\
\hline $04 / 19 / 07$ & 17,500 \\
\hline $04 / 10 / 08$ & 17,300 \\
\hline $04 / 15 / 09$ & 17,500 \\
\hline $04 / 27 / 10$ & 19,500 \\
\hline $04 / 07 / 11$ & 20,000 \\
\hline Average $\pm 1 \sigma$ & $17,700 \pm 1,100$ \\
\hline
\end{tabular}

Table F.4 RTL-11-V Exhaust Unit Temperature

\begin{tabular}{|c|c|}
\hline Date Measured & Average Temperature $\left({ }^{\circ} \mathbf{F}\right)$ \\
\hline $04 / 28 / 06$ & 80 \\
\hline $04 / 19 / 07$ & 76 \\
\hline $04 / 10 / 08$ & 78 \\
\hline $04 / 15 / 09$ & 80 \\
\hline $04 / 27 / 10$ & 79 \\
\hline $04 / 07 / 11$ & 80 \\
\hline Average $\pm 1 \sigma$ & $79 \pm 1.6$ \\
\hline
\end{tabular}

\section{$\underline{\text { Record Particulate Sample System Description }}$}

The record particulate sampling system for emission unit EP-RTL-11-V is operated in conformance with 40 CFR 61, Subpart I and ANSI N13.1-1969 requirements. See Stack Sampler Configuration Drawing R-M-2004-2.

The record sample probe is positioned in the horizontal duct $22 \mathrm{ft}, 11.6$ in. (8.64 equivalent diameters) downstream of the nearest flow disturbance and $5 \mathrm{ft}, 5.38 \mathrm{in}$. (2.05 equivalent diameters) upstream from the nearest flow disturbance. The sample extraction point position meets the 8:2 (downstream: upstream) duct-diameter placement recommendation from ANSI N13.1-1969.

A stainless steel, five-nozzle probe manufactured by Air Monitor Corporation is used to extract the sample from the duct. Each nozzle inlet has a 0.185 in. ID. The five sample nozzles are tapered and feed into a common 1.12 in. ID manifold that extends horizontally across the center of the duct. See vendor-supplied drawings for details: W36670AA, W36670BA, W36670BB, W36670BC, and W36670BD.

The sample transport line is constructed of 1.12 in. ID stainless steel tubing. The sample transport line extends $8.5 \mathrm{in}$. outside the duct and terminates in a cabinet containing the collection filter, rotameter, and sample flow rate adjustment valve. The sample line upstream of 
the collector is insulated, heat traced, and electrically grounded. The sample line temperature is maintained above that of the stack gas to prevent condensation from forming in the sample line.

\section{Vacuum Air Sample System}

Stack emission samples are withdrawn from the stack and through the sample system by means of the building vacuum air sampling system located in East Service Corridor of the RTL-520 Building. This system has redundant carbon vane vacuum pumps that are powered by normal and emergency power.

\section{$\underline{\text { Sample Collection }}$}

Particulate samples will be collected using an isokinetic sampling probe mounted in the exhaust dust in accordance with ANSI N13.1-1969. Components are calibrated annually. Inspections of the sampling system are performed prior to initiating a sampling event and every day (excluding holidays and weekends) during sample collection.

\section{Battelle Drawings}

Mechanical Exhaust Fan Demolition Plan; Rev.0

Mechanical Exhaust Fan Plan; Rev.2

Mechanical Exhaust Fan Section and Details; Rev.0

Stack Sampler Configuration EP-RTL-11-V; Rev.1

Air Sample Station Instrument Cabinet Assembly; Rev.8

Stack Sample Filter Holder Inlet; Rev.1

Stack Sample Filter Holder Outlet; Rev.0
Number

R-M-1967-1

R-M-1967-2

R-M-1967-3

R-M-2004-2

H-3-70282-1

H-3-70447-1

H-3-70570-1

Electronic access to these drawings is available.

\section{$\underline{\text { Air Monitor Corporation Drawings }}$}

SAMPLR-probe Threaded Nozzle; Rev.0

SAMPLR-probe Top Assembly; Rev. 1

SAMPLR-probe Sample Manifold; Rev. 0

SAMPLR-probe Mounting Plate \& Gasket; Rev. 1

SAMPLR-probe Radiused End Plug; Rev. 0

\section{Number}

W36670AA

W36670BA

W36670BB

W36670BC

W36670BD

Other drawings are vendor provided and not electronically available at this time. 



\section{Appendix G}

\section{Deregistered/Transitioned Emission Units}





\section{Appendix G: Deregistered/Transitioned Stack Sampler Systems}

Appendix $\mathrm{G}$ contains a description of the buildings, exhaust units, control technologies, and sample extraction details for each facility emission unit that has been deregistered or transitioned out of PNNL operations in the last five years. Additionally, applicable stack-samplerconfiguration drawings, figures, and photographs are provided for the following emission units: EP-320-01-S, EP-320-02-S, EP-320-04-S, EP-326-01-S, EP-329-01-S, and EP-3020-01-S; however, information in this appendix is not updated.

\section{Emission Unit EP-320-01-S: Analytical and Nuclear Research Laboratory}

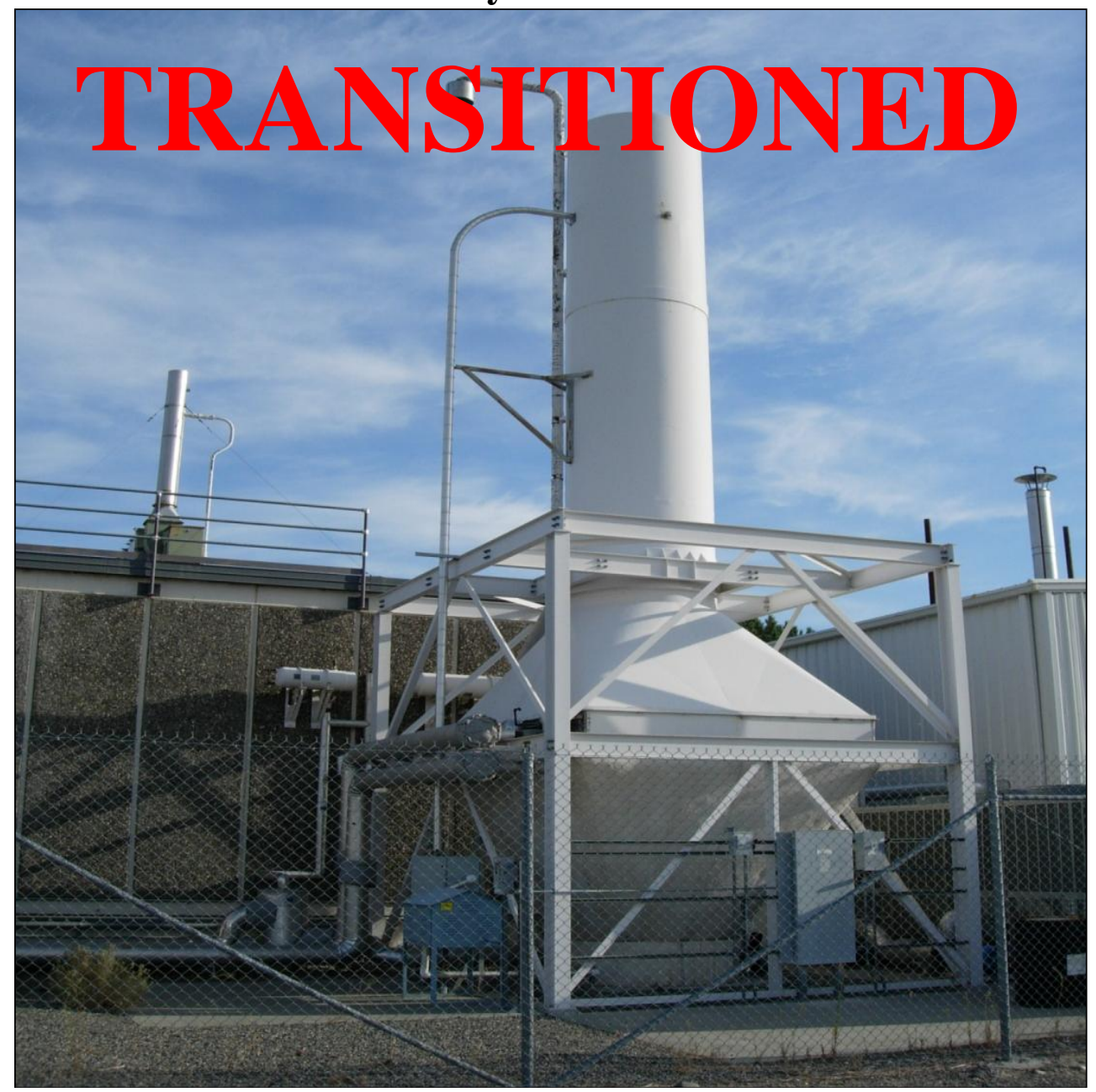

Emission Unit ID:

EP-320-01-S

Emission Sample Unit ID:

ESP-320-01-S

Traverse Point ID:

TP-320-01-1

Washington Geological Survey 84 Coordinates:

Latitude: 46.366 degrees

Longitude: 119.280 degrees 


\section{Facility/Process Description}

Research activities conducted in the 320 Building involved special-purpose separation and analytical chemistry techniques that allowed low-level and ultra-trace levels of material in environmental samples to be measured. Working with samples containing low/trace levels required special building features, such as a clean zone. A class 10,000 clean zone allowed for contamination-free preparation and analysis of samples containing extremely low levels of indicator radionuclides and trace organic compounds. Special instrumentation that is used for sample analysis included various mass spectrometers, electron-beam microscopes, X-ray diffraction, and radiation counters. Transition occurred in February 2011.

\section{Exhaust Unit Description}

EP-320-01-S exhausts air from areas where radionuclides are handled. The stack is located on the south side of the facility. The stack measures $39 \mathrm{ft}, 8 \mathrm{in}$. tall from the existing grade at the base of the stack to the point of discharge. The stack is $5 \mathrm{ft}$ in. diameter and has a cross-sectional area of $19.6 \mathrm{ft}^{2}$.

\section{Exhaust Unit Control Technology}

The following simplified drawing shows the effluent pathway and the installed control technology for the 320 Building emission unit:

Figure G.1 320-01-S Effluent Pathway

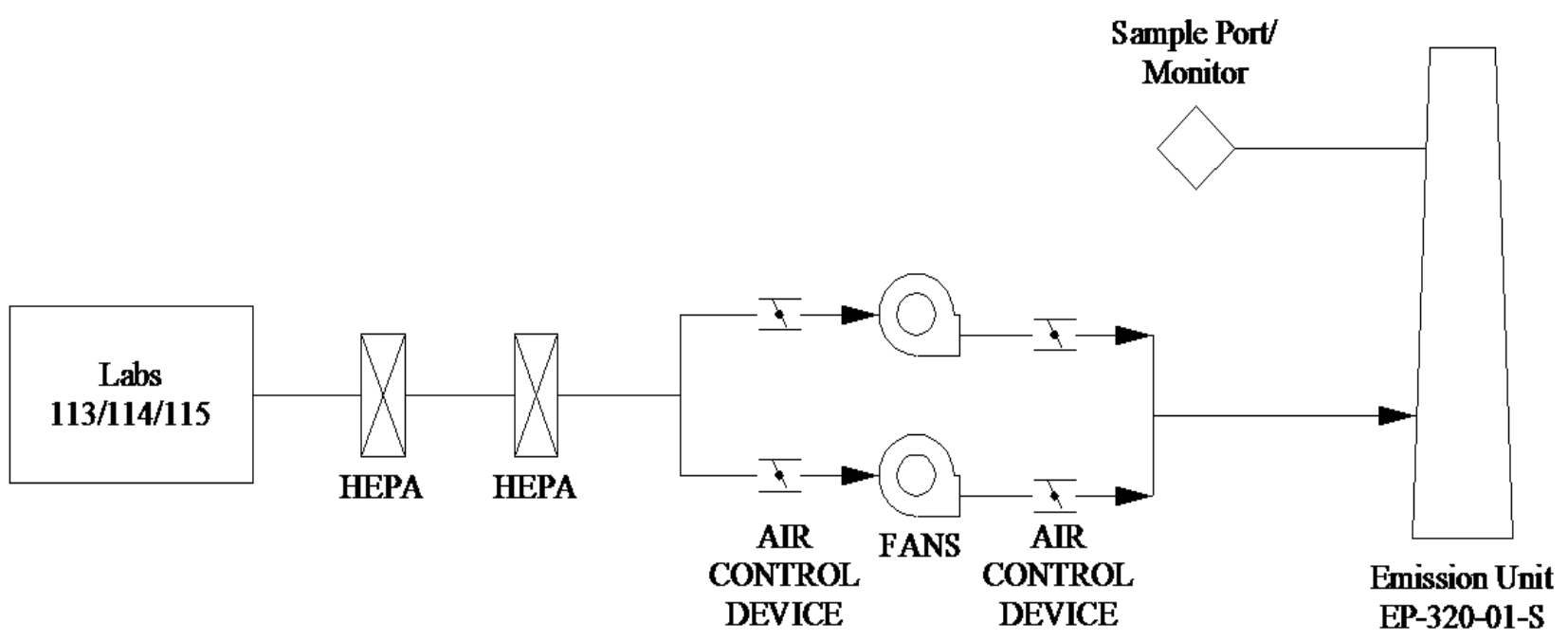

\section{Exhaust Unit Flow Rate and Temperature}

Exhaust flow rates and temperature are determined annually using EM procedure EPRP-AIR016, which was developed based on the requirements in 40 CFR 60, Appendix A, Method 2. The following tables provide historical flow rate and temperature measurements: 
Table G.1 320-01-S Exhaust Unit Flow Rate

\begin{tabular}{|c|c|}
\hline Date Measured & Flow Rate (CFM) \\
\hline $05 / 15 / 00$ & 31,870 \\
\hline $05 / 15 / 01$ & 31,100 \\
\hline $05 / 22 / 02$ & 27,200 \\
\hline $06 / 11 / 03$ & 33,200 \\
\hline $05 / 20 / 04$ & 28,000 \\
\hline $05 / 24 / 05$ & 26,300 \\
\hline $05 / 03 / 06$ & 31,600 \\
\hline $06 / 05 / 07$ & 28,100 \\
\hline $05 / 29 / 08$ & 27,500 \\
\hline $05 / 27 / 09$ & 28,600 \\
\hline $05 / 26 / 10$ & 30,400 \\
\hline Average $\pm 1 \sigma$ & $29,400 \pm 2,300$ \\
\hline
\end{tabular}

Table G.2 320-01-S Exhaust Unit Temperature

\begin{tabular}{|c|c|}
\hline Date Measured & Average Temperature $\left({ }^{\circ} \mathbf{F}\right)$ \\
\hline $05 / 03 / 06$ & 75 \\
\hline $06 / 05 / 07$ & 74 \\
\hline $05 / 29 / 08$ & 73 \\
\hline $05 / 27 / 09$ & 76 \\
\hline $05 / 26 / 10$ & 69 \\
\hline Average $\pm 1 \sigma$ & $73 \pm 2.7$ \\
\hline
\end{tabular}

\section{$\underline{\text { Record Particulate Sample System Description }}$}

The record particulate sampling system for emission unit EP-320-01-S was operated in conformance with 40 CFR 61, Subpart H and ANSI N13.1-1969 requirements. See Stack Sampler Configuration Drawing H-3-307242.

The sample was extracted from the stack about $34 \mathrm{ft}, 8$ in. above the existing grade at the stack base. The sample probe is positioned $18 \mathrm{ft}$ ( 3.6 equivalent diameters) downstream of the nearest flow disturbance and $5 \mathrm{ft}$ (1.0 equivalent diameters) from the top of the stack. During the modification to upgrade the stack, it was found that the original existing stack design would not support the extension of the stack to meet the 8:2 (downstream: upstream) duct-diameter placement recommendation from ANSI N13.1-1969. However, this design does comply with the alternative 2:0.5 criteria.

A stainless steel, six-nozzle probe manufactured by Air Monitor Corporation was used to extract the sample. Each nozzle inlet has a 0.223 in. ID. The six sample nozzles feed into a 1.12-in.-ID manifold that extends horizontally across the center of the duct. See vendor-supplied drawings for details: W23386DA, W23386DB, W23386DC, and W23386DD.

The sample transport line is constructed of 1.12-in. ID stainless steel tubing. The line extends 18 in. outside the stack before making a 90 degree, 36-in. radius of curvature bend downward and terminating in a cabinet containing the collection filter, rotameter, and sample-flow-rate adjustment valve. The sample line upstream of the collector is insulated, heat traced, and 
electrically grounded. The sample line temperature is maintained above that of the stack gas to prevent condensation from forming in the sample line.

\section{$\underline{\text { Vacuum Air Sample System }}$}

Stack emission samples were withdrawn from the stack and through the sample system via a single Rietschle carbon vane vacuum pump enclosed in a weatherproof housing for protection against the elements. The system is powered by normal power only.

\section{Battelle Drawings}

Stack Sampler Configuration EP-320-01-S; Rev. 1

Installation Plan \& Enlarged Plan; Rev. 0

Installation Elevations and Detail; Rev. 0

Electronic access to these drawings is available.

\section{$\underline{\text { Air Monitor Corp. Drawings }}$}

\#320 Isokinetic Sampling Probe; Rev. 2

Iso-Sampling Threaded Nozzle; Rev. 0

\#320 Isokinetic Sampling Manifold; Rev. 0

\#320 Iso-Sampling Probe Plate, Plug and Fitting; Rev. 1
Number

H-3-307242

H-3-301790-1

H-3-301790-2

Other drawings are provided by the vendor and are not available electronically at this time.

\section{$\underline{\text { Number }}$}

W23386DA

W23386DB

W23386DC

W23386DD 


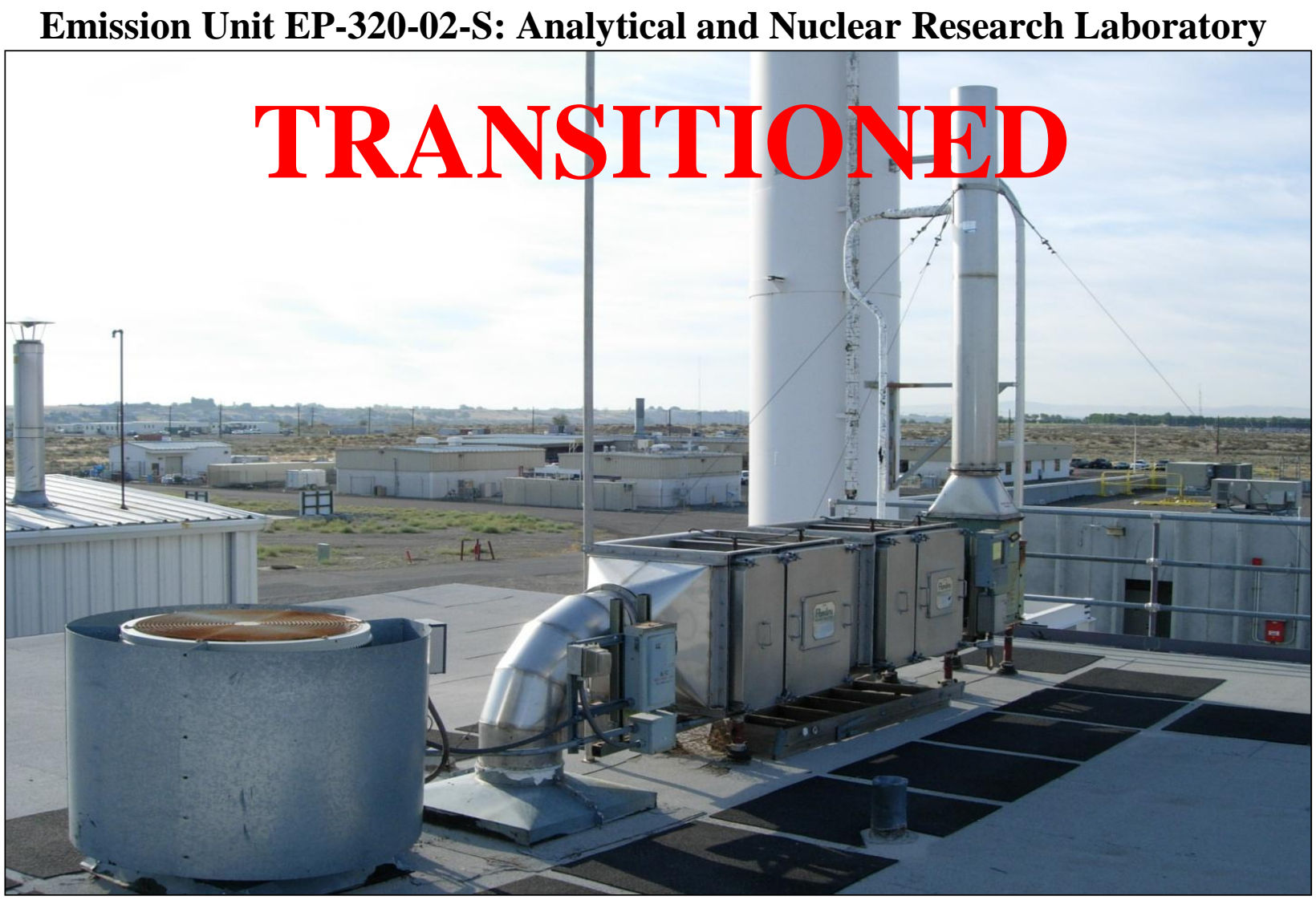
Emission Unit ID:
EP-320-02-S
Emission Sample Unit ID:
ESP-320-02-S
Traverse Point ID:
TP-320-02-1

Washington Geological Survey 84 Coordinates:

Latitude: 46.366 degrees

Longitude: 119.280 degrees

\section{Facility/Process Description}

Research activities conducted in the 320 Building involved special-purpose separation and analytical chemistry techniques that allowed low-level and ultra-trace levels of material in environmental samples to be measured. Working with samples containing low/trace levels required special building features, such as a clean zone. A class 10,000 clean zone allowed for contamination-free preparation and analysis of samples containing extremely low levels of indicator radionuclides and trace organic compounds. Special instrumentation that was used for sample analysis includes various mass spectrometers, electron-beam microscopes, X-ray diffraction, and radiation counters. Transition occurred in February 2011. 


\section{Exhaust Unit Description}

EP-320-02-S exhausts air from a hood in Room 148. The hood is HEPA filtered and is used for low-level radiochemistry studies. The stack outlet extends above the top of the roof $12 \mathrm{ft}, 9.5 \mathrm{in}$. and $31 \mathrm{ft}, 9.5 \mathrm{in}$. from the existing ground-level grade. The stack is $10 \mathrm{in}$. in diameter and has a cross-sectional area of $0.55 \mathrm{ft}^{2}$.

\section{Exhaust Unit Control Technology}

The following simplified drawing shows the effluent pathway and the installed control technology for the 320 Building emission unit:

Figure G.2 320-02-S Effluent Pathway

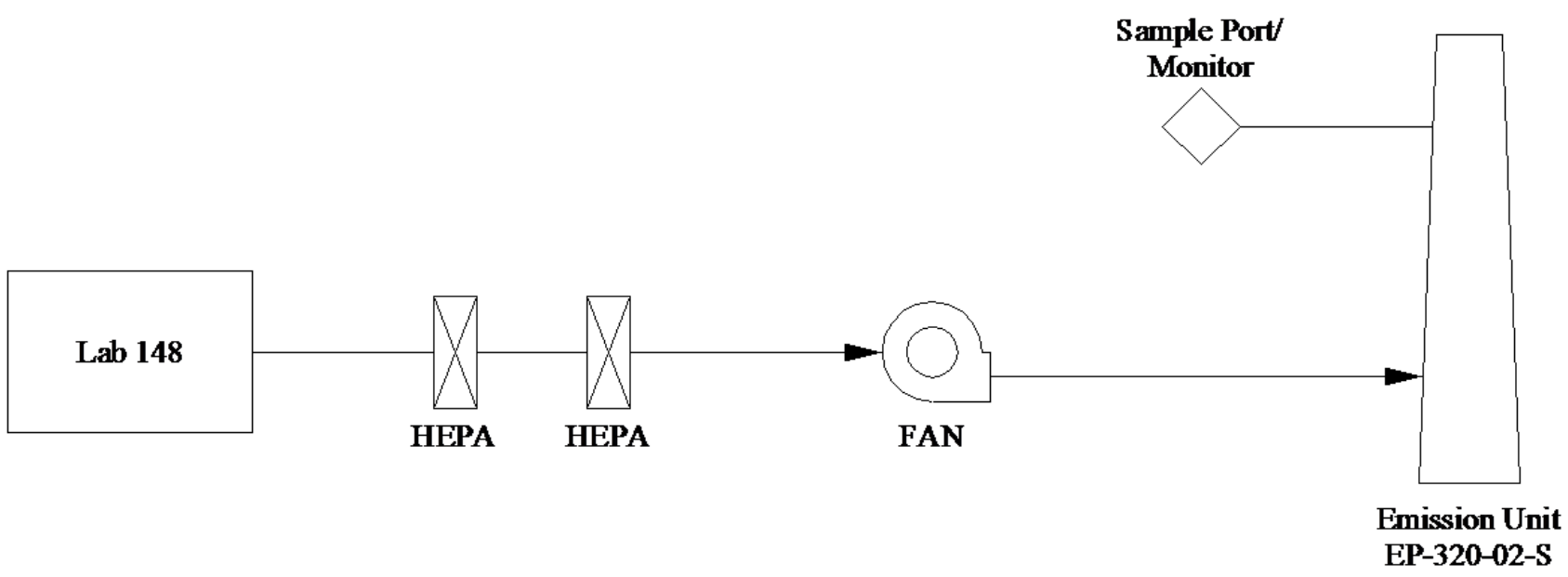

\section{$\underline{\text { Exhaust Unit Flow Rate and Temperature }}$}

Exhaust flow rates and temperature were determined annually using EM procedure EPRP-AIR016, which was developed based on the requirements in 40 CFR 60, Appendix A, Method 2. The following tables provide historical flow-rate and temperature measurements:

Table G.3 320-02-S Exhaust Unit Flow Rate

\begin{tabular}{|c|c|}
\hline Date Measured & Flow Rate (CFM) \\
\hline $04 / 20 / 00$ & 470 \\
\hline $09 / 26 / 01$ & 545 \\
\hline $05 / 17 / 02$ & 512 \\
\hline $06 / 26 / 03$ & 506 \\
\hline $05 / 21 / 04$ & 470 \\
\hline $05 / 24 / 05$ & 429 \\
\hline $05 / 10 / 06$ & 418 \\
\hline $05 / 24 / 07$ & 344 \\
\hline $06 / 12 / 08$ & 578 \\
\hline $05 / 20 / 09$ & 528 \\
\hline $06 / 02 / 10$ & 539 \\
\hline Average $\pm 1 \sigma$ & $490 \pm 68$ \\
\hline
\end{tabular}


Table G.4 320-02-S Exhaust Unit Temperature

\begin{tabular}{|c|c|}
\hline Date Measured & Average Temperature $\left({ }^{\circ} \mathbf{F}\right)$ \\
\hline $05 / 10 / 06$ & 83 \\
\hline $05 / 24 / 07$ & 83 \\
\hline $06 / 12 / 08$ & 85 \\
\hline $05 / 20 / 09$ & 74 \\
\hline $06 / 02 / 10$ & 74 \\
\hline Average $\pm 1 \sigma$ & $80 \pm 5.4$ \\
\hline
\end{tabular}

\section{$\underline{\text { Record Particulate Sample System Description }}$}

The record particulate sampling system for emission unit EP-320-02-S was operated in conformance with 40 CFR 61, Subpart H and ANSI N13.1-1969 requirements. See Stack Sampler Configuration Drawing H-3-307243.

The sample was extracted from the stack about $10 \mathrm{ft}, 3.5 \mathrm{in}$. above the existing rooftop at the stack base. The sample probe is positioned $5 \mathrm{ft}, 6$ in. (6.6 equivalent diameters) downstream of the nearest flow disturbance and $2 \mathrm{ft}, 6 \mathrm{in}$. (3.0 equivalent diameters) from the top of the stack. The stack meets the alternative 2:0.5 (downstream: upstream) duct-diameter placement recommendation from ANSI N13.1-1969.

A stainless steel, two-nozzle probe is used to extract the sample. Each nozzle inlet has a 0.402 in. ID. The two sample nozzles make a 5 in. radius bend before feeding into a common 0.62 in ID manifold.

The sample transport line is constructed of $0.62 \mathrm{in}$. ID stainless steel tubing. The line extends approximately $20 \mathrm{in}$. outside the stack before making a 90 degree, $6 \mathrm{in}$. radius of curvature bend downward. The sample line makes two more 45 degree, 4 in. radius of curvature bends before extending downward through the roof and into Laboratory 148 and terminating at the collection filter, rotameter, and sample flow-rate adjustment valve. The sample line is insulated from the point where it exits the stack to the point where it penetrates the roof.

\section{Vacuum Air Sample System}

Stack emission samples were withdrawn from the stack by means of the building vacuum air sampling system located in the basement of the 320 Building. This system has redundant Rietschle carbon vane vacuum pumps that are powered by normal and emergency power.

\section{Battelle Drawings}

Stack Sampler Configuration EP-320-02-S; Rev. 1

Electronic access to these drawings is available.

\section{Number}

H-3-307243 


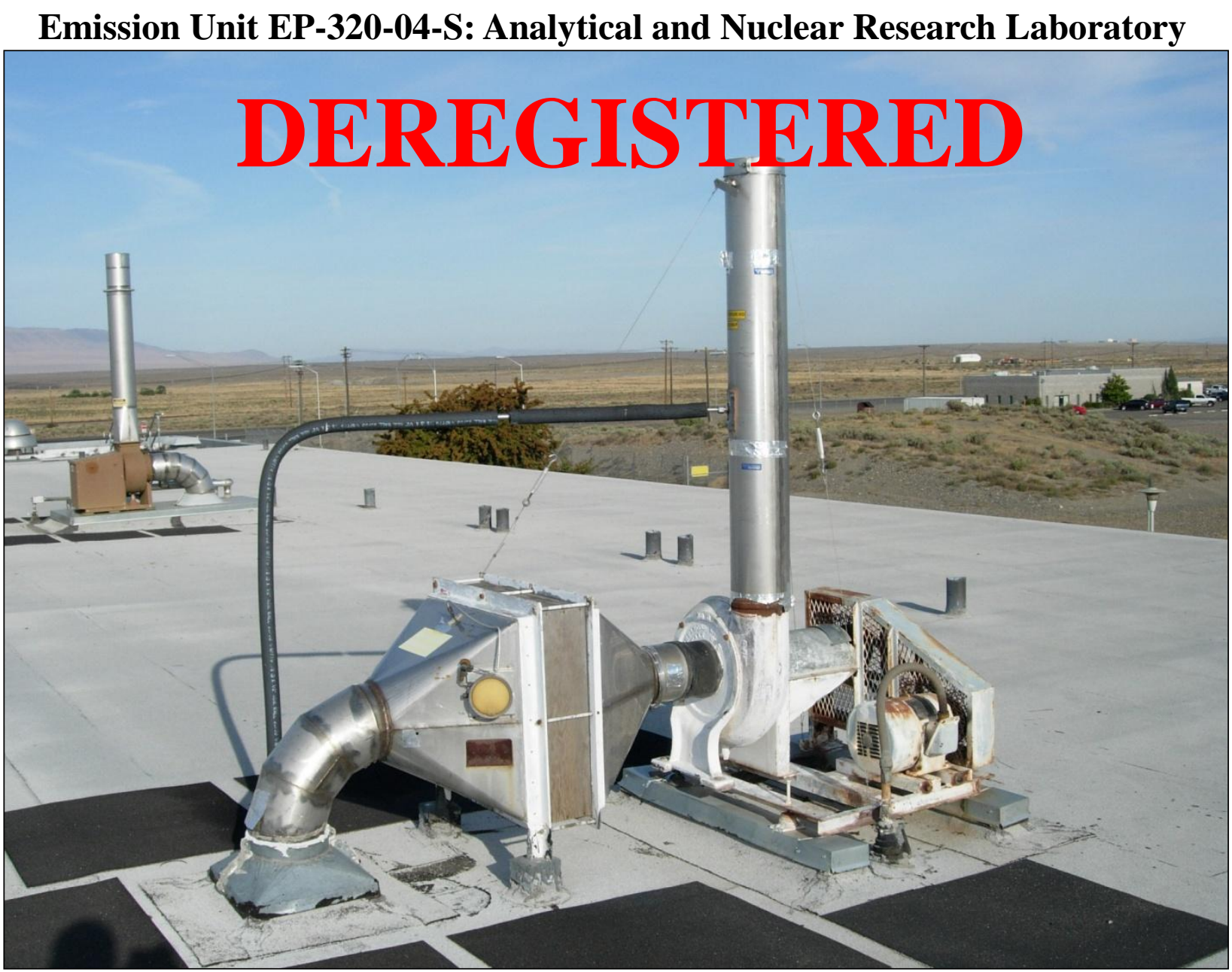

Emission Unit ID:

EP-320-04-S

Emission Sample Unit ID:

ESP-320-04-S

Traverse Point ID:

TP-320-04-1

Washington Geological Survey 84 Coordinates:

Latitude: 46.366 degrees

Longitude: 119.281 degrees

\section{Facility/Process Description}

Research activities conducted in the 320 Building involved special-purpose separation and analytical chemistry techniques that allowed measurement of low-level and ultra-trace levels of material in environmental samples. Working with samples containing low/trace levels required special building features, such as a clean zone. A class 10,000 clean zone allowed for contamination-free preparation and analysis of samples containing extremely low levels of indicator radionuclides and trace organic compounds. Special instrumentation used for sample analysis included various mass spectrometers, electron-beam microscopes, X-ray diffraction, and radiation counters. Closure occurred in February 2011 and was concurred with by the state in August 2011. 


\section{$\underline{\text { Exhaust Unit Description }}$}

EP-320-04-S exhausts air from a hood in Room 114. The hood is HEPA filtered and was used for low-level radiochemistry studies. The stack outlet extends above the top of the roof $7 \mathrm{ft}$ and $26 \mathrm{ft}$ from the existing ground-level grade. The stack is $7 \mathrm{in}$. in diameter and has a crosssectional area of $0.27 \mathrm{ft}^{2}$.

\section{Exhaust Unit Control Technology}

The following simplified drawing shows the effluent pathway and the installed control technology for the 320 Building emission unit:

Figure G.3 320-04-S Effluent Pathway

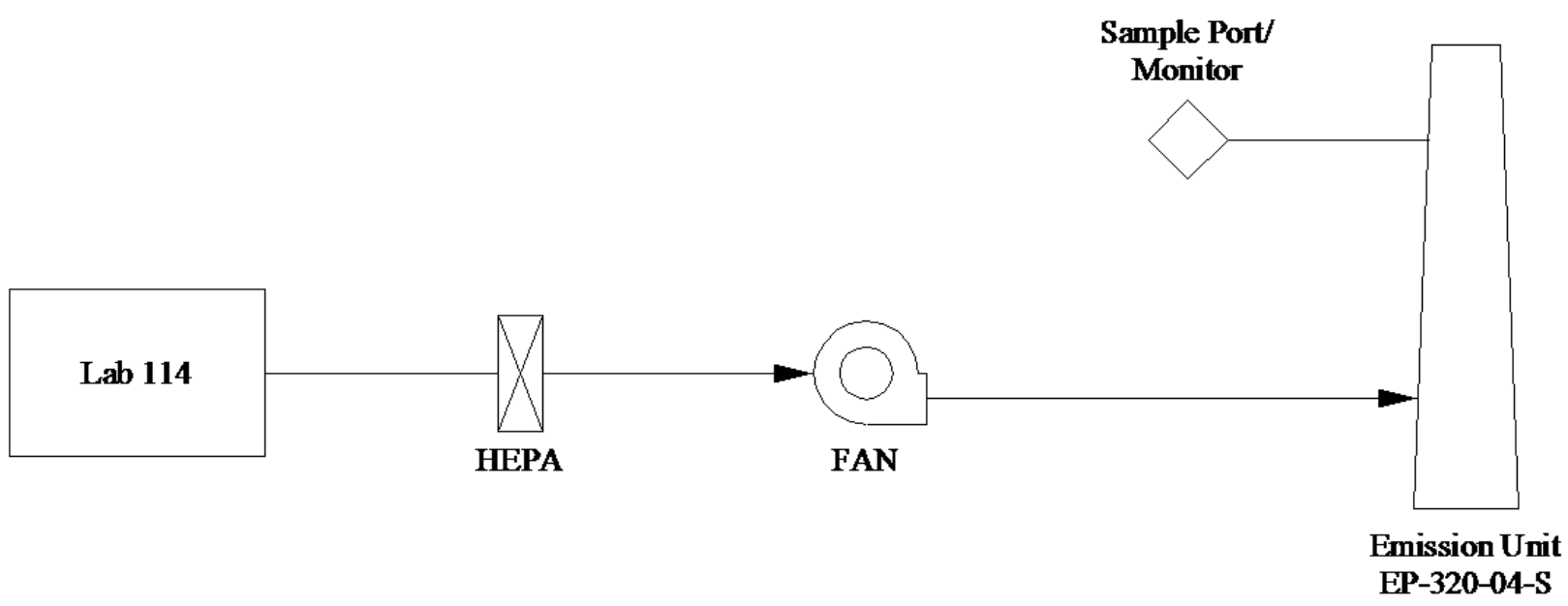

\section{Exhaust Unit Flow Rate and Temperature}

Exhaust flow rates were determined annually using EM procedure EPRP-AIR-016, which was developed based on the requirements in 40 CFR 60, Appendix A, Method 2. This emission unit is currently not operating; however, the following table provides historical flow rate measurements:

Table G.5 320-04-S Exhaust Unit Flow Rate

\begin{tabular}{|c|c|}
\hline Date Measured & Flow Rate (CFM) \\
\hline $04 / 20 / 00$ & 873 \\
\hline $09 / 26 / 01$ & 394 \\
\hline $05 / 17 / 02$ & 429 \\
\hline $06 / 26 / 03$ & 400 \\
\hline $05 / 21 / 04$ & 416 \\
\hline $05 / 24 / 05$ & 373 \\
\hline $05 / 10 / 06$ & 393 \\
\hline $05 / 24 / 07$ & 344 \\
\hline Average $\pm 1 \sigma$ & $450 \pm 170$ \\
\hline
\end{tabular}

No temperature information is available. 


\section{$\underline{\text { Record Particulate Sample System Description }}$}

The record particulate sampling system for emission unit EP-320-04-S was operated in conformance with 40 CFR 61, Subpart H and ANSI N13.1-1969 requirements. See Stack Sampler Configuration Drawing \#H-3-307245.

The sample was extracted from the stack about $4 \mathrm{ft}, 5.6 \mathrm{in}$. above the existing rooftop at the stack base. The sample probe is positioned $2 \mathrm{ft}$ ( 3.4 equivalent diameters) downstream of the nearest flow disturbance and $3 \mathrm{ft}, 6.38 \mathrm{in}$. (6.1 equivalent diameters) from the top of the stack. The stack meets the alternative 2:0.5 (downstream: upstream) duct-diameter placement recommendation from ANSI N13.1-1969.

A stainless steel, one-nozzle probe is used to extract the sample. The nozzle inlet has a 0.402 in. ID. The sample nozzle makes a 1.5 in. radius bend, and the sample tubing extends outside the stack wall 3 in. before expanding to the sample transport line ID.

The sample transport line is constructed of $0.62 \mathrm{in.} \mathrm{ID} \mathrm{stainless} \mathrm{steel} \mathrm{tubing.} \mathrm{The} \mathrm{line} \mathrm{extends}$ approximately $4 \mathrm{ft}, 6 \mathrm{in}$. from the tubing expansion and then makes a 90 degree, $13 \mathrm{in}$. radius of curvature bend downward. The sample line extends downward through the roof and into Laboratory 114 and terminates at the collection filter, rotameter, and sample flow-rate adjustment valve. The sample line is insulated from the point where it exits the stack to the point where it penetrates the roof.

\section{Vacuum Air Sample System}

Stack emission samples were withdrawn from the stack by means of the building vacuum air sampling system located in the basement of the 320 Building. This system has redundant Rietschle carbon vane vacuum pumps that are powered by normal and emergency power.

\section{Battelle Drawings}

Stack Sampler Configuration EP-320-04-S; Rev. 2

Electronic access to this drawing is available.
Number

H-3-307245 


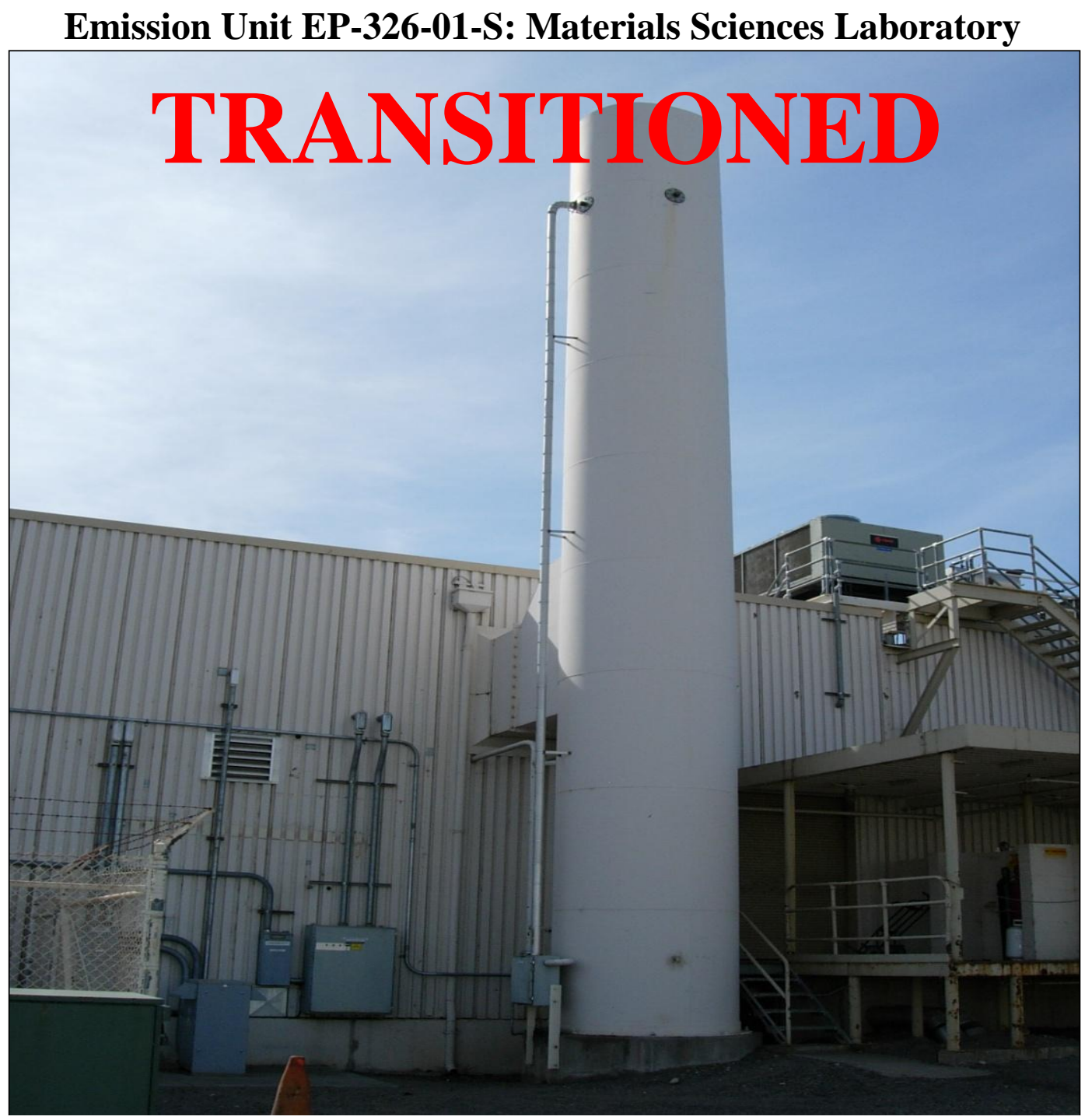

Emission Unit ID:

EP-326-01-S

Emission Sample Unit ID:

ESP-326-01-S

Traverse Point ID:

TP-326-01-1

Washington Geological Survey 84 Coordinates:

Latitude: 46.369 degrees

Longitude: 119.279 degrees

\section{$\underline{\text { Facility/Process Description }}$}

The building was used to conduct 1) mechanical testing of metallic and ceramic composite materials, 2) specimen preparation for optical/electron beam microscopes and the subsequent examination/characterization of these specimens, and 3) the preparation of specimens for X-ray diffraction analysis. Sample preparation activities include sample receiving and sample-size reduction (cutting, grinding, punching, breaking, electropolishing, and ion micromilling). Other activities in the building included analytical characterization of samples from the radioactive 
waste tanks at Hanford, storage of sealed sources with a high radiation level, and a radiological counting laboratory. Transition occurred in February 2011.

\section{$\underline{\text { Exhaust Unit Description }}$}

EP-326-01-S exhausts air from all areas where radionuclides are handled. The stack also exhausts air from some unfiltered (non-rad) areas of the facility. Located on the north side of the facility, the stack measures $47 \mathrm{ft}, 8 \mathrm{in}$. tall from the existing grade at the base of the stack to the point of discharge. The stack is 72 inches in diameter and has a cross-sectional area of $28.3 \mathrm{ft}^{2}$.

\section{Exhaust Unit Control Technology}

The following simplified drawing shows the effluent pathway and the installed control technology for the 326 Building emission unit:

Figure G.4 326-01-S Effluent Pathway

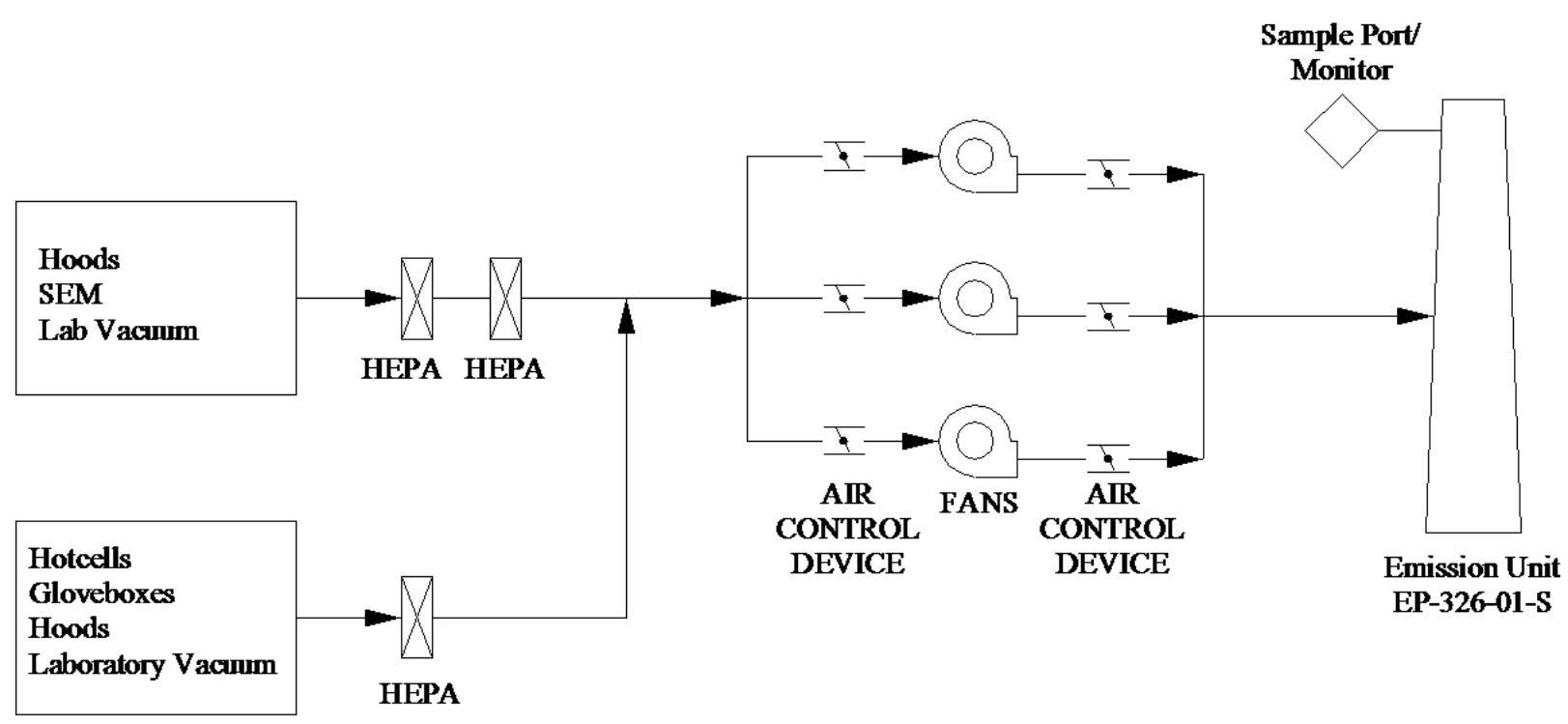

\section{$\underline{\text { Exhaust Unit Flow Rate and Temperature }}$}

Exhaust flow rates and temperature were determined annually using EM procedure EPRP-AIR016, which was developed based on the requirements in 40 CFR 60, Appendix A, Method 2. The following tables provide historical flow rate and temperature measurements: 
Table G.6 326-01-S Exhaust Unit Flow Rate

\begin{tabular}{|c|c|}
\hline Date Measured & Flow Rate (CFM) \\
\hline $03 / 30 / 00$ & 40,695 \\
\hline $05 / 15 / 01$ & 45,100 \\
\hline $05 / 16 / 02$ & 52,200 \\
\hline $06 / 11 / 03$ & 53,100 \\
\hline $05 / 25 / 04$ & 55,900 \\
\hline $06 / 01 / 05$ & 49,700 \\
\hline $05 / 03 / 06$ & 49,700 \\
\hline $06 / 05 / 07$ & 48,300 \\
\hline $06 / 03 / 08$ & 47,700 \\
\hline $05 / 28 / 09$ & 43,900 \\
\hline $05 / 26 / 10$ & 45,800 \\
\hline Average $\pm 1 \sigma$ & $48,400 \pm 4,400$ \\
\hline
\end{tabular}

Table G.7 326-01-S Exhaust Unit Temperature

\begin{tabular}{|c|c|}
\hline Date Measured & Average Temperature $\left({ }^{\circ} \mathbf{F}\right)$ \\
\hline $05 / 03 / 06$ & 79 \\
\hline $06 / 05 / 07$ & 77 \\
\hline $06 / 03 / 08$ & 74 \\
\hline $05 / 28 / 09$ & 83 \\
\hline $05 / 26 / 10$ & 77 \\
\hline Average $\pm 1 \sigma$ & $78 \pm 3.3$ \\
\hline
\end{tabular}

\section{$\underline{\text { Record Particulate Sample System Description }}$}

The record particulate sampling system for emission unit EP-326-01-S was operated in conformance with 40 CFR 61, Subpart H and ANSI N13.1-1969 requirements. See Stack Sampler Configuration Drawing H-3-307238.

The sample is extracted from the stack about $42 \mathrm{ft}, 5$ in. above the existing grade at the stack base. The sample probe is positioned $18 \mathrm{ft}$ (3.0 equivalent diameters) downstream of the nearest flow disturbance and $5 \mathrm{ft}, 3$ in. (0.875 equivalent diameters) from the top of the stack. During the modification to upgrade the stack, it was found that the original existing stack design would not support the extension of the stack to meet the 8:2 (downstream: upstream) duct-diameter placement recommendation from ANSI N13.1-1969. However, this design does comply with the alternative $2: 0.5$ criteria.

A stainless steel, six-nozzle probe manufactured by Air Monitor Corporation is used to extract the sample. Each nozzle inlet has a $0.231 \mathrm{in}$. ID. The six sample nozzles feed into a $1.12 \mathrm{in}$. ID manifold that extends horizontally across the center of the duct. See vendor-supplied drawings for details: W20628BA and W20628EA.

The sample transport line is constructed of 1.12 in. ID stainless steel tubing. The line makes a 90 degree, 7 in. radius of curvature bend downward upon exiting the stack and terminates in a cabinet containing the collection filter, rotameter, and sample flow rate adjustment valve. The sample line upstream of the collector is insulated, heat traced, and electrically grounded. The 
sample line temperature is maintained above that of the stack gas to prevent condensation from forming in the sample line.

\section{$\underline{\text { Vacuum Air Sample System }}$}

Stack emission samples were withdrawn from the stack and through the sample system by means of the building vacuum air sampling system located in the main equipment room of the 326 Building. This system has redundant vacuum pumps that are powered by normal and emergency power.

\section{Battelle Drawings}

Stack Sampler Configuration EP-326-01-S; Rev. 1

Electronic access to these drawings is available.

\section{$\underline{\text { Air Monitor Corp. Drawings }}$}

Sampler-Probe Assembly; Rev. 2

Iso-Sampling Threaded Nozzle; Rev. 1

\section{Number}

H-3-307238-1

Other drawings are provided by the vendor and are not available electronically at this time.

\section{Number}

W20628BA

W20628EA 
Emission Unit EP-329-01-S: Chemical Sciences Laboratory

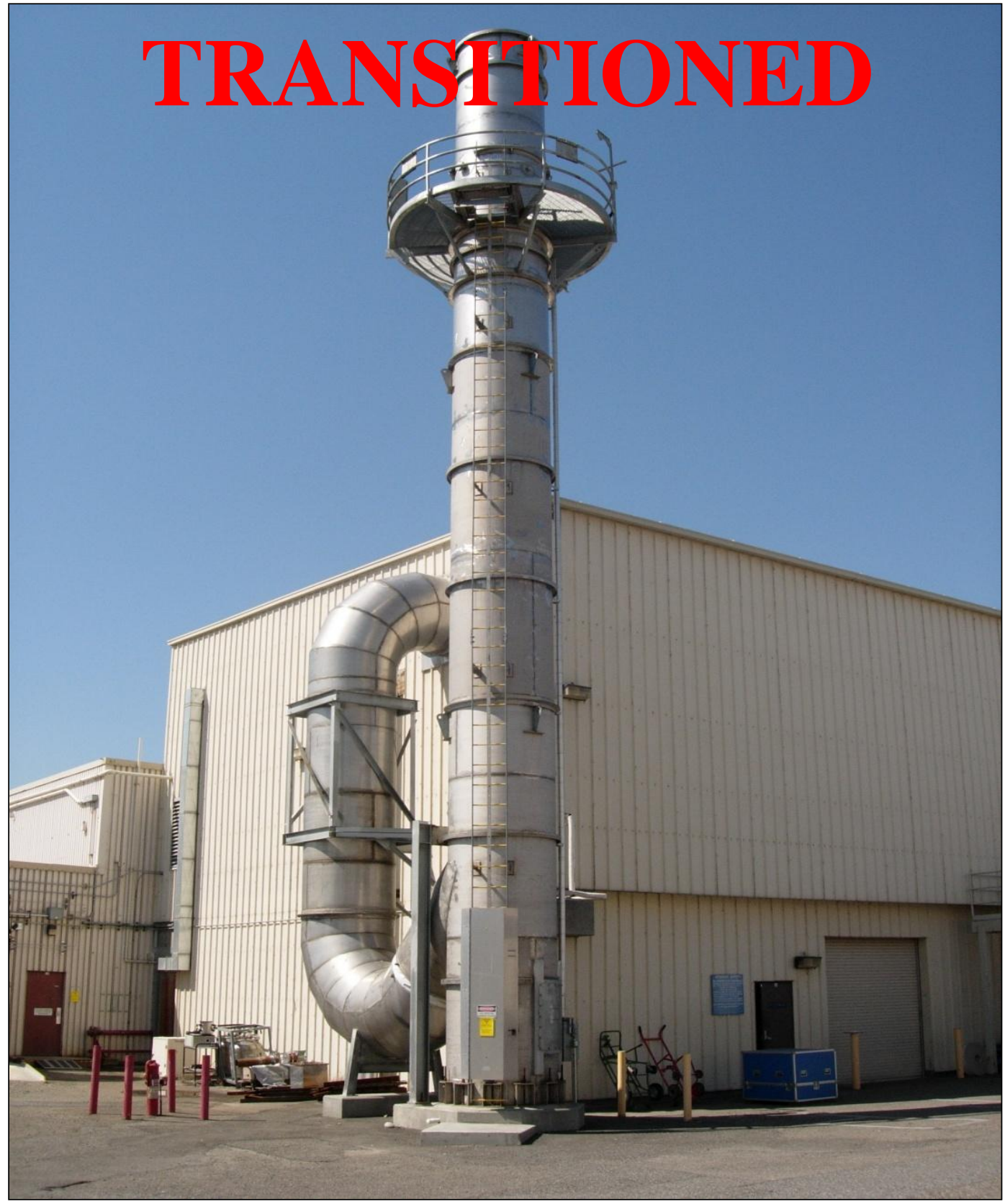

Emission Unit ID:

EP-329-01-S

Emission Sample Unit ID:

ESP-329-01-S

Traverse Point ID:

TP-329-01-1

Washington Geological Survey 84 Coordinates:

Latitude: 46.369 degrees

Longitude: 119.280 degrees 


\section{Facility/Process Description}

This building was used to conduct measurements and develop procedures in support of the Hanford Site environmental restoration and waste management activities. Environmental samples, including soils, vegetation, water, decommissioning materials, and samples of highlevel tank waste were analyzed for all radionuclides and hazardous constituents. Advanced analytical procedures were also developed, tested, and applied. In addition, R\&D activities in the nuclear sciences were conducted, particularly in the areas of radiation instrumentation development and applications, low-level radioactive waste characterization and management, radiological decommissioning, environmental radioactivity measurements, radiochemical separations and measurements, and basic nuclear chemistry and physics. Transition occurred in February 2011.

\section{Exhaust Unit Description}

EP-329-01-S exhausts air from all areas where radionuclides are handled. Located on the north end of the facility, the stack measures $62 \mathrm{ft}, 6 \mathrm{in}$. tall from the existing grade at the base of the stack to the point of discharge. The stack is $5 \mathrm{ft}$ in. diameter and has a cross-sectional area of $19.6 \mathrm{ft}^{2}$.

\section{Exhaust Unit Control Technology}

The following simplified drawing shows the effluent pathway and the installed control technology for the 329 Building emission unit:

Figure G.5 329-01-S Effluent Pathway

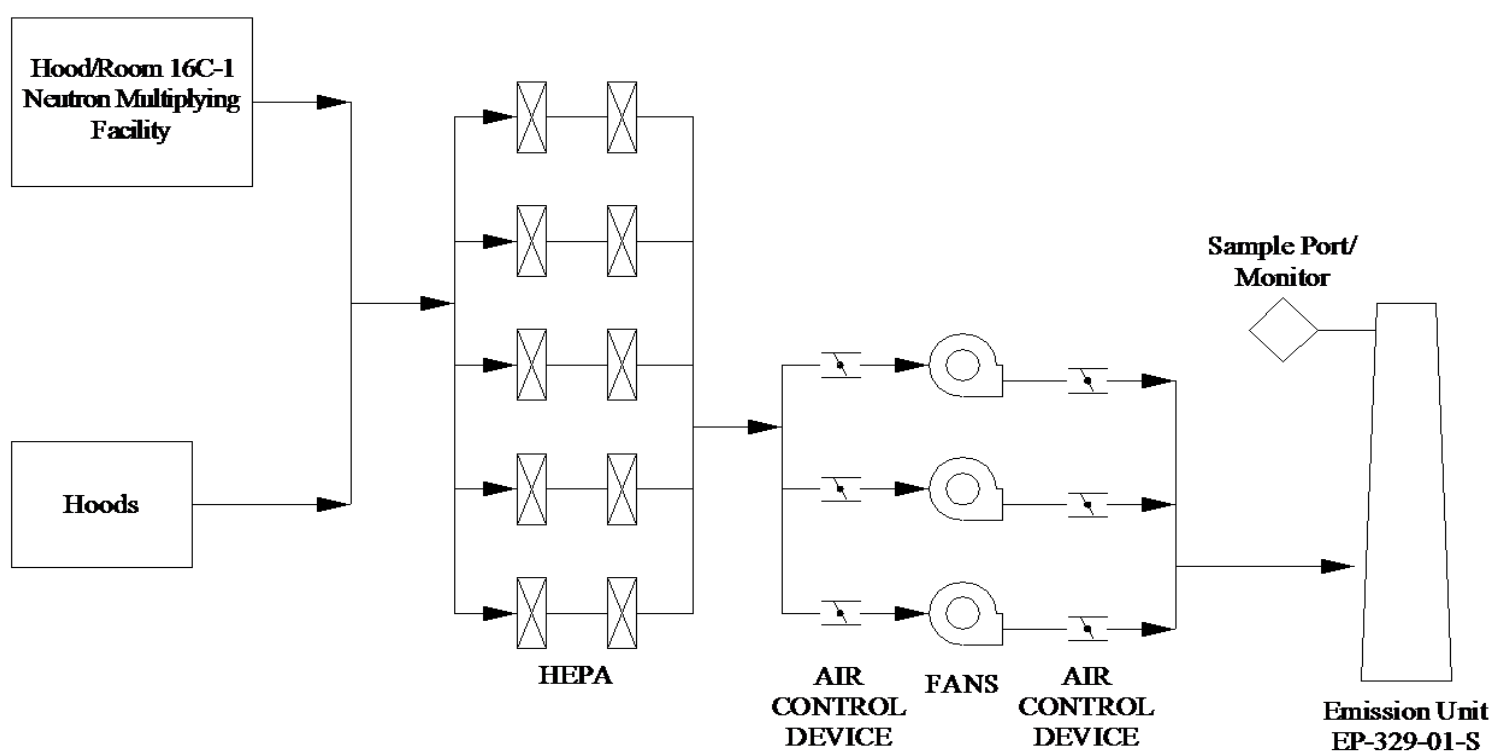




\section{Exhaust Unit Flow Rate and Temperature}

Exhaust flow rates and temperature were determined annually using EM procedure EPRP-AIR016, which was developed based on the requirements in 40 CFR 60, Appendix A, Method 2. The following tables provide historical flow rate and temperature measurements:

Table G.8 329-01-S Exhaust Unit Flow Rate

\begin{tabular}{|c|c|}
\hline Date Measured & Flow Rate (CFM) \\
\hline $11 / 13 / 01$ & 43,900 \\
\hline $10 / 22 / 02$ & 48,300 \\
\hline $07 / 29 / 03$ & 46,000 \\
\hline $11 / 16 / 04$ & 45,200 \\
\hline $10 / 11 / 05$ & 45,300 \\
\hline $10 / 18 / 06$ & 44,700 \\
\hline $10 / 24 / 07$ & 44,600 \\
\hline $10 / 16 / 08$ & 45,600 \\
\hline $10 / 17 / 09$ & 44,900 \\
\hline $10 / 20 / 10$ & 45,800 \\
\hline Average $\pm 1 \sigma$ & $45,400 \pm 1,200$ \\
\hline
\end{tabular}

Table G.9 329-01-S Exhaust Unit Temperature

\begin{tabular}{|c|c|}
\hline Date Measured & Average Temperature $\left({ }^{\circ} \mathbf{F}\right)$ \\
\hline $10 / 18 / 06$ & 76 \\
\hline $10 / 24 / 07$ & 74 \\
\hline $10 / 16 / 08$ & 76 \\
\hline $10 / 17 / 09$ & 75 \\
\hline $10 / 20 / 10$ & 78 \\
\hline Average $\pm 1 \sigma$ & $76 \pm 1.5$ \\
\hline
\end{tabular}

\section{$\underline{\text { Record Particulate Sample System Description }}$}

The record particulate sampling system for emission unit EP-329-01-S was operated in conformance with 40 CFR 61, Subpart H and ANSI N13.1-1969 requirements. See Stack Sampler Configuration Drawing H-3-307237-1.

The sample is extracted from the stack about $52 \mathrm{ft}, 6 \mathrm{in}$. above the existing grade at the stack base. The sample probe is positioned $40 \mathrm{ft}$ ( 8.0 equivalent diameters) downstream of the nearest flow disturbance and $10 \mathrm{ft}$ ( 2.0 equivalent diameters) from the top of the stack. The position of the sample extraction point meets the 8:2 (downstream: upstream) duct-diameter placement recommendation from ANSI N13.1-1969.

A stainless steel, six-nozzle probe manufactured by Air Monitor Corporation is used to extract the sample. Each nozzle inlet has a 0.183 in. ID. The six sample nozzles feed into a $1.12 \mathrm{in}$. ID manifold that extends horizontally across the center of the stack. See vendor-supplied drawings for details: W20628CA and W20628EA. 
The sample transport line is constructed of $1.12 \mathrm{in.} \mathrm{ID} \mathrm{stainless} \mathrm{steel} \mathrm{tubing.} \mathrm{The} \mathrm{line} \mathrm{makes} \mathrm{a}$ 90 degree, 7 in. radius of curvature bend downward upon exiting the stack and terminates in a cabinet containing the collection filter, rotameter, and sample-flow-rate adjustment valve. The sample line upstream of the collector is insulated, heat traced, and electrically grounded. The sample line temperature is maintained above that of the stack gas to prevent condensation from forming in the sample line.

\section{$\underline{\text { Vacuum Air Sample System }}$}

Stack emission samples are withdrawn from the stack and through the sample system by means of the building vacuum air sampling system located in the basement equipment room of the 329 Building. This system has redundant vacuum pumps that are powered by normal and emergency power. See drawing H-3-307967-1 for details.

\section{Battelle Drawings}

Number

Stack Sampler Configuration EP-329-01-S; Rev. 1

H-3-307237-1

Vacuum Air Sample Piping Schematic; Rev. 0

H-3-307967-1

Electronic access to these drawings is available.

\section{$\underline{\text { Air Monitor Corp. Drawings }}$}

Flo-Sampler Probe Assembly; Rev. 2

Iso-Sampling Threaded Nozzle; Rev. 1 $\underline{\text { Number }}$

W20628CA

W20628EA

Other drawings are provided by the vendor and are not available electronically at this time. 


\section{Emission Unit EP-3020-01-S: Environmental Molecular Sciences Laboratory}

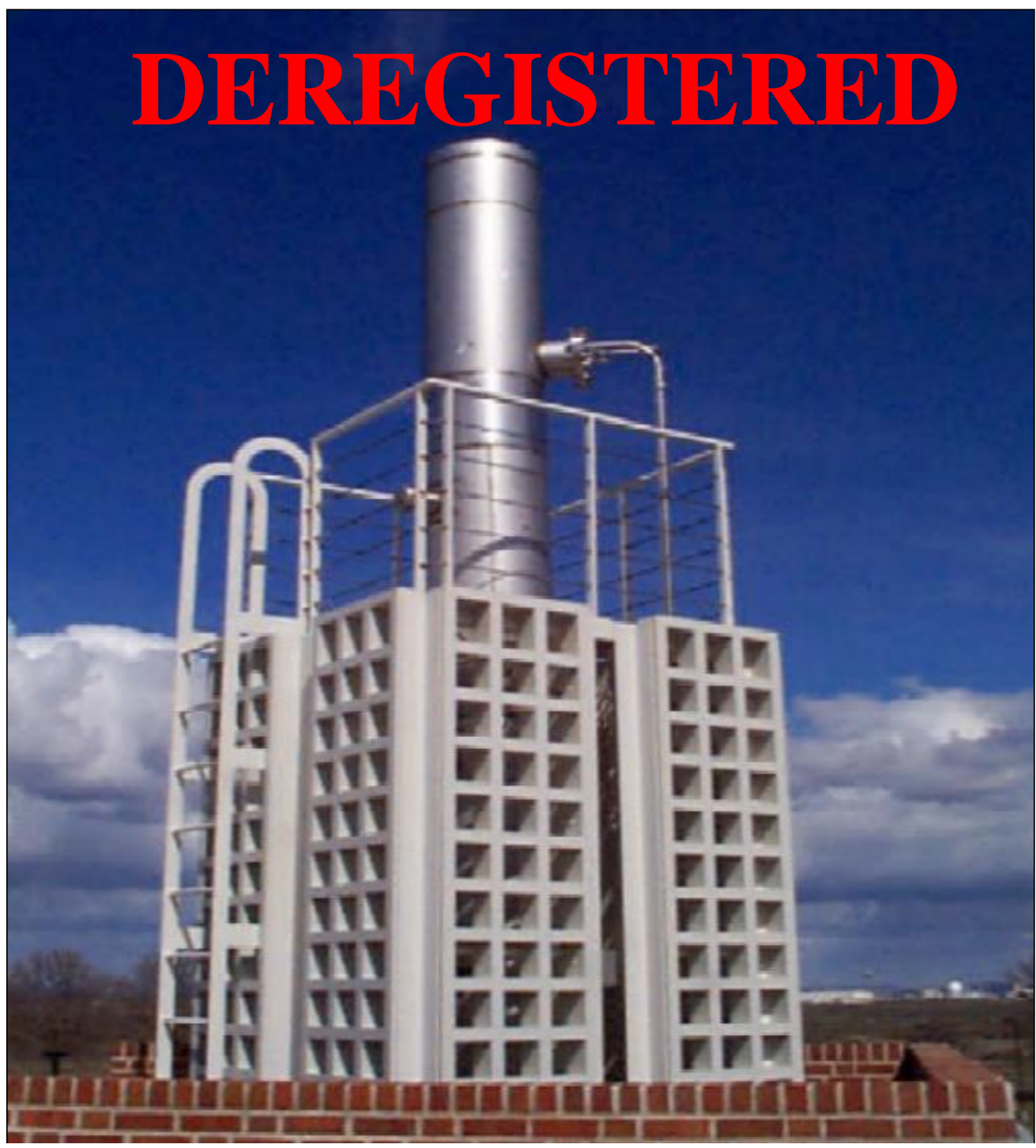

Emission Unit ID:

EP-3020-01-S

Emission Sample Unit ID:

ESP-3020-01-S

Traverse Point ID:

TP-3020-01-1

Washington Geological Survey 84 Coordinates:

Latitude: 46.369 degrees

Longitude: 119.280 degrees

\section{Facility/Process Description}

The Environmental Molecular Science Laboratory (EMSL; 3020 Building) provides integrated laboratory, computer, and seminar functions and contains basic, multi-disciplinary research programs involving chemical, biological, materials, and computational sciences. R\&D activities are undertaken in EMSL to advance the understanding of molecular sciences and to apply the advanced understanding gained to a broad spectrum of environmental restoration and waste 
management missions. Deregistration occurred in 2004; however, this building maintains permitted activities of a fugitive nature resulting in this information being maintained beyond the normal 5 years.

\section{Exhaust Unit Description}

EP-3020-01-S exhausts air from fume hoods, snorkels, and laboratory spaces within the 3020 Building. This emission unit was established in the spring of 1996. The stack is located atop the $33 \mathrm{ft}, 6 \mathrm{in}$. high facility. The stack measures $20 \mathrm{ft}, 0.75 \mathrm{in}$. tall from the top of the roof to the point of discharge. The stack is $1 \mathrm{ft}, 10 \mathrm{in}$. in diameter and has a cross-sectional area of $2.6 \mathrm{ft}^{2}$.

\section{Exhaust Unit Control Technology}

The following simplified drawing shows the effluent pathway and the installed control technology for the 3020 Building emission unit:

Figure G.6 3020-01-S Effluent Pathway

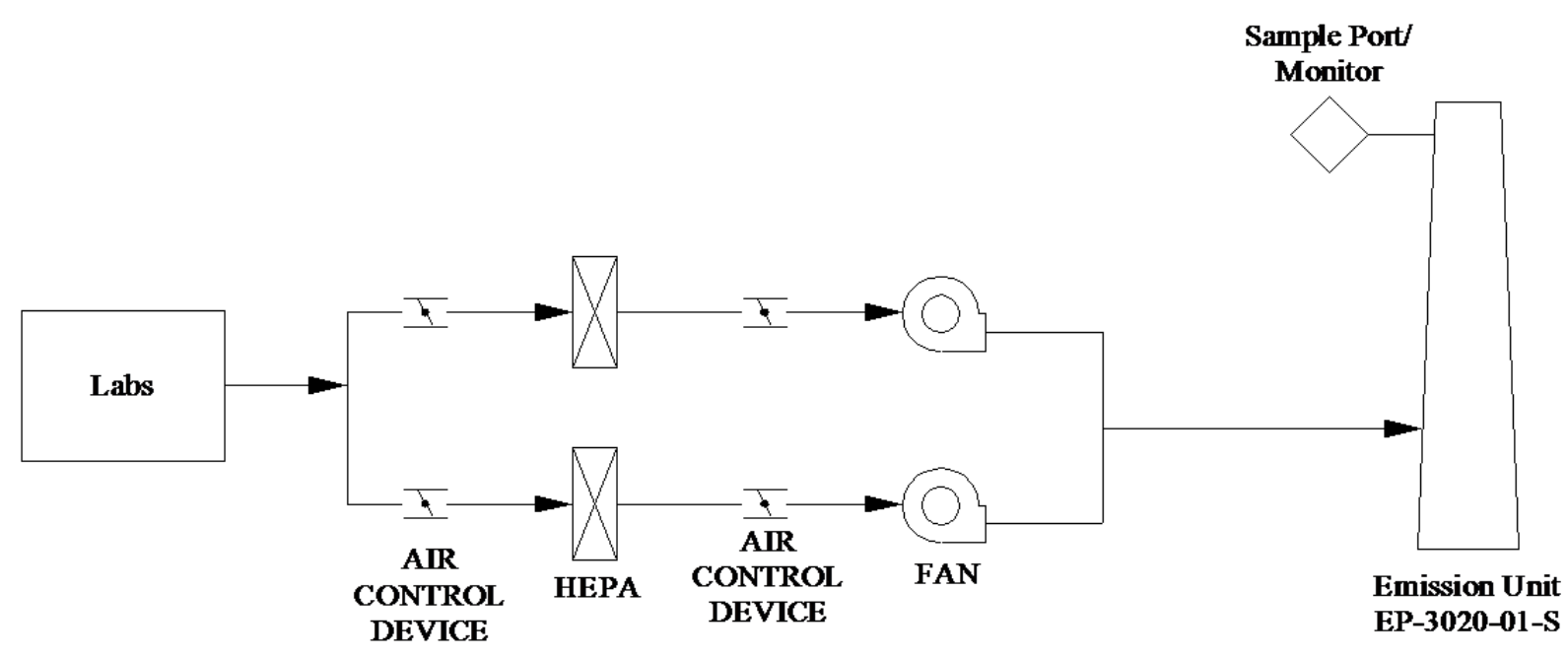

\section{$\underline{\text { Exhaust Unit Flow Rate and Temperature }}$}

Exhaust flow rates were determined annually using EM procedure EPRP-AIR-016, which was developed based on the requirements in 40 CFR 60, Appendix A, Method 2. The following table provides historical flow rate measurements:

Table G.10 3020-01-S Effluent Pathway

\begin{tabular}{|c|c|}
\hline Date Measured & Flow Rate (CFM) \\
\hline $10 / 13 / 99$ & 6,778 \\
\hline $10 / 31 / 00$ & 6,990 \\
\hline $8 / 30 / 01$ & 6,850 \\
\hline $7 / 23 / 02$ & 6,900 \\
\hline $6 / 23 / 03$ & 6,860 \\
\hline $7 / 27 / 04$ & 7,030 \\
\hline Average $\pm 1 \sigma$ & $6,900 \pm 94$ \\
\hline
\end{tabular}


Flow measurements were canceled from the annual frequency in the year 2005; no temperature information is available.

\section{$\underline{\text { Record Particulate Sample System Description }}$}

The record particulate sampling system for emission unit EP-3020-01-S was operated in conformance with 40 CFR 61, Subpart H and ANSI N13.1-1969 requirements. See attached Stack Sampler Configuration Drawing H-3-307826-1.

The sample was extracted from the stack about $12 \mathrm{ft}, 9 \mathrm{in}$. above the stack base. The sample probe is positioned $21 \mathrm{ft}, 7 \mathrm{in}$. (11.77 equivalent diameters) downstream of the nearest flow disturbance and $4 \mathrm{ft}$ (2.18 equivalent diameters) from the top of the stack. The sample extraction point position meets the 8:2 (downstream: upstream) duct-diameter placement recommendation from ANSI N13.1-1969.

A stainless steel, four-nozzle probe manufactured by Air Monitor Corporation was used to extract the sample. Each nozzle inlet has a 0.174 in. ID. See attached vendor-supplied drawings for details: W22192CA, Rev. 1.

The sample transport line is constructed of 1.12 in. ID stainless steel tubing. The line makes a 90 degree, 6 in. radius of curvature bend downward upon exiting the stack and terminates in a cabinet containing the collection filter, rotameter, and sample flow-rate adjustment valve. The sample line upstream of the collector is insulated, heat traced, and electrically grounded. The sample line temperature is maintained above that of the stack gas to prevent condensation from forming in the sample line.

\section{Vacuum Air Sample System}

Vacuum air was supplied to the sample system by a single Rietschle carbon vane pump enclosed in a weatherproof housing for protection against the elements.

\section{Battelle Drawings}

Stack Sampler Configuration EP-3020-01-S; Rev. 1

Electronic access to these drawings is available.

\section{$\underline{\text { Air Monitor Corp. Drawings }}$}

Flow-Sampler Probe with Temp Installation Details; Rev. 1

\section{Number}

H-3-307826-1

Other drawings are provided by the vendor and are not available electronically at this time. 
This page left blank intentionally. 



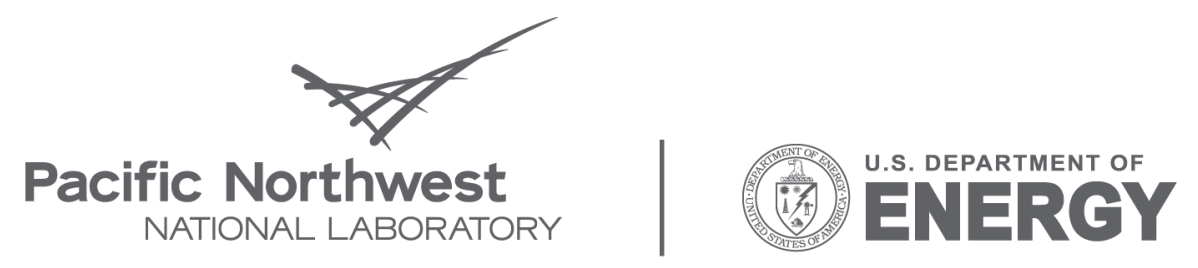

Proudly Operated by Battelle Since 1965

902 Battelle Boulevard

P.O. Box 999

Richland, WA 99352

1-888-375-PNNL (7665)

www.pnl.gov 